\title{
Expanding the Field of View: Station Design for the AAMID SKA Radio Telescope
}

\author{
by
}

Jan Geralt Bij de Vaate

Dissertation presented for the degree of Doctor of Philosophy in Electronic Engineering in the Faculty of Engineering at Stellenbosch University

Supervisor: Prof. D. I. L. de Villiers

Co-supervisor: Prof. D. B. Davidson 


\section{Decleration}

By submitting this thesis electronically, I declare that the entirety of the work contained therein is my own, original work, that I am the sole author thereof (save to the extent explicitly otherwise stated), that reproduction and publication thereof by Stellenbosch University will not infringe any third party rights and that I have not previously in its entirety or in part submitted it for obtaining any qualification.

December 2019 


\section{Table of Contents}

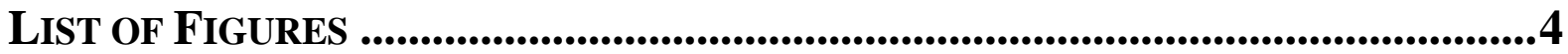

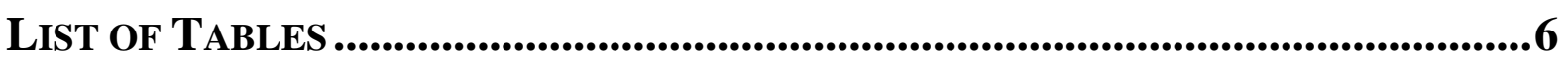

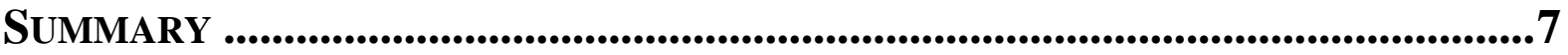

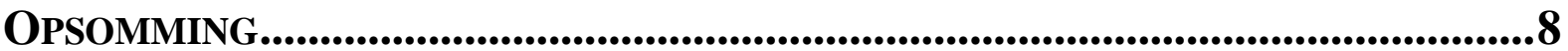

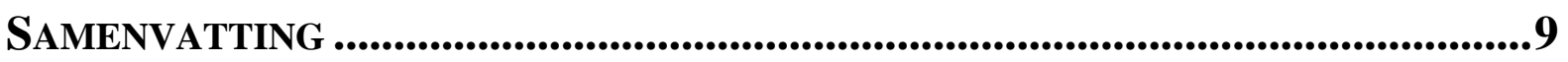

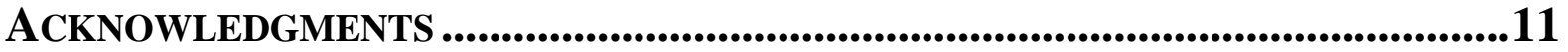

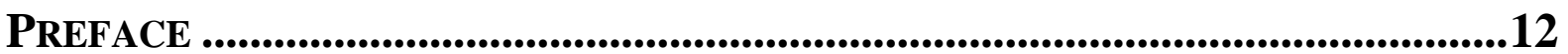

1 The Mid Frequency APERTURe ARRAy Telescope............................13

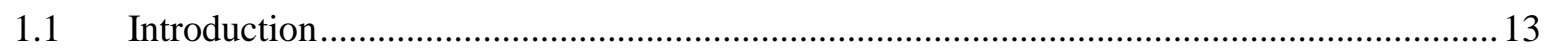

1.2 Aperture Arrays in Radio Astronomy ……………………………………………......14

1.3 Conception of the Square Kilometre Array: the HI telescope …………………………….....15

1.4 Research in AAs for the MID frequencies..........................................................................18

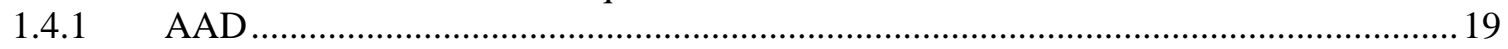

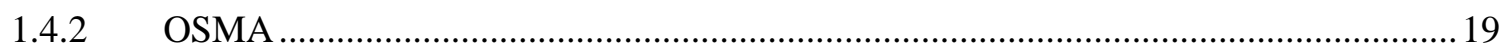

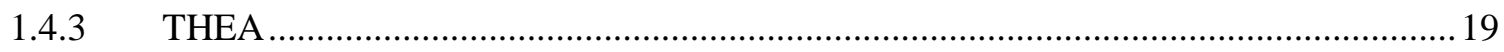

1.4.4 SKADS and EMBRACE ……………………………………………………........

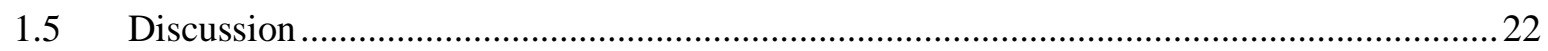

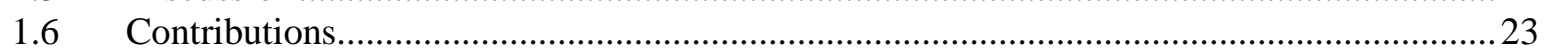

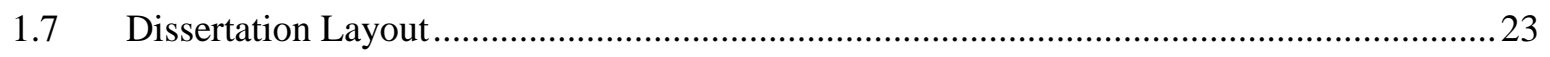

2 SYSTEM REQUIREMENTS..................................................................25

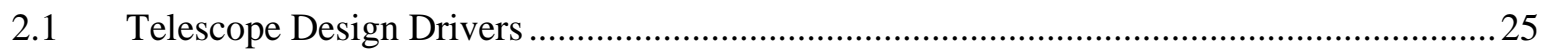

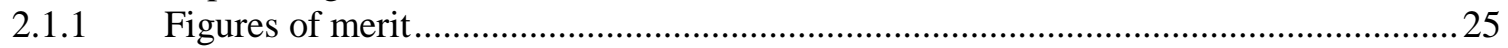

$2.2 \quad$ Science Requirements .............................................................................................22

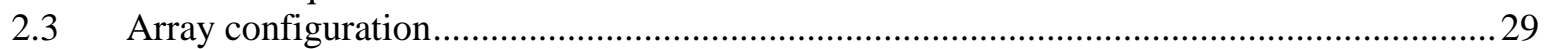

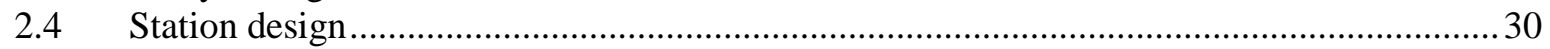

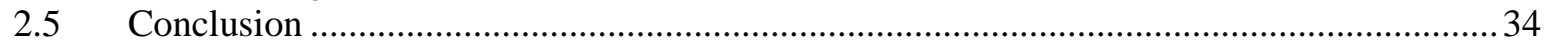

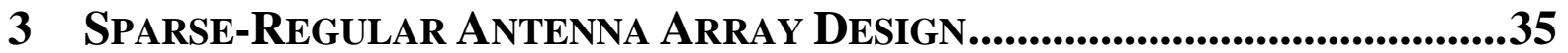

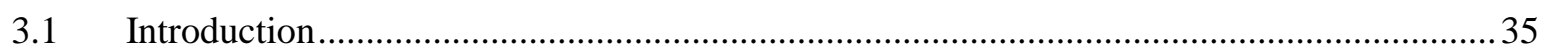

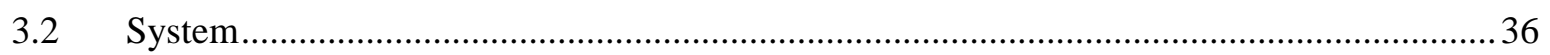

$3.3 \quad$ Sparse-regular array response .................................................................................

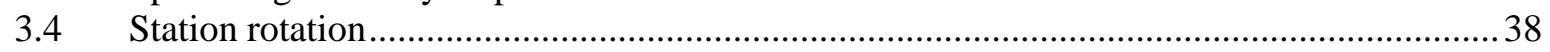

$3.5 \quad$ Time dispersion of grating responses.............................................................................. 40

3.6 Frequency or chromatic dispersion of grating responses ........................................................4

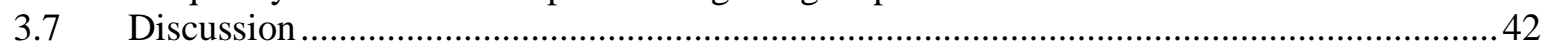

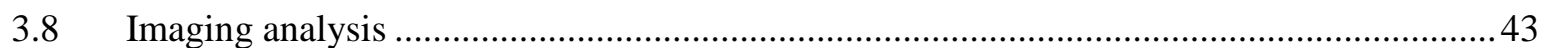

3.9 Station implementation considerations ..........................................................................4

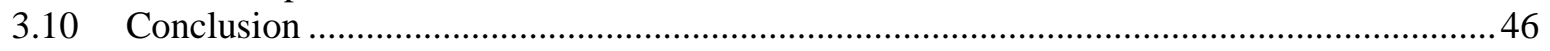

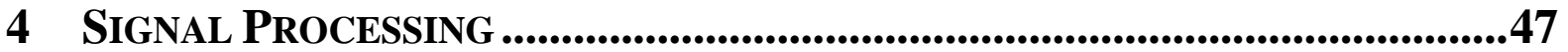

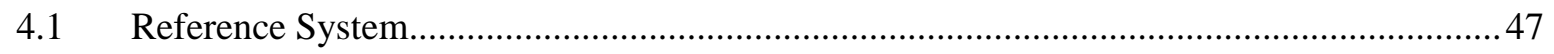

4.2 Calibration and Channelization.................................................................................. 48

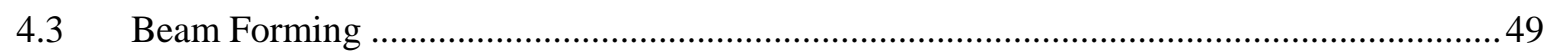

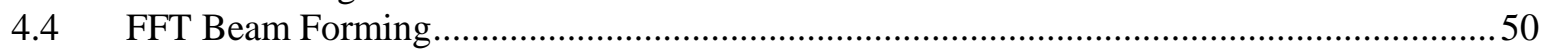

$4.5 \quad$ System optimization..................................................................................................52 


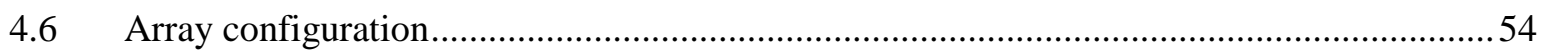

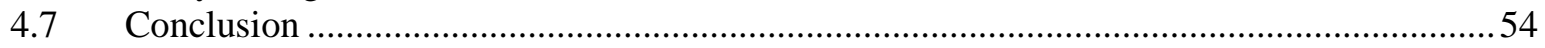

5 APERTURE ARRAY STATION REALIZATION ..............................................56

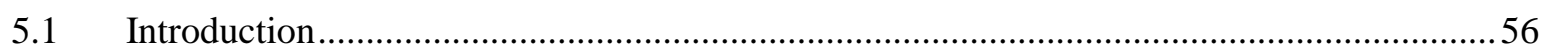

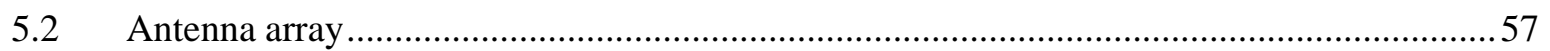

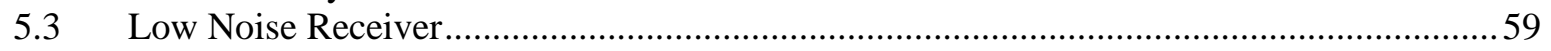

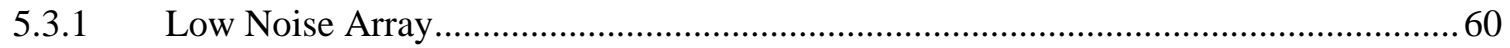

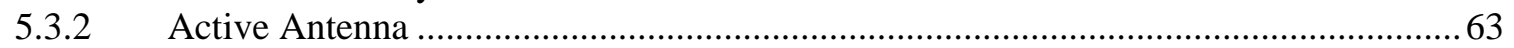

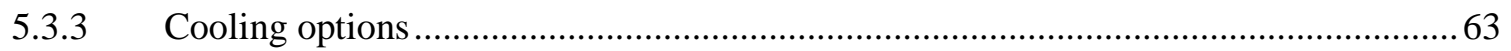

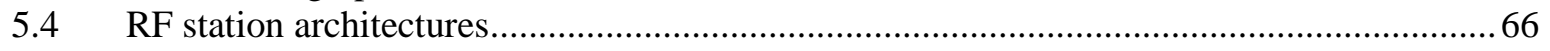

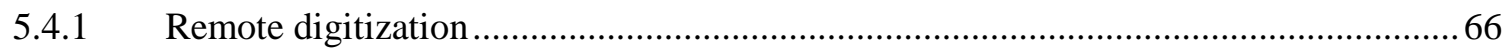

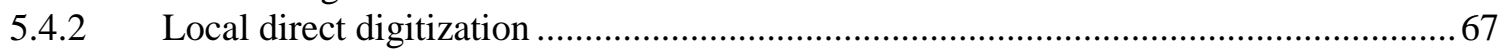

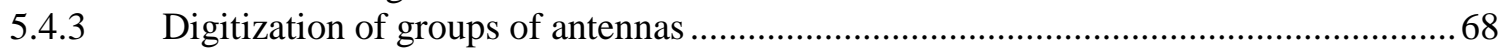

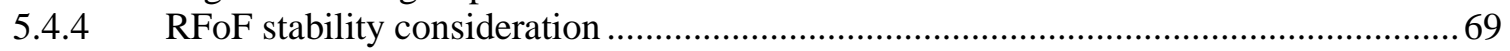

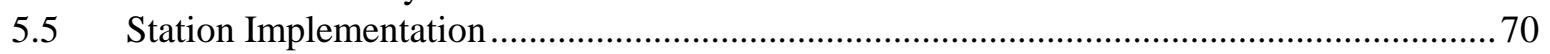

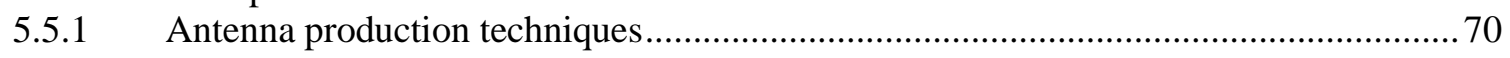

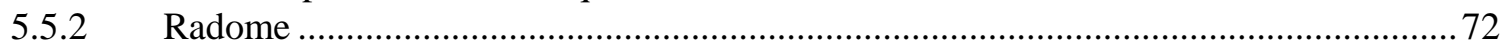

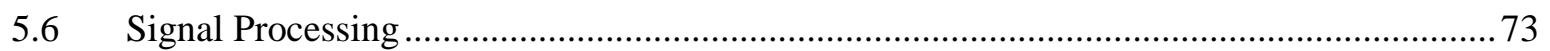

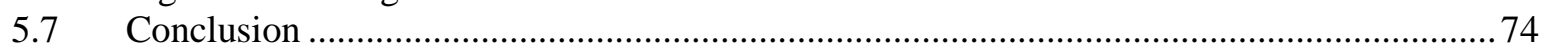

6 COSTING ..................................................................................................................75

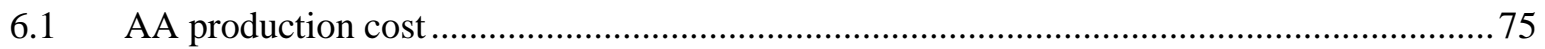

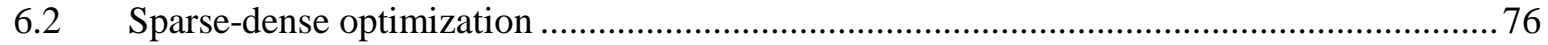

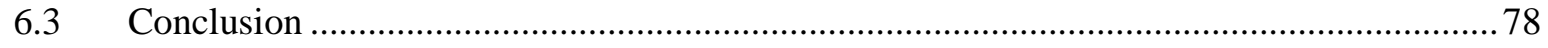

7 CONCLUSIONS AND RECOMMENDATIONS.......................................................79

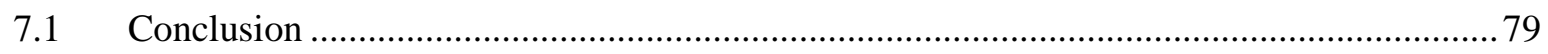

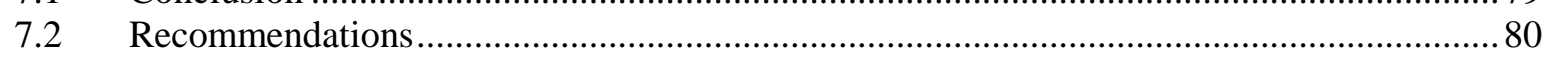

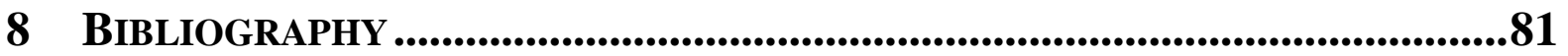




\section{List of Figures}

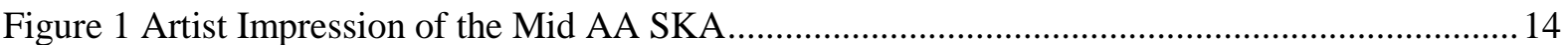

Figure 2 Impression of AA capabilities: pointing the telescope at many sources on the sky simultaneously .14

Figure 3 First SKA configuration concept study, 100m diameter dishes, depicted in the quiet region of the Netherlands and Germany. The Dutch area later became home to LOFAR (credit van

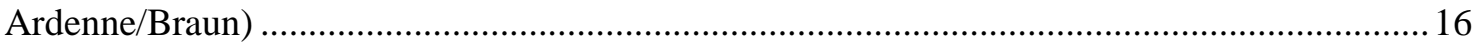

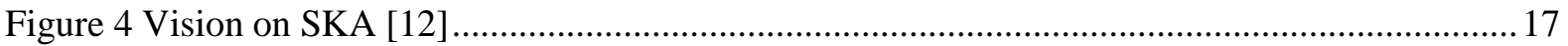

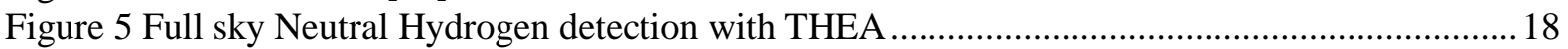

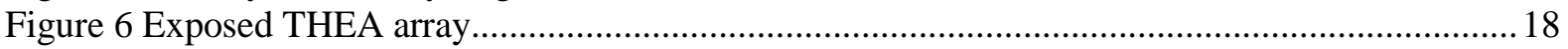

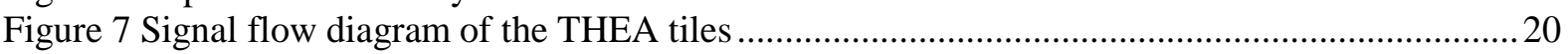

Figure 8 Full sky scan detecting GPS satellites at $1575 \mathrm{MHz}$ on a uv plot. Circles are real satellite

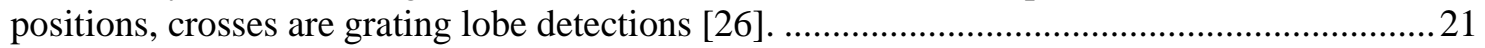

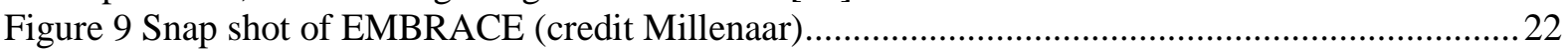

Figure $10 \mathrm{~A}_{\text {eff }} / \mathrm{T}_{\text {sys }}$ simulation of a random-sparse array for different zenith angle $\theta$ scan angles (reproduced from [34]) ....................................................................................................... 31

Figure $11 \mathrm{~A}_{\text {eff }} / \mathrm{T}_{\text {sys }}$ simulation of a dense AA system for different zenith angle $\theta$ scan angles (reproduced

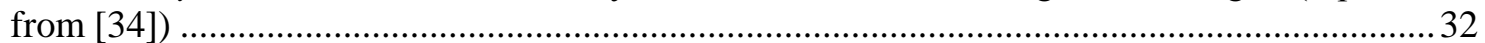

Figure 12 Representative visualisation of a sparse-random mini-station with 400 elements ................32

Figure 13 Representative visualisation of a dense-regular mini-station with 1000 elements ................ 33

Figure 14 Representative visualisation of a sparse-regular mini-station with 400 elements .................33

Figure 15 Array factor calculation for $45^{\circ}$ elevation and $45^{\circ}$ azimuth scan at $1 \mathrm{GHz}$ of the typical station

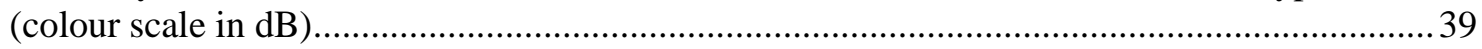

Figure 16 Array factor calculation for $45^{\circ}$ elevation and $45^{\circ}$ azimuth scan at $1 \mathrm{GHz}$ with the station

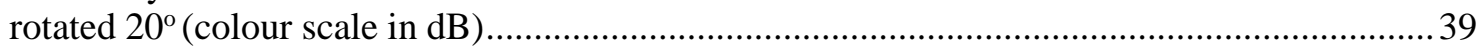

Figure 17 Summed correlations of 9 stations (colour scale in $\mathrm{dB}$ ) ...................................................40

Figure 18 Time for a grating lobe at $1 \mathrm{GHz}$ to move a station beamwidth, depending on station diameter

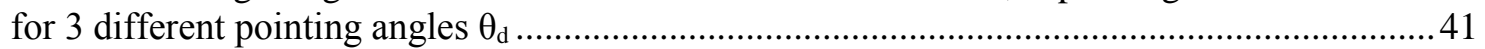

Figure 19 Frequency shift for a grating lobe at $1 \mathrm{GHz}$ to move a station beamwidth, depending on station

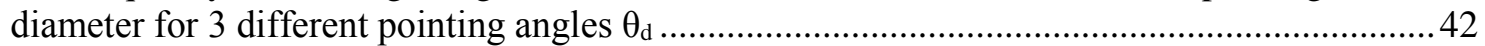

Figure 20 Observable sky in brightness temperature for AAMID based on the Haslam survey [59]. Cold

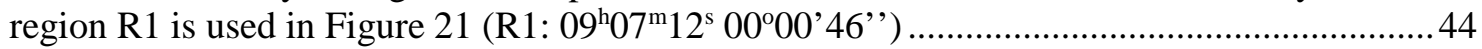

Figure 21 Array temperature computed at $100 \mathrm{MHz}$ for R1 (reproduced from [58]).............................4 44

Figure 22 Array factor calculation of $45^{\circ}$ elevation and $45^{\circ}$ azimuth scan at $1 \mathrm{GHz}$ of a square station (colour scale in $\mathrm{dB}$ ) with $16384\left(2^{14}\right)$ elements, $38 \mathrm{~m}$ diameter and one $\lambda$ element spacing. ..... 46

Figure 23 Visualisation of FFT array beams of a sparse regular array (reproduced from [74]) ........... 51

Figure 24 Required number of stations beams for a constant FoV (blue) and for a constant survey speed

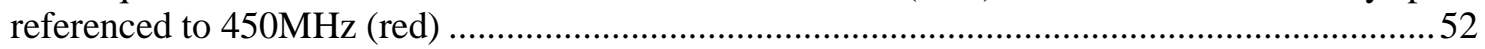

Figure 25 Number of beams required for a $200 \mathrm{deg}^{2} \mathrm{FoV}$ at $1450 \mathrm{MHz}$ for a square station with $2^{14}$ elements in relation to the sparsity of the array at $1450 \mathrm{MHz}$ (from dense to very sparse) ........53

Figure 26 Operations per second for the station processing of a regular station. 'FFT' is applicable to a dense array. 'Oversampled FFT' is applicable to the reference sparse array. ..............................54

Figure 27 Reflection coefficient simulation of a regular array of Log Periodic antennas (blue curve) and the same antenna in a random orientation (red curve) [80]....................................................... 56

Figure 28 Active reflection coefficient simulation of a pyramidal sinuous array with an element spacing $\mathrm{d}=\lambda$ at $450 \mathrm{MHz}(0.67 \mathrm{~m})$ for 450,950 and $1450 \mathrm{MHz}$ for scans to $30^{\circ}$ elevation angles. Reference impedance is $300 \Omega$.

Figure 29 Thinned sparse-regular array concept, x direction thinned only. Red crosses are element

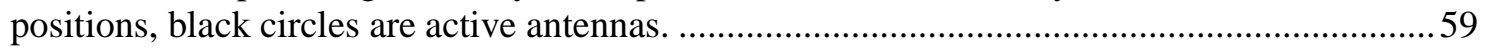

Figure 30 Noise temperature measurements of a small active Vivaldi array [98] as a function of scan angle. South-North in $\sin (\theta) \sin (\varphi)$, West-East in $\sin (\theta) \cos (\varphi)$. Colour scale in kelvin............... 61 
Figure 31 Active reflection coefficient simulation of a 64-element Vivaldi array with $0.1 \mathrm{~m}$ antenna pitch as function of scan angle. Scale in $\mathrm{dB}\left(\Gamma_{\text {act }}\right)$

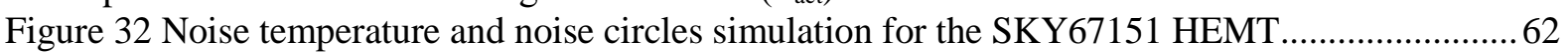

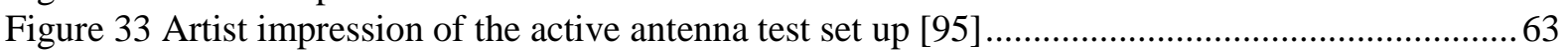

Figure 34 GaAs Low Noise Amplifier mounted on a Peltier element ....................................................64

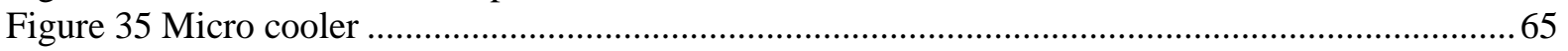

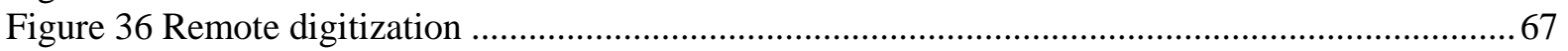

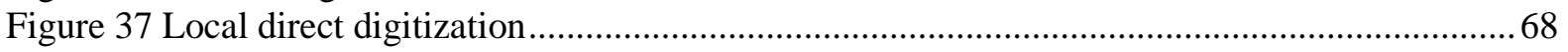

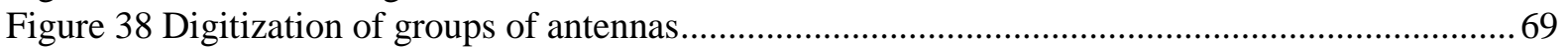

Figure 39 Four element antenna and beamformer board used in THEA ............................................. 71

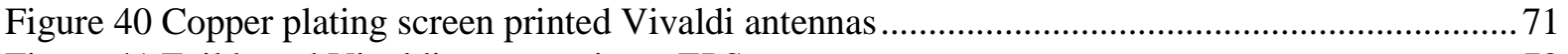

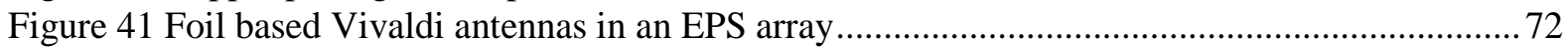

Figure 42 Global THEA Radome, after a snow blizzard ..................................................................... 73

Figure 43 Local shielding, environmental proto types at the SKA site in the Karoo, South Africa..... 73

Figure 44 Front end cost dependence on the antenna element pitch based on LOFAR and EMBRACE

Figure 45 Normalized average $A_{\text {eff }}$ / cost for an AA system with 200 deg $^{2}$ FoV for different antenna element spacings (d) and for three different front-end back-end cost ratios. 


\section{List of Tables}

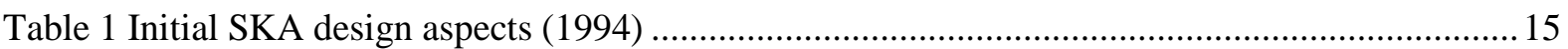

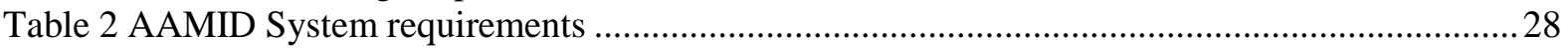

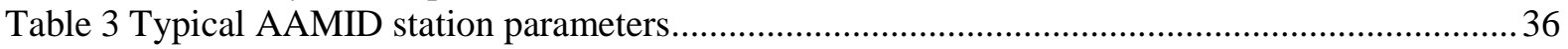

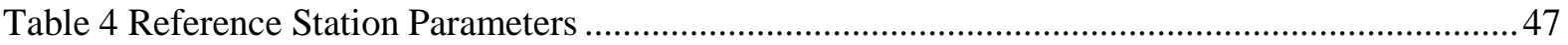

Table 5 Comparison of cooling methods and noise temperature .......................................................... 65 


\section{Summary}

The discovery of radio astronomy dates back to 1928, when Karl Jansky made the first detection of cosmic noise static. Radio astronomy is therefore a relatively young science and its development is completely in parallel with the radio technology enhancements, including the modern information technology. Radio astronomy has been often at the forefront; the first adopters of new technologies and capabilities. Very often radio astronomy triggered inventions that have been of direct use for other sciences and society.

With the advent of digital signal processing, faster and smaller computers, radio astronomy has progressed at a very high pace. Arrays are being designed and built that contain thousands of individual antennas, connected and processed with digital signal processing, enabling very high performance.

The conception of the Square Kilometre Array can be directly linked to the potential of Aperture Arrays (AA). As early as 1994 first sketches of the Square Kilometre Array consisted of flat electronically steerable panels. This AA telescope, briefly called the HI telescope, after the HI resonant line at $1421 \mathrm{MHz}$, would run from 150 to $1450 \mathrm{MHz}$. Although AAs are technically feasible, SKA1 will use dishes for the frequencies above $350 \mathrm{MHz}$. This dissertation addresses the requirements, system design and possible implementation of an AA system for the SKA2, the second phase of the square kilometre array project. Aperture Arrays have the potential of instantaneous all-sky observations, creating a very powerful telescope. However, the realization of this telescope is not without challenges in cost, power consumption and operational performance. The research in this dissertation explores the potential of the sparse-regular array concept. Sparse-regular arrays are in use for lower frequency telescopes but implementation of this concept has not been considered for higher frequencies; up to the $\mathrm{HI}$ line at $1421 \mathrm{MHz}$. It will be argued with a new proposed figure of merit, average sensitivity divided by system cost, that a sparse-regular design can be superior to a dense or sparse-random system.

This dissertation therefore provides an alternative solution for aperture arrays for the SKA and in particular focusses on a possible realization. A realization which takes signal processing into account that goes a step further than 'just' build a telescope that can do the same as dishes, but a bit better. For this it is proposed to use Fast Fourier Transform signal processing, enabled by a regular antenna placement structure. FFT signal processing will reduce the processing load significantly and fully utilizes the potential of AA's. Therefore, regular arrays, sparse or dense, will be lower in cost and power consumption and superior in performance when compared to random arrays. This dissertation concludes that the sparse-regular concept, although technically feasible, has a number of significant drawbacks and therefore might not be the design of choice for SKA2. 


\section{Opsomming}

Die ontdekking van radiosterrekunde dateer terug na 1928 toe Karl Jansky die eerste waarneming van kosmiese ruis gedoen het. Radiosterrekunde is derhalwe 'n relatiewe jong wetenskap, en sy ontwikkeling verloop volledig in parallel met die van radio tegnologie, insluitend moderne informasie tegnologie. Radiosterrekunde loop dikwels op die voor front van ontwikkel met die dat die gemeenskap graag nuwe tegnologie vroeg opneem in hulle stelsels. Dikwels het radiosterrekunde ook tot gevolg die ontwikkeling van nuwe innoverende tegnologie met meer direkte toepassing in die breër wetenskappe en samelewing.

Met die onlangse vooruitgang van syferseinverwerking, en kleiner en vinniger rekenaars, het radiosterrekunde teen 'n uiters hoë tempo ontwikkel. Antenna samestellings word ontwerp en gebou met duisende individuele elemente, almal verbind en die afvoer data verwerk deur syferseinverwerking, wat baie hoë werkverrigting stelsels tot gevolg het.

Die idee van die "Square Kilometre Array" (SKA) teleskoop hou direk verband met die potensiaal van stralingsvlak samestellings (AA). So vroeg soos 1994 het die eerste sketse van die SKA plat elektronies stuurbare antennas voorgestel. Hierdie AA teleskoop, tydelik bekend as die Waterstof teleskoop, na die Waterstof resonante lyn by $1421 \mathrm{MHz}$, sou 'n bandwydte van 150 tot $1450 \mathrm{MHz}$ hê. Alhoewel AAs tegnies lewensvatbaar is, sal die SKA1 teleskoop weerkaatser antennas gebruik vir frekwensies bo $350 \mathrm{MHz}$. Hierdie proefskrif spreek die behoeftes, stelsel ontwerp en moontlike implementering van 'n AA stelsel vir SKA2, die tweede fase van die SKA teleskoop projek, aan. Stralingsvlak samestellings het die potensiaal vir oombliklike vol hemelruim waarnemings, en skep so 'n uiters kragtige teleskoop. Die praktiese uitvoerbaarheid van so 'n teleskoop is egter nie sonder sy uitdagings nie - spesifiek in koste, kraggebruik en operasionele werkverrigting. Die navorsing in hierdie proefskrif ondersoek die potensiaal van die yl-reëlmatige samestelling konsep. Yl-reëlmatige samestellings word vir laer frekwensie teleskope gebruik, maar die implementering van hierdie konsep is nog nie ondersoek vir hoër frekwensies, tot by die Waterstof lyn by $1421 \mathrm{MHz}$, nie. Daar sal geargumenteer word dat met 'n nuwe voorgestelde werkverrigtingsmaatstaf, gemiddelde sensitiwiteit gedeel deur stelsel koste, dat'n yl-reëlmatige ontwerp kan verbeter op 'n digte-reëlmatige of yl-lukrake stelsel.

Hierdie proefskrif bied dus 'n alternatiewe oplossing vir die stralingsvlak samestellings vir die SKA, en fokus spesifiek op 'n moontlike relaisering daarvan. Die realisering neem syferseinverwerking behoeftes in ag, en gaan 'n stap verder as om net'n teleskoop te ontwikkel wat dieselfde as 'n ekwivalente weerkaatser antenna gebaseerde teleskoop kan doen. Hiervoor word daar voorgestel dat vinnige Fourier transvorm (FFT) seinverwerking ingespan word, wat moontlik gemaak word deur die reëlmatige verspreiding van die antenna elemente. FFT seinverwerking sal die bewerkingslas van die stelsel dramaties verlaag, en sodoende die volle potensiaal van stralingsvlak samestellings kan uitbyt. Daarom sal die reëlmatige samestelling konsep, yl of dig, laer koste in terme van verwerkingslas en kraggebruik hê, en beter werkverrigting bied, as ekwivalente lukrake samestellings. Hierdie proefskrif kom tot die gevolgtrekking dat die $y l$-reëlmatige konsep, al is dit tegnies lewensvatbaar, steeds ' $\mathrm{n}$ aantal beduidende nadele inhou, en daarvoor nie noodwendig die ontwerpkeuse vir die SKA2 behoort te wees nie. 


\section{Samenvatting}

Astronomie is waarschijnlijk zo oud als de mensheid, de eerste waarnemingen van radiogolven zijn echter van relatief recente datum. In 1928 werkte de jonge radio-ingenieur Karl Jansky aan ontvangers voor Bell Labs in de Verenigde Staten en ontdekte dat de storende ruis op de lijn, die de intercontinentale verbinding praktisch onmogelijk maakte, uit het heelal kwam: kosmische ruis. Landen tijdgenoot Grote Reber lokaliseerde zes jaar later met een zelfgebouwde radiotelescoop de radiogolven expliciet in de Melkweg.

Toen de Leidse sterrenkundige prof. Jan Hendrik Oort in de vroege oorlogsjaren Rebers' artikel in de Astrophysical Journal had gelezen tekenden zich de eerste contouren van een nieuwe wetenschap af. Hoewel student Henk van de Hulst al in 1944 tijdens een geheime bijeenkomst in de donkere kamer van de Leidse Sterrewacht voorspelde dat de radiogolven afkomstig moesten zijn van waterstofatomen, duurde het nog tot 1951 voor Lex Muller in Kootwijk met een afgedankte Würzburg radarschotel de waterstoflijn waarnam. Met dit tastbare bewijs werd de weg vrijgemaakt voor de bouw van de Dwingeloo Radio Telescoop en de stichting van de Nederlandse Radiosterrenwacht (ASTRON). Radioastronomie is daarmee een relatief jonge wetenschap waarvan de ontwikkeling vaak parallel loopt met de voortgang van de technologie. Radioastronomie is zelfs vaak de trigger geweest voor nieuwe ontdekkingen in de techniek, onze wifi communicatiestandaarden bijvoorbeeld hebben hun oorsprong in toenemende kennis over radiogolven. De ontwikkeling in de computerindustrie van steeds snellere en kleinere systemen heeft de radioastronomie een belangrijke impuls gegeven: grote reeksen (arrays) van duizenden individuele antennes (dit betreft zowel de traditionele schotels als innovatieve ontwerpen) worden met elkaar verbonden door middel van digitale signaal processors, waardoor grote gevoeligheden worden bereikt en het heelal steeds nauwkeuriger bestudeerd kan worden. In Nederland werd met de veertien traditionele schotelantennes van de Westerbork Synthese Radiotelescoop (1971) onder andere het bestaan van Dark Matter aangetoond.

In de zoektocht naar diepere kennis van ons universum werd begin jaren '90 het plan voorgesteld om een telescoop te realiseren met een honderd keer hogere gevoeligheid dan bestaande instrumenten. Dit zou mogelijk moeten zijn met een ontwerp ter grote van een vierkante kilometer, de Square Kilometre Array (SKA). Het concept van de SKA radiotelescoop is direct gerelateerd aan de potentie van Aperture Arrays (AA): vele duizenden en mogelijk miljoenen kleine antennes. De eerste schetsen van SKA uit 1994 gaven een beeld van platte elektronisch bestuurbare antennes. Het ontwerp was gericht op het waarnemen van dezelfde waterstoflijn die door Lex Muller al werd waargenomen: de spectrale lijn uitgestraald door het waterstofatoom op $1421 \mathrm{MHz}$. Nu, 25 jaar later, wordt in de Murchison in West Australië en in de Zuid-Afrikaanse Karoo de eerste fase van SKA gebouwd: SKA1. In SKA1 worden 100,000 antennes in een AA gerealiseerd voor het lagere frequentiespectrum tot 350 MHz. Voor de hogere frequenties zullen in SKA1 meer traditionele telescopen, de bekende schotels, worden gebruikt.

Dit proefschrift richt zich daarom op de eisen, het systeemontwerp en mogelijke implementatie van AA's in de tweede fase van SKA en dan met name voor de hogere frequenties tot $1421 \mathrm{MHz}$. AA's hebben de mogelijkheid om de gehele zichtbare hemel tegelijkertijd te observeren omdat het blikveld van de individuele antennes niet begrensd is. Een dergelijke telescoop met miljoenen antennes blijkt met de bestaande technologie niet kosteneffectief te realiseren.

Het onderzoek is toegespitst op de mogelijkheid om een kostenbesparende uitvoering van een AA te bouwen en richt zich voornamelijk op het systeemontwerp van de antenne arrays. Een zogenaamd sparse-regular array concept waarbij in het ontwerp minder antennes worden gebruikt door ze ver uit elkaar te plaatsen (sparse). Indien de besparing regelmatig (regular) gedaan wordt uit een regelmatige antenne array dan kan, ook na het uitdunnen, een kosteneffectieve signaalprocessing techniek worden 
toegepast, de zogenaamde Fast Fourier Transform (FFT). Met FFT bundelvorming kan de volledige capaciteit van AA's worden benut, namelijk een volledige complete hemelobservatie. Voor de vergelijking van de verschillende array opties wordt een evaluatiecriterium voorgesteld: gemiddelde systeemgevoeligheid gedeeld door systeemkosten. Dit criterium is doorgerekend voor een aantal besparende ontwerpen en verschillende verhoudingen van antenne- en signaalprocessingkosten. De toepassing van dit criterium levert een interessante conclusie op, namelijk dat een uitgedund array weliswaar een optie is voor SKA2, echter ook dat het sparse-regular concept mogelijk niet de beste keuze is voor SKA2. 


\section{Acknowledgments}

Many people have contributed to the work in this dissertation. In particularly I want to emphasize that a telescope of the scale of AAMID will be the work of many and the prototype and engineering research work I participated in was no exception; colleagues, from ASTRON and international partner institutes, students and trainees made a broad exploration possible. Only a small part of that work has been brought forward in this dissertation. Without trying to list all names, I want to thank the team that worked with me on THEA, the consortium members of SKADS and MFAA, the students who came to ASTRON for a BSc, MSc or PhD project and the students at Stellenbosch University. The following people have been essential in the completion of this dissertation:

- Arnold van Ardenne's inspiration has been central for the AA work at ASTRON. His initiative to start a comprehensive research program at ASTRON and to initiate European projects has been crucial for the progress in aperture arrays.

- My supervisors, Prof. David Davidson and Prof. Dirk De Villers, for their guidance, support and fruitful discussions. My extended stays at Stellenbosch University have always been very useful and pleasant.

- Andy Faulkner, for his vision and driving force to get things going.

- The travel grant, co-funded by the South African National Research Foundation (NRF) and the Dutch Nederland Wetenschappelijk Onderzoek (NWO), NRF-NWO Exchange Programme in Astronomy and Enabling Technologies for Astronomy, facilitated the exchange and supported the travel cost.

- Nima Razavi-Ghods, for providing Xarray.

- Inger Bij de Vaate, for her assistance with Matlab.

- Dagmar Bij de Vaate, for her work on checking my grammar and spelling.

- My wife, Anke, and our children Inger, Igor and Dagmar for their never ending support in the process of the work on this dissertation. 


\section{Preface}

In the early 90's, I started my career to work on phased array systems for defence purposes. At that time the radar systems, for defence and civil applications, consisted mainly of rotating reflector antennas, the classic image of the ship and airport radar. The main concern with these systems is that a lot can happen between two detections of a target, when the antenna is scanning around, and targets can be missed or detected too late. This triggered the introduction of a new technology, the phased array systems with an, in principle, instantaneous all-sky capability. This was actually a re-introduction since phased array technology has been used successfully in the 30's and 40's for enemy plane and ship detection prior to and in World War II, at that time with limited capabilities and no smart electronics.

The phased array system I was assigned to had only a single beam, but had one essential advantage over the rotating reflector radar: very fast pointing to every possible direction. The significant extra cost of the system, at least one order of magnitude higher than existing solutions, for the construction and operation of $\sim 10,000$ antenna elements, was acceptable for the customer. In a conservative environment, as defence decision making bodies tend to be, a new technology, with all the risks associated, could be introduced successfully.

Moving from radar defence systems to radio astronomy systems in 1998, I was faced with a similar situation with the introduction of phased arrays - aperture arrays - for radio astronomy. Potentially very capable, however excellent science was and still is done with dishes. Would a new technology, with possibly millions of antennas, be of interest to the community?

The introduction of new technology, triggering a revolution, has been the topic of study for many scientists, managers and politicians. Technology push or market pull? Without trying to summarize and simplify large international studies, I think a number of conditions have to be met: the customer should get something which is otherwise not possible, technology should be sufficiently mature, and the price level should be right. From this the first condition is most essential.

The target in the early 2000s, to introduce phased array technology for frequencies up to $1421 \mathrm{MHz}$ in the early phases of Square Kilometre Array (SKA) [1], failed. At the same time aperture array technology has been very successfully introduced in the lower frequency range, with LOFAR and SKA1-Low as good examples. Interestingly, this reveals another analogy with my radar experience. Although the X-band phased array radar $(\sim 10 \mathrm{GHz})$ I worked on has been successful, the lower frequency L-band phased array systems $(1.2 \mathrm{GHz})$ have been a much better sell.

Early implementation proposals of phased arrays for the mid frequencies of SKA did not comply with the first condition postulated above. Due to limitations of available technology a larger field of view could be provided but only for a very limited number of directions on the sky, basically one or two. This would be more than a dish can provide, however with a very high added cost and complexity. In this dissertation I will argue that the two decades of research I participated in have been very useful, however when we shoot for a higher goal using technology that will become available in 10 to 15 years from now, a phased array system can be realized that will comply with all conditions: exceptional science will be possible with aperture arrays, with mature technology, and for the right price. Dishes will become redundant for the frequencies under consideration. This era is still to come. 


\section{The Mid Frequency Aperture Array Telescope}

\subsection{Introduction}

The sky has always been a strong source of man kind's imagination and science of astronomy dates back to ancient times, with the naked eye as the single instrument until the invention of the optical telescope $\sim 1500$ CE. Radio astronomy is a relatively young science and only represents a modest part of the range of astronomical wavelengths. Optical astronomy in the visible regime (a human eye responds to wavelengths of 380 to $740 \mathrm{~nm}$ ) is as old as mankind, and still very powerful. Extra-terrestrial radiation can be observed in a much wider range from very low frequencies with wavelengths of hundreds of meters to X-ray radiation with 0.01 nanometer wavelengths. From this range the radio waves extend from $30 \mathrm{~m}$ to $0.3 \mathrm{~mm}(10 \mathrm{MHz}$ to $1 \mathrm{THz}$ ), far infrared, visible optical light and X-rays broadly covers $1 \mathrm{~mm}$ to $0.01 \mathrm{~nm}$; five decades for the typical radio range and another eight decades for the other wavelengths. Not all wavelengths provide interesting science, but it is very often the combination of different observations that creates the understanding of physical phenomena. The demarcation of radio and optical is not very specific and only relates to detection techniques. For low frequencies, typically below $1 \mathrm{THz}$, it is relatively straightforward to realize phase coherent receivers. This allows in-phase addition or correlation of signals of different receptors, essential for the realization of very large collecting areas since steerable telescopes cannot be made infinitely large. The drive to large areas, lenses, mirrors or (radio) dishes, relates to one of the key figures of merits in astronomy, the sensitivity to weak signals. A second key Figure of Merit (FoM), the resolution, depends on the diameter of the receiving system. Both these figures of merit are very well served with a large number of distributed sensors and coherent detection. This makes the radio astronomy systems very powerful.

A special case forms the frequencies below $30 \mathrm{MHz}$. The ionosphere blocks low frequency radiation from reaching the earth and therefore these systems need to be space based, either in an orbit around the earth, the moon or at a Lagrange point. Plans to deploy large arrays in space are considered but only modest single element receivers have been realized [2].

This work will concentrate on the development of the largest of the next generation radio telescopes, the Square Kilometre Array (SKA). The full SKA will be 100x more sensitive and will survey the sky a million times faster than any present radio telescope. The selected frequency range, driven by a wide range of science cases, is $50 \mathrm{MHz}$ to $22 \mathrm{GHz}$. This range will be covered by different types of receptors. The lower frequency system(s) will be realized with arrays of non-moving, electronically steerable, antennas; phased-arrays or also known as aperture arrays in the field of radio astronomy. The higher frequencies will be received with a reflector type system. The division in the frequency band for the two receiver types, aperture arrays or dishes, is a very complex consideration between cost and performance but also in terms of technology readiness level (TRL). For SKA1 it has been decided to use aperture arrays (AA's) for 50 to $350 \mathrm{MHz}$ and dishes for $350 \mathrm{MHz}$ to $22 \mathrm{GHz}$. For the full SKA, SKA2, AA's are considered for higher frequencies as well, up to $1.45 \mathrm{GHz}$. The SKA will be built in Southern Africa and in Australia.

The SKA project will be executed in two phases, SKA1 and SKA2. SKA1 will have $10 \%$ of the final size and will have reduced capabilities. Still, SKA1 will be a very power instrument in its own right with better performance than any existing telescope in this frequency range.

Aperture Arrays (AA's) are the enabling technology that will fulfil one of the promises of the SKA: A transformational survey machine [3]. The Mid Frequency Aperture Array (MFAA) is planned to operate from 350 to $1450 \mathrm{MHz}$ and is particularly well suited to perform the billion galaxy survey [4]. This will advance our understanding of galaxy formation and evolution, and help determine the nature of dark energy. In addition, MFAA will accommodate a range of survey related science projects 
profiting from the wide field-of-view, large bandwidth, and the unique capability of aperture arrays to observe multiple fields-of-view simultaneously. See Figure 1 and Figure 2 for an artist impression of the stations and their potential capability: four different observations are run independently. This is clearly not possible with a mechanical steerable reflector system.

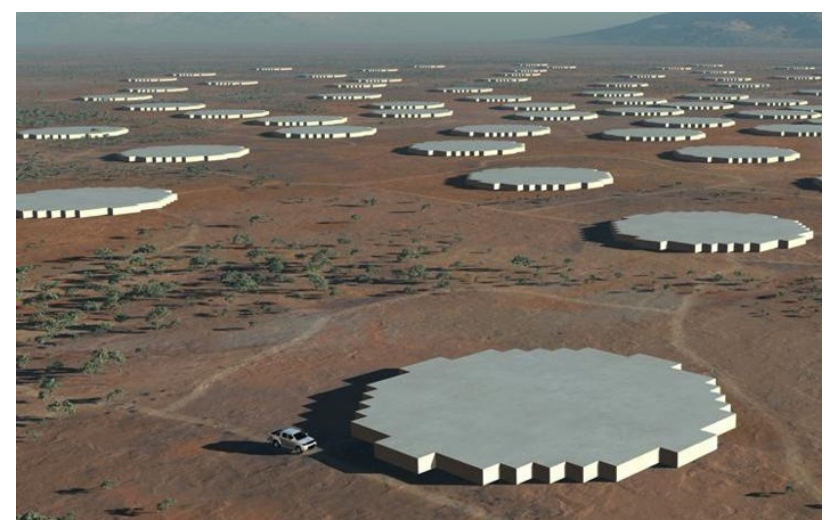

Figure 1 Artist Impression of the Mid AA SKA

The MFAA based system is currently in its initial design phase. A system requirements review has been held in July 2016 and the realisation of a large scale prototype in the Karoo, South Africa, is considered for 2020-2022.

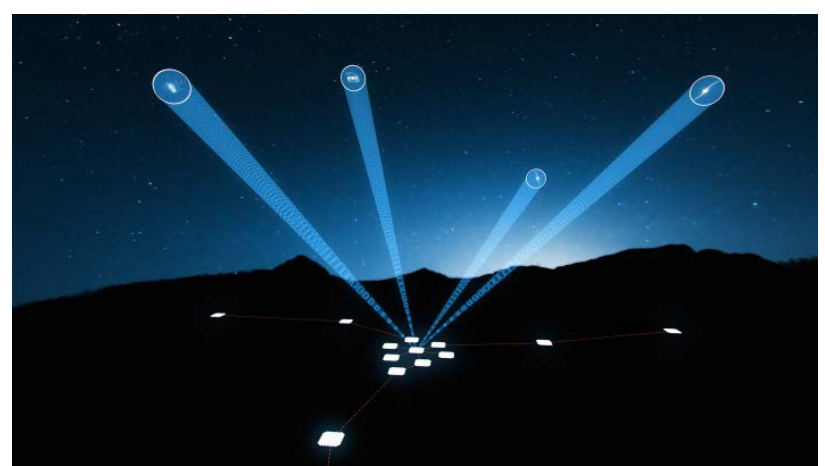

Figure 2 Impression of AA capabilities: pointing the telescope at many sources on the sky simultaneously

In the terminology of the SKA, MFAA only deals with the antenna stations, which will be connected to an infrastructure, correlator and imaging system. In this dissertation the term AAMID telescope will be used to refer to the complete Aperture Array MID frequency system.

\subsection{Aperture Arrays in Radio Astronomy}

Radio Astronomy has for long been synonymous with the use of large metal reflectors: dish based telescopes in which the radio waves are reflected to a single antenna receiver. The first detection of radio waves from the universe were however realised with a two element dipole array, a $20.5 \mathrm{MHz}$ receiver build by K. G. Jansky in 1928 [5] and [6]. This detection triggered the radio astronomy research and an avalanche of discoveries in the $20^{\text {th }}$ century. Parallel to the realisation of large reflector instruments low frequency dipole arrays have been built in the 1950s and 60s. The most successful and largest of these early arrays is the Interplanetary Scintillation Array (IPS) [7], a radio telescope realized at the Mullard Radio Astronomy Observatory near Cambridge UK with 4096 dipoles operating at 81.5 MHz. The large total aperture of $36,000 \mathrm{~m}^{2}$ was only surpassed by the stationary 305 meter diameter 
Arecibo radio telescope. The IPS Array became famous with the discovery of pulsars by Jocelyn Bell. Only recently, with the advance of integrated low cost electronics, new very powerful aperture array telescopes are being constructed. LOFAR [8], an SKA pathfinder, and MWA [9] , an SKA precursor, both consist of a large number of dipole antennas with electronic beam steering and require (and benefit) from digital signal processing in order to form beams on the sky. LOFAR and MWA have a maximum operating frequency of $240 \mathrm{MHz}$.

\subsection{Conception of the Square Kilometre Array: the HI telescope}

First SKA sketches, drawn as early as 1994, show a telescope concept existing of (dipole) antenna arrays, based on the assumption that a dish array of the size of a square kilometre could not be built cost effectively and would not give the required performance enhancement [10]. This assumption triggered a sequence of research and development plans based on closely packed antenna arrays with electronic beam steering: Aperture Arrays. The initial requirements laid out even earlier in 1991 are surprisingly relevant today [11], with possibly the location, the Netherlands, as the most significant difference with the current vision on SKA. Some of these numbers are in Table 1.

Table 1 Initial SKA design aspects (1994)

\begin{tabular}{|c|c|c|}
\hline Parameter & Quantity & Updates \\
\hline Effective area & $1 \mathrm{~km}^{2}$ & MFAA System design suggests $0.5 \mathrm{~km} 2 \mathrm{might}$ be sufficient \\
\hline System temp & $50 \mathrm{~K}$ & Room temperature device, current target $40 \mathrm{~K}$ \\
\hline Frequency range & $150-1500 \mathrm{MHz}$ & $\begin{array}{l}\text { SKA1-Low will cover the } 50-350 \mathrm{MHz} \text {, SKA has been extended } \\
\text { to } 22 \mathrm{GHz}\end{array}$ \\
\hline Cost envelope & $\$ 200$ million & $\begin{array}{l}\text { The high frequency SKA2 MFAA stations are estimated to be } \\
€ 600 \text { million. The full SKA1 is in that same price range }\end{array}$ \\
\hline \#number of stations & 100 & $\begin{array}{l}\text { Each consisting of } 10,000 \text { tiles of } 1 \mathrm{~m}^{2} \text { size }(100 \times 100 \mathrm{~m} \text { station } \\
\text { size), still considered }\end{array}$ \\
\hline Beams & Many & Multiple beam capacity very important \\
\hline
\end{tabular}

The production version of these tiles was envisioned to be low cost flat structures, easy to install, no maintenance with simple dipole style antenna. Limited consideration was given to the signal processing at that time. Realizing a decade wide band low cost antenna element is however complicated, a multiple band approach will mitigate the complexity of the antenna design. 


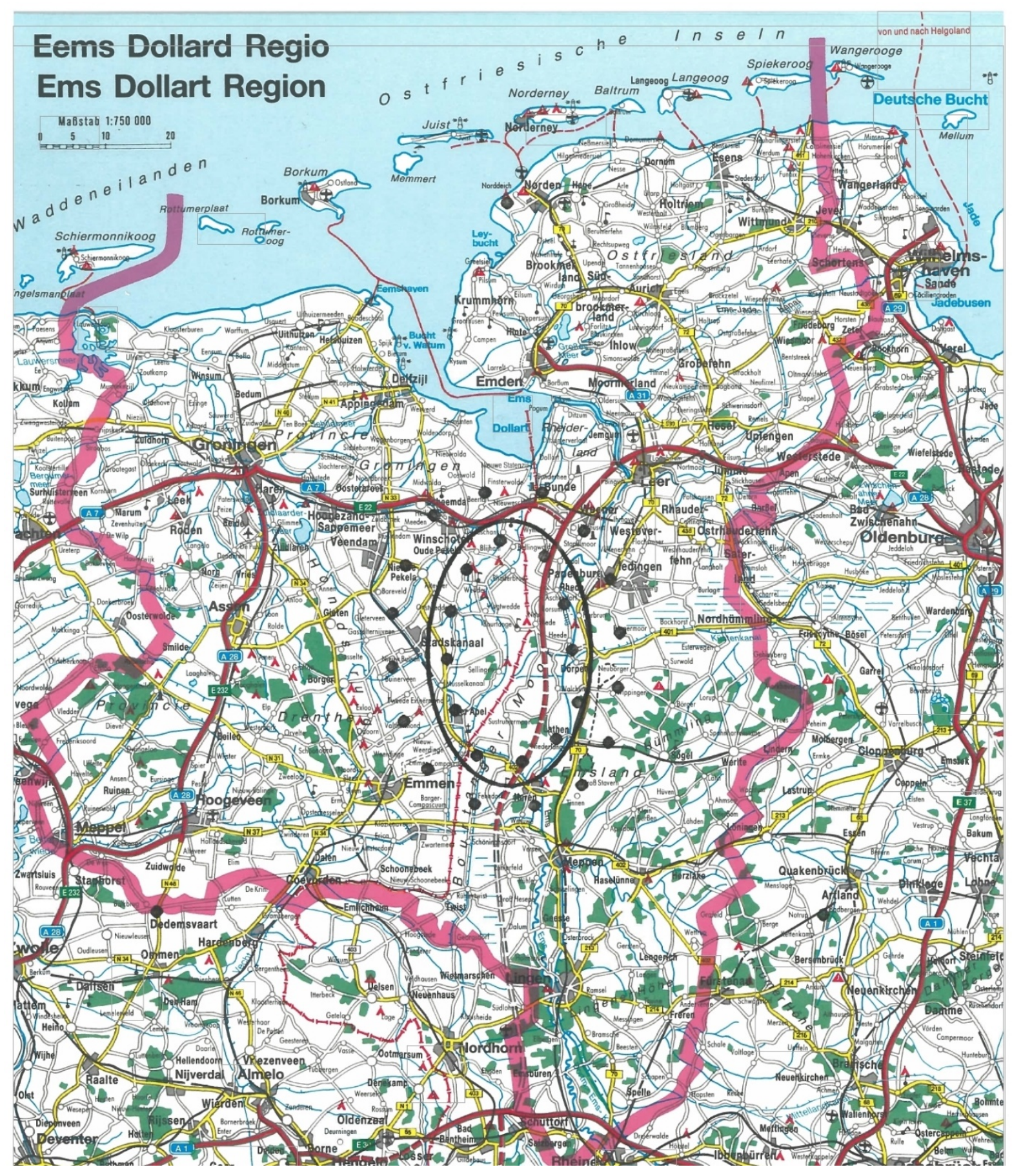

Figure 3 First SKA configuration concept study, 100m diameter dishes, depicted in the quiet region of the Netherlands and Germany. The Dutch area later became home to LOFAR (credit van Ardenne/Braun) 


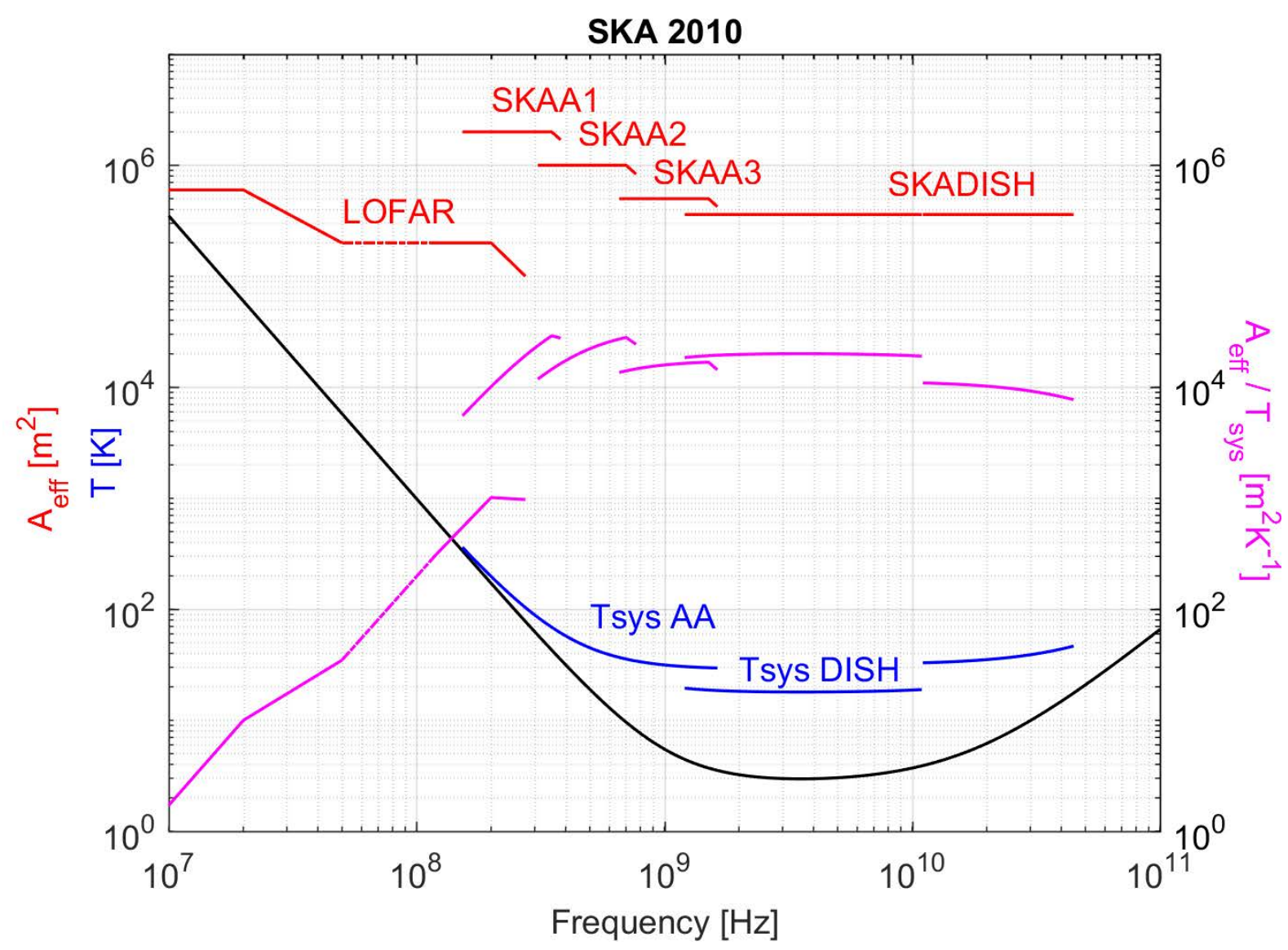

Figure 4 Vision on SKA [12]

Figure 4 depicts an earlier SKA system study, when the SKA was assumed to be built in 2010. Three types of relatively narrow band AAs would cover the first decade of the frequency band, A1 to A3, complemented with an array of small dishes (reproduced from [12]). In this:

- $\quad$ SKAA1 equals 2 million square meter, $2.10^{6} \mathrm{~m}^{2}$

- $\quad$ SKAA2 equals $1.10^{6} \mathrm{~m}^{2}$

- $\quad$ SKAA3 equals $0.5 \cdot 10^{6} \mathrm{~m}^{2}$

With a 70\% aperture efficiency and $12 \mathrm{~m}$ diameter 4500 dishes would be needed for the dish array.

In [13] scientific requirements of this early phase SKA are evaluated. One aspect is the possible need for widely spaced beams: beams or fields-of-view which can be pointed at different objects on the sky separated by significantly more than the primary beamwidth of the system. Nearly $50 \%$ of the science cases would benefit from widely spaced multi-beams. This is only possible with aperture arrays.

The research on AA's for astronomy of the last two decades represents a significant knowledge base and has delivered prototype instruments in the higher frequency regime and operational telescopes for lower frequencies (e.g. MWA and LOFAR). However, for the building and realization of the AAMID telescope a number of fundamental questions are still to be solved. The research in this $\mathrm{PhD}$ project will concentrate on a unique solution to harvest the full potential of AA's. 


\subsection{Research in AAs for the MID frequencies}

Soon after the conception of the SKA, the Netherlands Institute for Radio Astronomy, ASTRON, established a research program targeting at the development of AA technology for HI frequencies with moderate to high red shifts [14]. The first results of that program delivered the Adaptive Array Demonstrator (AAD) [15], an 8 element array, the One Square Meter Array (OSMA) [16] and the Thousand Element Array (THEA) [17]. OSMA was a scaled frequency version, demonstrating technology, but it was with THEA that the first radio astronomy observations at the nominal HI frequency of $1421 \mathrm{MHz}$ have been realized with an aperture array [18] [19] [20]. This led to the first all-sky 24hour HI observation which was only possible with the agile electronic beamforming of the AA concept; a snapshot is plotted in Figure 5.

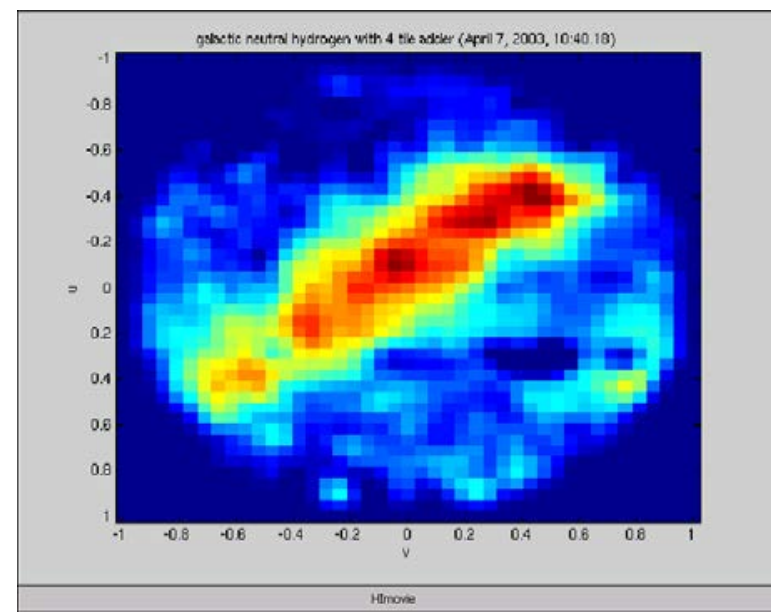

Figure 5 Full sky Neutral Hydrogen detection with THEA

The photograph in Figure 6 shows the single polarization THEA Vivaldi array with radome removed.

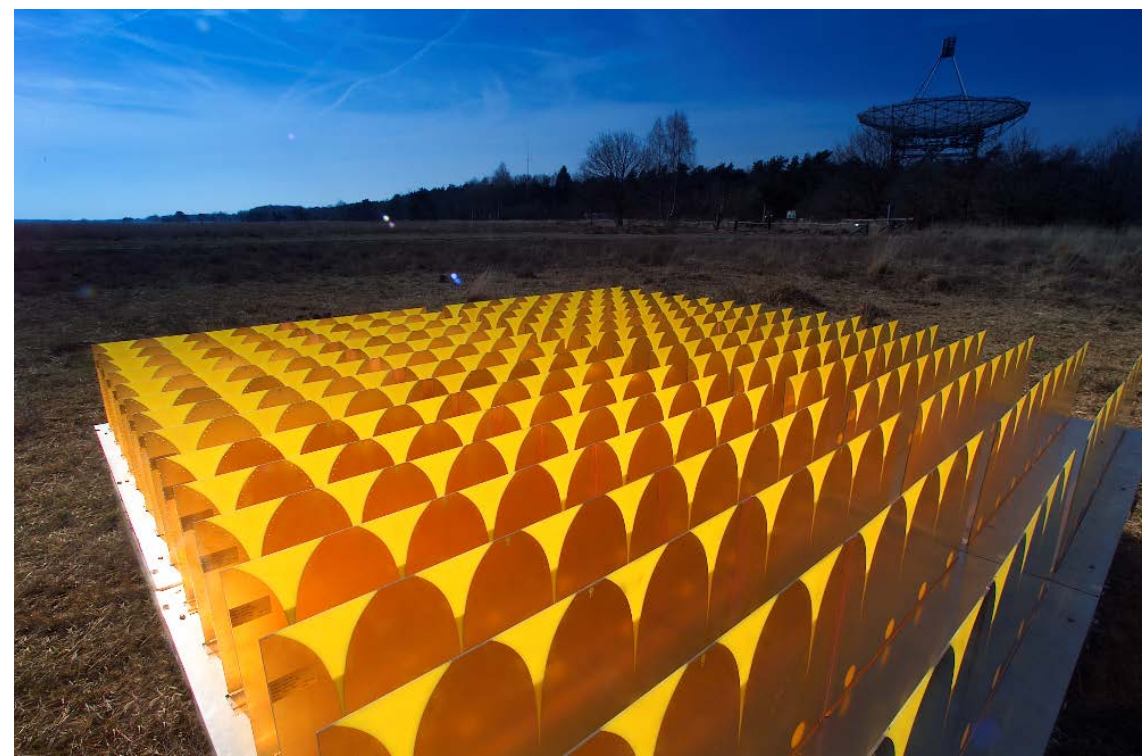

Figure 6 Exposed THEA array

These demonstrations of the capabilities of AA technology formed the basis of a large SKA EU program: SKA Design Study (SKADS) [21] [22], which ran from 2006 to 2011. Two large, $100 \mathrm{~m}^{2}$, AA demonstrator systems have been realized in SKADS, one in the Netherlands near the Westerbork 
Synthesis Telescope and one in France near the Nançay Radio Telescope. As a lead up to this, AA's had been coined "The European Concept for the SKA" [23] and larger prototypes, up to $1000 \mathrm{~m}^{2}$, have been proposed [24].

\subsubsection{AAD}

The Adaptive Array Demonstrator (AAD) consisted of 8 patch antenna elements configured in a 2x4 regular arrangement operating at $5.2 \mathrm{GHz}$ width a bandwidth of $200 \mathrm{MHz}$ and a baseband of $4 \mathrm{MHz}$ wide. It was used to develop and evaluate adaptive array processing algorithms with a focus on rejecting Radio Frequency Interference (RFI). It was early recognised that aperture arrays, with an intrinsic low gain wide angle antenna beam would be more susceptible to RFI, in particular with the growing spectral use by consumer and military applications. In comparison, a dish will have a natural shielding from terrestrial RFI. Although it should be noted that satellite RFI will also affect a dish based system, more options of e.g. band select filters are available when the number of receivers is modest and the cost therefore relatively small.

\subsubsection{OSMA}

The One Square Metre Array consisted of 144 elements with linearly polarized dipole antennas and operated at a frequency range of 1.5-3 GHz. The scaling of the frequency by a factor of 2 reduced the overall size of the array, allowing performance assessment in the modest-size indoor near field scanner antenna test range available in Dwingeloo. The beamforming was a mixed analogue and digital adaptive-beamforming. From the antennas only the inner eight-by-eight elements were connected to the beam former. After a four bit time delay and an eight bit variable attenuator 4 signals were added in the first stage beamforming, followed by digitization and digital beamforming of the remaining 16 channels. One of the goals of OSMA, to establish the potential of Radio Frequency Interference (RFI) nulling by adaptive beam control has been demonstrated. It was shown that deterministic nulling at the $\mathrm{RF}$ beamformer level improves the rejection of interference by up to $32 \mathrm{~dB}$, thus reducing the requirements of analogue-to-digital conversion. The distortion of the mean beam due to the placement of the deterministic nulls was limited to $0.4 \mathrm{~dB}$ over all directions. A good phase and amplitude calibration is a prerequisite for accurate nulling [25].

\subsubsection{THEA}

The main goal of the Thousand Element Array was the demonstration of the astronomical capabilities at higher frequencies. Instruments like the very first Jansky's two element dipole array or the 3.6 ha IPS Array operated in the regime where high sky noise dominates the system noise temperature, avoiding the need for low noise receiver designs. Also, earlier systems typically were transient instruments with limited or no active beam steering. And in the lower frequency regime the antenna size, typically $\lambda / 2$, is large, requiring less elements for a desired collecting area. The earlier demonstrators, AAD and OSMA, had not been tested on astronomical signals and although high frequency phased arrays had been used in military radar, radio astronomy but also telecommunication and medical applications had not been using phased arrays.

The 1024 elements of THEA, of which in the final system only 256 have been realized, were grouped in tiles with 64 antennas. Signals of each receiving element were, after the first low noise amplifiers, split to form two independent beams, followed by phase and amplitude control with a vector modulator chip. The signals of the 64 channels were summed in Wilkinson combiners to form the two 
beams, see Figure 7. The RF signals of these beams were subsequently down converted and digitized in the outdoor tiles and a dedicated fibre link transported the digital data to a dedicated indoor backend.

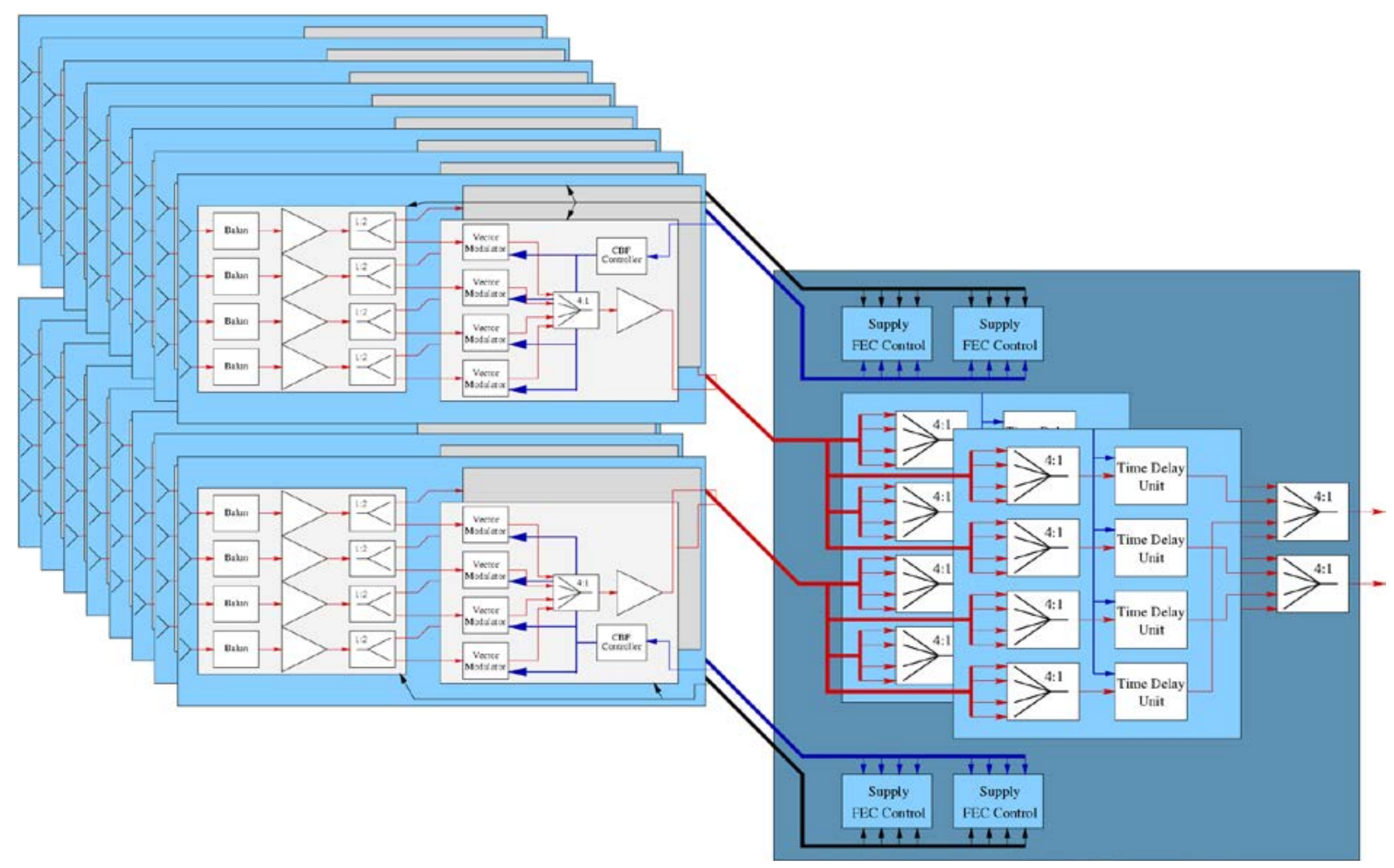

Figure 7 Signal flow diagram of the THEA tiles

In the digital data processing of the THEA, two major parts could be distinguished: the Adaptive Digital Beamformer (ADBF) and the Reduction and Acquisition unit (RAP). The ADBF consisted of the Adaptive Weight Estimator (AWE) and the actual digital beamformer. The RAP consist of a memory / beam selection board and a digital signal processing board. The Digital Beamformer was controlled by the AWE. The AWE determines from snapshots of the raw data the optimal, in terms of RFI suppression, complex weights of the DBF. The processing unit performed a 1024 points FFT. The number of integrations could be set with a minimum of 32 spectra (100 $\mu$ s each) and a maximum of 4000 spectra $(100 \mathrm{~ms})$. With post processing the integration time could be enlarged up to one hour.

The very versatile front-end and back-end of THEA allowed some interesting experiments. In Figure 8 the received signal power from GPS satellites is plotted [26]. The commercial frequency of GPS is $1575 \mathrm{MHz}$, this is in regime were THEA is sparse with a $\lambda / 2$ spacing at $1200 \mathrm{MHz}$. The array therefore produces grating lobes (see discussion in section 3.3), these detections are marked with a cross. A small calibration error explains the displacement of the detected signal and the known positions of the satellites. The flexibility of an AA system like THEA led to spin-offs in search and rescue and spacecraft tracking applications. A full size AA SKA system would be very well suited to perform other tasks in parallel to the astronomy [27]. 


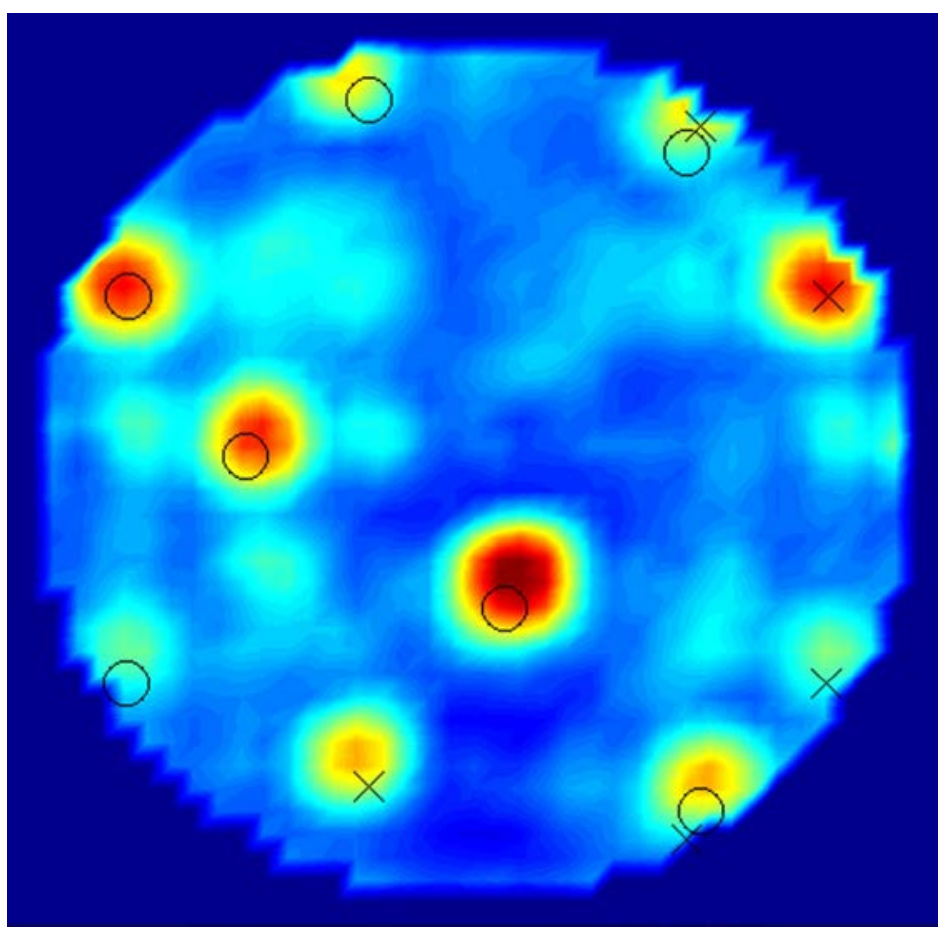

Figure 8 Full sky scan detecting GPS satellites at $1575 \mathrm{MHz}$ on a uv plot. Circles are real satellite positions, crosses are grating lobe detections [26].

\subsubsection{SKADS and EMBRACE}

As part of the SKA European Design Study (SKADS) the Electronic Multi-Beam Radio Astronomy Concept (EMBRACE) [28][29] was conceived. EMBRACE is the largest mid frequency AA prototype realized to date. The EMBRACE system consists of 20,000 antenna elements and has a physical area of about $160 \mathrm{~m}^{2}$. The antenna system, covering a 500-1500 MHz frequency range, is designed as a dual polarized system, however only signals of one polarization are processed. RF analogue beamforming is performed on tile level (36 antenna elements). The analogue beamformer forms two independent beams, two Field's of View (FoV), and eight digital beams within each of the two FoVs. The instantaneous bandwidth is $40 \mathrm{MHz}$ per FoV. The beam steering in EMBRACE uses phase control instead of time delay, which restricts the accuracy of the pointing to a limited bandwidth: the beam starts to squint outside the selected bandwidth. Time delay circuits, often implemented by different signal length traces with selection switches on either side, are large.

The EMBRACE system was successful, demonstrating all the capability of a large AA system. 


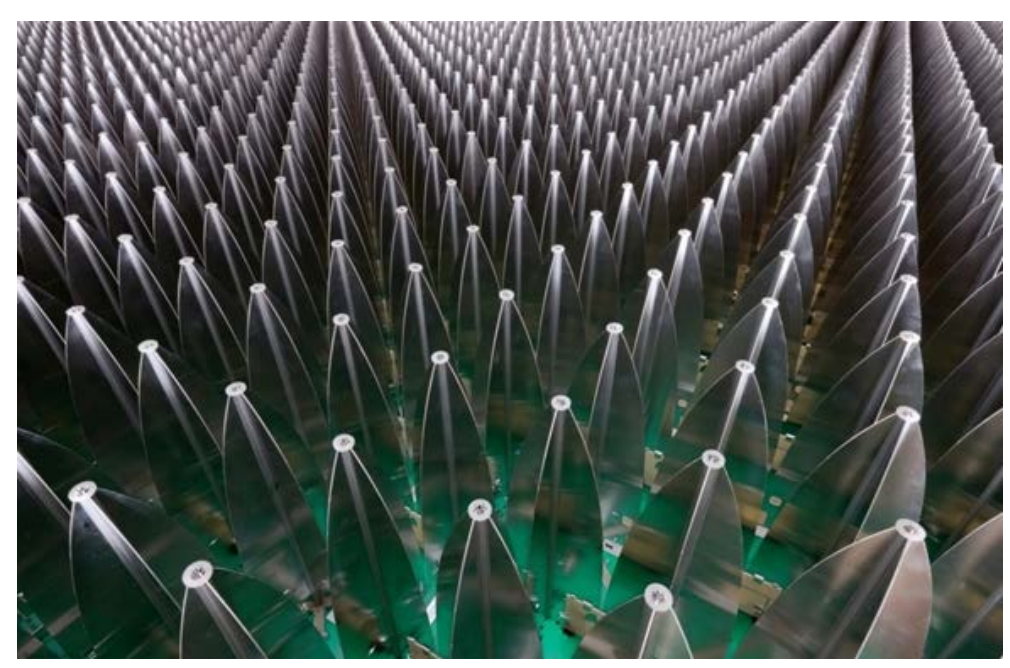

Figure 9 Snap shot of EMBRACE (credit Millenaar)

Within the SKADS program a smaller all digital array has been realized, the 2PAD (2 Polarisation All Digital) demonstrator [30]. This system explored direct digital sampling, instead of down conversion and narrow bandwidth sampling, and the real time processing of the (high data rate) signals. Due to technology constraints, limited availability of high sample rate ADC's and high data rate signal processing units, 2PAD turned out to be on the edge of the technology's capabilities. 2PAD realized an array with 16 channels.

\subsection{Discussion}

The first AA prototypes demonstrated all the expected capabilities of AA's: they are astronomically viable, have multiple fields of view, flexible, RFI mitigation capability, wide bandwidth and more. Given the success of the aperture array demonstrators in the first decade of the Square Kilometre Array concept studies, a full adaption of the technology has been considered for SKA phase 1. SKA phase 1 will use AA's for the lower frequency band, 50 to $350 \mathrm{MHz}$, and dishes for the frequencies of $350 \mathrm{MHz}$ and up. The large potential of AA's, e.g. very high survey speed, for the frequencies up to $1.4 \mathrm{GHz}$ is therefore out of reach for SKA1.

It has been argued that a large scientifically capable demonstrator needs to be realized, a system capable of competitive science, before full adoption of AA technology for the mid frequency range can be considered. This will be discussed in more detail in Chapter 2. Further, more research is required on a wide range of AA implementations aspects:

- Low cost antenna realization

- Wide bandwidth room temperature low noise front-ends

- Low cost and low power receivers

- Calibration

- High performance computing

- Processing software, specific for AA's: handling strong pointing dependencies

On all these aspects significant research has been dedicated with clear goals; to realize a system which is competitive with a dish based telescope. For the implementation, different options are considered of which one is crucial; to use analogue beam forming preceding digitization or to digitize each antenna output. Typically analogue beamforming is used to reduce the compute load; THEA combined 64 antenna signals to form two beams and EMBRACE did the same on 36 antennas. The analogue 
beamforming step however also reduces the capabilities since signals are removed in the combination step. In an extreme case when many elements are combined with an analogue beamformer, an AA system does not out-perform a reflector system. In this dissertation it will be argued that harvesting the full capabilities of AA's, a fully digital AA system is required. The LOFAR low band array is a fully digital system and also SKA1-Low will be fully digital. The total number of elements of the LOFAR low band, all stations combined, is $\sim 5000$. SKA1-Low will have 100,000 elements. An SKA mid AA system, however, will require many more elements, possibly up to 100 million, and will have a higher bandwidth. Combined with the argued need for an all-digital concept it is clear that in order to realize such a system cost effectively a dedicated design is needed. This dissertation will explore possible solutions for this design challenge with a focus on the station design and the station signal processing.

\subsection{Contributions}

The primary contributions put forth in this dissertation are complemented and placed in context by earlier research on aperture array components and prototypes. In this context, the dissertation focusses on research the author of this dissertation participated in. These are the following:

- Leadership of the Thousand Element Array, the first AA system with on sky measurements of $\mathrm{HI}$ and full sky observations.

- Research and prototyping of low noise amplifiers, with a focus on Gallium Arsenide integrated circuit design but also including CMOS and SiGe transistors.

- Active antenna research.

- Low cost antenna development research, which led to printing Vivaldi antennas on RFID material.

- Localized cooling projects with Peltier elements and microcooling. Various MSc projects led to an understanding of the options for the SKA.

- Research on low cost low power Analogue to Digital Convertors.

- Leadership of the Mid Frequency Aperture Array consortium, in which antenna prototypes have been development, including test set-ups in the Karoo, South Africa.

Specifically for this dissertation the following research has been carried out:

- Investigation of the sparse-regular concept and of the impact of this concept on the array performance.

- Signal processing load assessment and an investigation on the possibility to mitigate processing cost by applying Fast Fourier Transform techniques.

- Research on system costing, which led to a proposed FoM for assessing a system solution based on average sensitivity divided by cost.

\subsection{Dissertation Layout}

The introductory chapter provides context of the aperture array developments for radio astronomy with a focus on its role in the SKA conception and design. The second chapter presents a discussion on radio astronomy design criteria with a focus on AA's and SKA2.

Chapter 3 comprises a study on the proposed alternative solution: sparse-regular arrays. Advantages and drawbacks are analysed with a focus on grating lobe handling. Grating lobes are normally avoided 
in an AA system but their impact on radio astronomy observations might actually be small if the right measures are taken. These measures are discussed and analysed.

Chapter 4 provides an analysis on the signal processing load of a selected reference system for SKA2. Classic beamforming, 2-stage beamforming and FFT beamforming are compared.

Chapter 5 zooms in on the elements of an AA station and Chapter 6 presents a cost analysis and an unconventional FoM. The cost FoM proposed in this chapter, average sensitivity divided by system cost, provides guidance for a design choice on the sparsity of the array. Conclusions are presented in Chapter 7 , followed by the bibliography. 


\section{System Requirements}

The performance of Radio Astronomy telescopes can be characterised by specific FoM's. The relevance of each FoM strongly depends on the specific science case for which the telescope will be used. In this phase of the development of the full SKA, and given the likely high cost, it has to be assumed that the telescope should be designed and built to be as versatile as possible. Nevertheless, design choices will have to be made.

\subsection{Telescope Design Drivers}

Excellent books on radio astronomy are available of which the book by Thomson, Moran and Swenson, Interferometry and Synthesis in Radio Astronomy, is very useful [31].

In this section typical design drivers for a radio telescopes will be described and in particular design drivers in which aperture arrays are distinct from dish-based telescopes. Telescope design for requirements like system noise temperature, sensitivity and resolution are not specifically different for AAs, although realization can be easier or more complex.

\subsubsection{Figures of merit}

Almost all radio signals from celestial objects are very weak, with very low signal strengths, typically $30-50 \mathrm{~dB}$ below the system noise floor. The detection of these (noise like) signals requires dedicated techniques: the signals can be narrow band spectral lines, inherently broadband (continuum) or pulsating signals. The astronomical sources can be small or large compared to the station beam, which also influences the detection technique. In the following, the brightness of the source is the intensity of the source. Flux density, or power received by a telescope, is the integration of brightness over the solid angle of the station beam. If a source is unresolved, meaning that it is much smaller than the station beam, its flux density can be measured but its brightness cannot. If a source is much larger than the station beam, its brightness can be measured, but its flux density can only be calculated by integrating the observed brightness over the source solid angle. When two or more stations are combined in an interferometer the station beam in the above needs to be replaced by the synthesized beam of the stations. The basic interferometer is a pair of stations whose output voltage are correlated (multiplied and averaged). The output of an interferometer is proportional to the flux density of the source and the gain or effective area of the two stations. Uncorrelated noise from the receivers of the two stations is significantly reduced in the correlator output.

An aperture synthesis array can be characterized by three sensitivities: sensitivity to point sources (unresolved sources), survey sensitivity or survey speed, and sensitivity to surface brightness.

The sensitivity to point sources, $S$, can be expressed as

$$
S=\frac{A_{\text {eff }}}{T_{\text {sys }}}
$$

Equation (2.1) leads to straightforward design criteria: a large effective collecting area $\left(A_{\text {eff }}\right)$ should be combined with a low system noise temperature $\left(T_{\text {sys }}\right)$.

For the survey speed, the time needed to cover a sky area, it depends on the science application if the frequency bandwidth is included or excluded. Therefore two definitions of FoM's are used 


$$
S S=\Omega_{A}\left(\frac{A_{e f f}}{T_{s y s}}\right)^{2},
$$

with $\Omega_{A}$ the Field of View (FoV) or solid angle of the station beam.

Since frequency bandwidth is important for many science cases, survey speed can also be defined as

with $\Delta f_{\text {signal }}$ the frequency bandwidth.

$$
S S_{f}=\Delta f_{\text {signal }} \Omega_{A}\left(\frac{A_{e f f}}{T_{\text {sys }}}\right)^{2},
$$

The frequency bandwidth of a modern telescope can be very large, extending beyond a realistic single science case. This is particularly the case for AA systems. With the exception of new developments on wide band single pixel feeds, which aim for multiple octave performance, most feeds on dish-based systems are restricted to one octave bandwidth. This is sufficient for most science cases. The extension to e.g. 3 octaves for AA systems or wide band dish feeds improves the instruments capabilities but typically does not increase the survey speed for a particular science case. Since receiver and back-end signal processing bandwidth does not form a constraint in modern instruments (2.3) is not used in this work.

Alternative to (2.1) the System Equivalent Flux Density (SEFD), the sensitivity to point sources, can be expressed as

$$
S E F D=\frac{2 T_{\text {sys }} k_{B}}{A_{\text {eff }}}
$$

with $k_{B}$ the Boltzman constant. The SEFD is often expressed in Jansky $\left(10^{-26} \mathrm{Wm}^{-2} \mathrm{~Hz}^{-1}\right)$ and is equal to the flux density of a point source in the main beam of the antenna that would cause the noise power in the receiver to be twice that of the system noise in the absence of a source. The Root Mean Square (RMS) of the flux density of the observed source, $S_{r m s}$, the radiometer equation, can expressed as

$$
S_{\text {rms }}=\frac{S E F D}{\sqrt{\Delta f_{\text {signal }} \tau}},
$$

with $\tau$ the integration time. RMS flux density variations decrease with increased integration time and bandwidth. Equation (2.4) and (2.5) are the basis of a radio telescope design. Detection of faint sources

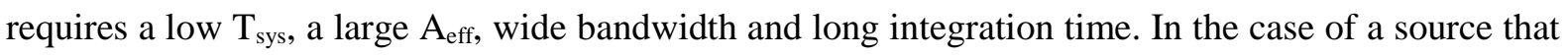
is wider than the synthesized beam, the brightness sensitivity, $B$, should used

$$
B=S_{r m s} / \Omega_{A}
$$

with $\Omega_{A}$ the beam solid angle of the system. Equation (2.6) can be used for a single station or dish but also for an interferometer in which two or more station or dish outputs are superimposed. The brightness sensitivity of an interferometer is worse than a single station because the synthesized beam solid angle of an interferometer is smaller than the beam of a single station of the same effective area. This relates to the filling factor of the array (ratio of the area covered by the antennas to the area spanned by the interferometer array). A high filling factor, closely packed stations, will improve brightness sensitivity. Very sparse stations will limit the filling factor of the array of stations but the theory of AA's in this respect is under development [32]. Sparse arrays need to consider the filling factor of the station and the filling factor of the array. Dish arrays only need to consider the latter. 
Very high spatial resolution, $\lambda / \mathrm{D}$, with $\mathrm{D}$ the diameter of the system, is best served with high radio frequencies (short wavelengths) and a large base-line. Very Long Baseline Interferometry (VLBI) has been very successful in the high $\mathrm{GHz}$ range and recent successes have been achieved up to hundreds of $\mathrm{GHz}$ and a base-line of the size of the earth. AA's are not likely to play an important role in high spatial resolution science: the wavelength will typically by large. However AA technology, like any radio telescope, is capable of participating in VLBI, but only when specific science requires the lower frequencies.

\subsection{Science Requirements}

Aperture Arrays are the enabling technology that will lead to the realization of a transformational survey machine. The unprecedented FoV capability of an AAMID telescope will bring radio astronomy in a new era. The neutral hydrogen 'billion galaxy survey', understanding of galaxy formation and evolution and determining the nature of dark energy, all come within reach with AAMID. The conception of the SKA can be directly linked to the wish of mapping HI with high sensitivity to high red-shifts. This is triggered by very compelling science: cosmology, studies of the origin and evolution of the universe, from the Big Bang to today.

The SKA organization published a large comprehensive science book, Advancing Astrophysics with the Square Kilometre Array, in two big volumes [33]. Key parameters will be evaluated and an assessment of the impact on the design of an AA system is part of this dissertation (Chapter 3). The science of SKA includes:

- The history of hydrogen in the Universe and the mystery of dark energy

- Galactic structure and star formation

- The structure of the Universe

- The dynamic radio sky: 1) Transients and variables, 2) Pulsar astronomy

- The origin and evolution of cosmic magnetism

- SETI, search for extra-terrestrial intelligence

Table 2 gives a subset of the performance criteria for an SKA2 AA mid frequency band system [34] (AAMID), in particular highlighting requirements of relevance for the antenna arrays. 
The imaging dynamic range requirement cannot be directly related to a requirement for the level of side lobes and grating lobes. In [36] the brightness dynamic range for imaging is defined as: the ratio of peak brightness to RMS brightness, where the RMS fluctuation level is measured within the entire (primary) beam of a dish or station, but may exclude an area of 5x5 of the beamwidth centred on the brightness peak. The RMS of the brightness or noise picked up by the side (and grating) lobes depends on the field of observation and the ratio depends on the to-be-observed source brightness as well. For SKA1-MID, the dish array, the requirement is $60 \mathrm{~dB}$ with at 0.5 arcsec spatial and $1 \mathrm{MHz}$ spectral resolution. For SKA1-Low it is set at $50 \mathrm{~dB}$. The (related) side lobe levels of SKA1-Low are not specified but it is expected that the design of the Low station with a random element configuration and far-out side lobe levels of $\sim-30 \mathrm{~dB}$ will be sufficient to reach the $50 \mathrm{~dB}$ after calibration. This is supported by [37] in which the authors analysed the impact of far-out side lobes on the imaging performance of the SKA1-Low telescope. Rather than focussing on the imaging dynamic range, which depends on the target source brightness, this work concentrates on the Far Side lobe Confusion Noise (FSCN): the amount of noise power received from interfering sources. It is shown that the SKA1-Low design reaches sufficiently low levels of FSCN and with significantly more margin at higher frequencies. A similar analyses for the AAMID system is required, however, falls outside the scope of this dissertation. The working assumption used in the following chapters is that $\sim-30 \mathrm{~dB}$ of side and grating lobe power level in correlation between two stations is sufficient to reach the imaging dynamic range requirement.

\subsection{Array configuration}

The AA telescope concept is very flexible; stations can be made small or large and in one array a mix of sizes could even be considered. The principle unit, antenna or tiles of antennas, can be reconfigured and signal processing units can be reprogrammed for different station sizes. At this moment one telescope utilizes this option; the LOFAR high band international stations are larger than the Dutch high band stations. This degree of freedom creates the possibility to optimize the array for a wide range of science cases. Reconfiguration is also possible after installation; in [38] a sea of elements is considered for the core of SKA1-Low, in which stations can be formed arbitrary.

A very large core station would be ideal for cosmology and pulsar science and has been proposed by Tegmark [47][48]. However, constructing an array with e.g. $500 \mathrm{~m}$ diameter and millions of elements, and the design of a signal processing system with these amount of inputs would be a challenge in its own right. It can be argued that the HERA telescope [39], although consisting of reflectors, is of this type; a sea of elements on a grid. A single large core compromises the system for resolution and uv-coverage, for which outrigger stations will be required. Still, the outriggers could be simple stations with limited FoV to provide the uv-coverage and long baseline visibilities.

Utilizing the full flexibility of AA's with static or dynamic station (size) configurations will require new calibration, correlation and imaging hard- and software. Existing AA telescopes are already more complicated than reflector telescopes due to the Direction Dependent Effects (DDE), which occur every time the telescope is repointed. Due to antenna coupling and antenna element pattern effects, DDE's are much more than projection effects, requiring explicit calibration and modelling effort.

In the analyses in this dissertation, it is assumed that a collection of relatively small stations would be the system design of choice for the AAMID telescope. Small in this context is $35-50 \mathrm{~m}$, which is significantly larger than the current SKA dish $(\sim 15 \mathrm{~m})$ and would lead to a total number of stations of AAMID in the range of 256 to 512. Assuming the diameter of an AAMID station is not restricted by mechanical or electrical constraints, the optimum choice depends on the required uv-coverage and the 
correlator and image compute cost. Many smaller stations will provide more baselines, which will improve the image quality at the cost of a large correlator and more image processing. In [40] it is

argued that the image compute load has a $\frac{1}{D^{6}}$ relation, with $D$ the diameter of the station or dish. The FoV of an AA station does not depend on the diameter, in contrast with a reflector telescope, and therefore $D$ can be made large, reducing the compute load for the correlator and imager. The needed uv-coverage, determining the minimum number of stations (and maximum $D$ ), requires further system studies but investigations for SKA1-Low, with 512 stations, indicates that 512 will give an excellent uv-coverage and a smaller number of stations can be considered.

\subsection{Station design}

One of the main challenges of an AA system is cost versus bandwidth. A reflector based system will typically have as many receiver (or a small factor more) systems as it has dishes. The thousands of dishes for SKA2 will still have three orders of magnitude fewer receivers than an AAMID telescope with millions of antennas. In the case of a phased array feed system, with e.g. 100 antenna elements per dish, the total will still be limited. The cost of reflector based systems is therefore less dependent on the bandwidth coverage of the feeds and small, e.g. octave, bandwidth feeds are typically acceptable.

One important design choice in the realization of AAMID station implementation is the positioning of the antenna elements. Earlier prototypes, such as THEA and EMBRACE but also 2PAD, followed a dense array approach. In a dense system, antennas are placed at a $\lambda_{\min } / 2$ pitch, such that grating lobes never appear in the visible space (see Section 3.3). If the array is dense for the complete frequency band, oversampling will occur for the lower frequencies, leading to inefficiencies. In a (fully) sparse array, antennas are placed at a distance larger or equal to $\lambda_{\max } / 2$, with the effect that the array is larger for a given number of antennas. In this, $\lambda_{\max }$ is the wavelength at the low end and $\lambda_{\min }$ at the high end of the frequency band.

In [34] two system options are compared, a dense-regular and a sparse-random solution. The simulated $\mathrm{A}_{\text {eff }} / \mathrm{T}_{\text {sys }}$ of these systems are reproduced in Figure 10 and Figure 11. In this work the authors constrained the system cost such that both options are estimated to be equal in cost. The dense solution, with more antennas, uses a level of analogue beamforming and the sparse solution has fewer elements but is all-digital. The random sparse solution does not meet the sensitivity requirement but has the advantage of digital beamforming and all the flexibility associated with that. The dense solution complies with all requirements but is not fully utilizing the potential of AA's. For an AA of diameter $D$ with $N_{a}$ antennas, the effective station area is given by

$$
\mathrm{A}_{\text {eff }}=N_{a} \lambda^{2} \frac{G}{4 \pi} \text { as long as } \mathrm{A}_{\mathrm{eff}}<(\pi / 4) \mathrm{D}^{2} \text {, }
$$

with $G$ the antenna gain of the individual antenna element. $G$ is approximately equal to $4 \pi /$ solid beam angle [41]. From (2.7) it is clear that $A_{\text {eff }}$ will increase for longer wavelengths until it reaches the physical area. As long as the station operates in the sparse regime the $A_{\text {eff }}$ follows the intensity increase of sky noise $\left(\sim \lambda^{2.75}\right)$. The sky noise from galactic emission is dominated by synchrotron emission and can be approximated by

$$
\mathrm{T}_{\text {sky }}=2.73+20(0.408 / f)^{2.75}
$$

with $f$ the frequency in GHz [42]. This means that the sparse stations, in the frequency regime where $\mathrm{T}_{\text {sky }}$ dominates the system noise temperature, have a relative constant signal to noise ratio for the majority of objects in the FoV. This explains why sparse arrays are the design of choice for the lower 
frequencies since increased sky noise is compensated automatically. The sky noise will drop below 15 $\mathrm{K}$ for higher frequencies, above $450 \mathrm{MHz}$, which means that, with a typical receiver noise temperature of an uncooled low noise amplifier of $35 \mathrm{~K}$, in an AAMID telescope the system noise is dominated by the receiver noise. The sensitivity of the system will therefore increase with longer wavelengths for sparse stations. This might be an advantage, since longer wavelengths equal higher HI redshift related to weaker more distant sources, but this requires further investigation. Contrary to sparse systems, a fully dense system, dense at all frequencies, will be over-sampling the aperture field at the low frequency end of the operating frequency range.

In SKA memo 87, Aperture Arrays for the SKA: Dense or Sparse? [43], the authors motivate a preference for a sparse system that covers the $70-700 \mathrm{MHz}$ range with two antenna systems that share receivers. This concept has been considered for SKA1-Low, but is currently not implemented. This frequency range is also reflected in the first comprehensive requirements summary of the in SKA Memo 100 [44]. This memo sketches out a number of scenarios for SKA2 and with that key parameters for an AA system: survey speed should be $2 \times 10^{10} \mathrm{~m}^{4} \mathrm{deg}^{2} / \mathrm{K}^{2}$ for $200-700 \mathrm{MHz}$, relaxing down to $4 \times 10^{7}$ at 1.4 GHz. The significantly reduced performance for the higher frequencies in memo 100 would tailor a sparse solution. This is not adopted in later requirements documents.

The two systems which are compared in the framework of the system requirements review of AAMID show the characteristics discussed above. The $A_{\text {eff }} / T_{\text {sys }}$ of the sparse system in Figure 10 drops with increasing frequency and the $\mathrm{A}_{\text {eff }} / \mathrm{T}_{\text {sys }}$ of the dense system in Figure 11 is nearly constant. Within the solution space one option is not considered: sparse-regular. Sparse-regular systems will have the following characteristics:

a) The sensitivity will increase for longer wavelengths for a given number of antennas, similar to the sparse-random option. No over-sampling occurs. This also means that $A_{\text {eff }}$ will not be constant over the frequency band.

b) Signal processing, mainly beamforming, can be simplified with FFT processing (Section 4.4).

c) Except for high grating lobes, side lobes can be very low, see discussion in Section 3.3. High dynamic range imaging requires good control over the side lobes [31].

d) The construction of the array can be straightforward. Placing millions of antennas individually is likely to be time consuming and therefore expensive, which would be required in a random configuration.

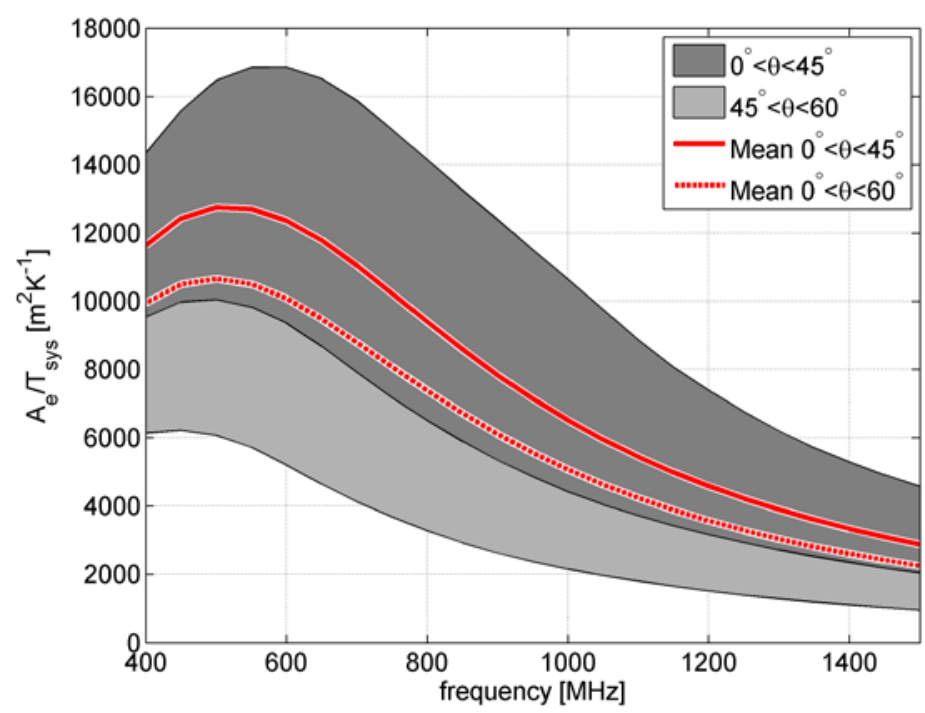

Figure $10 \mathrm{~A}_{\text {eff }} / \mathrm{T}_{\text {sys }}$ simulation of a random-sparse array for different zenith angle $\theta$ scan angles (reproduced from [34]) 


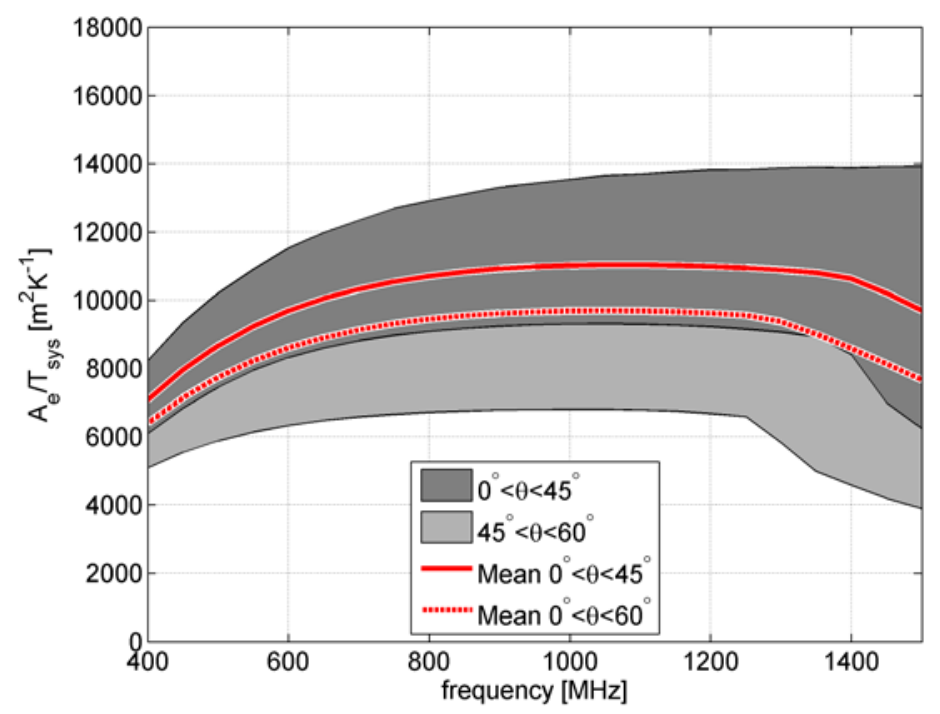

Figure $11 \mathrm{~A}_{\text {eff }} / \mathrm{T}_{\text {sys }}$ simulation of a dense AA system for different zenith angle $\theta$ scan angles (reproduced from [34])

In order to visualize the difference between the antenna configurations compared in Figure 10 and Figure 11, representative visualisations are plotted in Figure 12, Figure 13 and Figure 14. The chosen size and number of elements has been kept small in order to distinguish the individual elements in the plots. The difference between the number of elements, 400 for the sparse configurations and 1000 for the dense configuration is similar to difference between the total number of elements in Figure 10 and Figure 11. The sparse-random station has an average antenna spacing of $0.38 \mathrm{~m}$, close to $\lambda / 2$ at 450 $\mathrm{MHz}$ and the dense-regular has an antenna spacing of $0.125 \mathrm{~m}, \lambda / 2$ at $1200 \mathrm{MHz}$. From the plots it is clear that the sparse array is significantly larger, leading to the larger $\mathrm{A}_{\text {eff }}$ for lower frequencies, than the dense array even with the smaller number of antennas. The sparse-regular layout is a little smaller than the random layout with an antenna spacing of $0.33 \mathrm{~m}$ for the latter. Random placement is constrained by a physical antenna size, typically leading to a limitation on minimum distance.

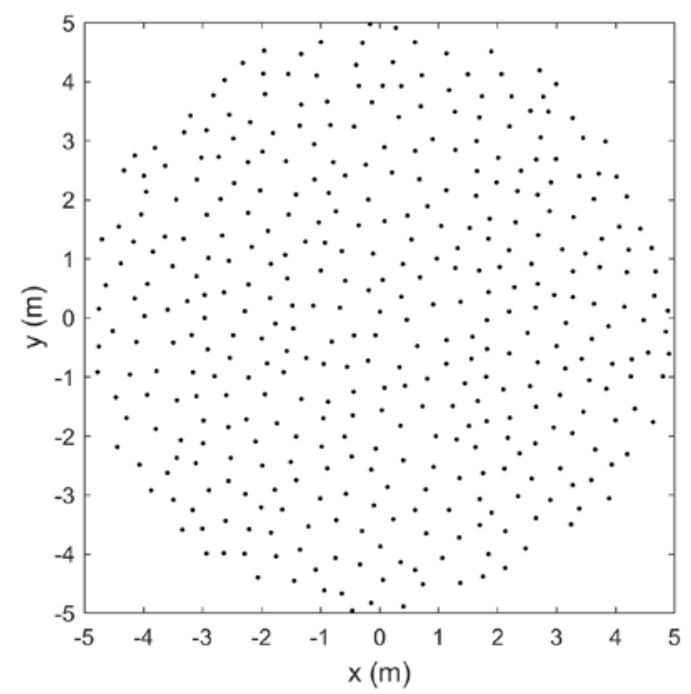

Figure 12 Representative visualisation of a sparse-random mini-station with 400 elements 


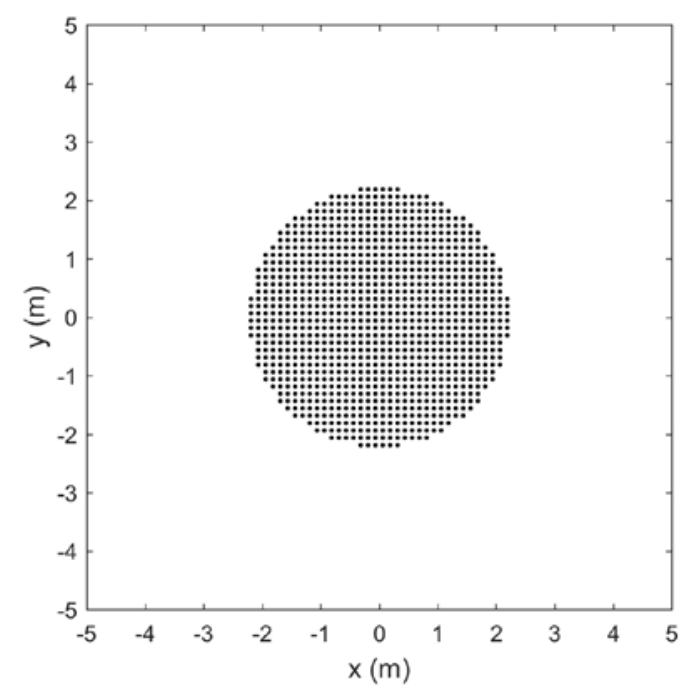

Figure 13 Representative visualisation of a dense-regular mini-station with 1000 elements

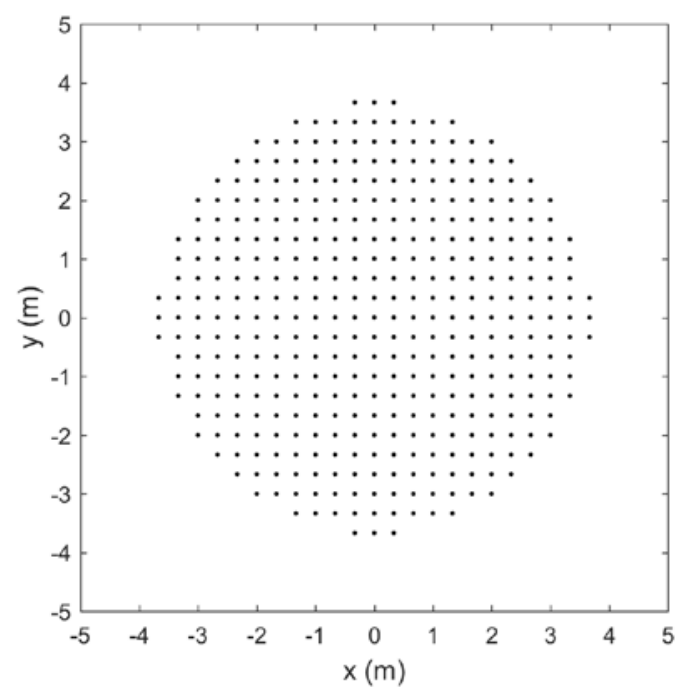

Figure 14 Representative visualisation of a sparse-regular mini-station with 400 elements

Inter station calibration needs to be carefully investigated if the station is designed to be very sparse. The solid angle of the station beam is proportional to wavelength squared which leads to fewer detectable sources per station at higher frequencies, therefore the sensitivity needs to increase per unit station aperture to provide sufficient self-calibration sources per beam per ionosphere coherence time. A sparse station will be larger for a given sensitivity and therefore will have a smaller station beam (on top of the wavelength effect). If the diameter is not increased the sensitivity will be less compared to a dense station. Both effects, less sensitivity or larger station, compromise ionospheric calibration for sparse stations.

The application of FFTs for a regular array structure has first been identified by Tegmark et al. [47][48] for a specific science application (cosmology). 


\subsection{Conclusion}

From the SKA system requirements and the concise review of options it can be concluded that a sparseregular station design could comply with the requirements with better overall performance, including cost, than currently considered designs. This concept will be further explored in Chapter 3. 


\section{Sparse-Regular Antenna Array Design}

The system concepts under consideration for AAMID as described in Chapter 2 are dense-regular arrays and sparse-random arrays. The concept demonstrators THEA and EMBRACE used a dense-regular antenna array. The LOFAR low band and SKA1-Low are of the sparse-random type. An alternative to these concepts is the sparse-regular array. The LOFAR high band array is in principle of this type, although most science is done in the regime where the array is not very sparse [49]. In this chapter the application of the sparse-regular concept for AAMID will be investigated [50][51][52].

In Chapter 2 the possible benefits for the array sensitivity of a sparse array have been described. The sparse-regular array has potential benefits over the sparse-random array in terms of processing costs. This will be discussed in Chapter 4 .

A sparse-regular array concept is typically avoided in practice since grating lobes will appear. Grating lobes are transmit or receive beams, in different directions from the main lobe, but with equal gain properties. These are very damaging in radar applications since signals from the main and grating lobes cannot be distinguished. For radio astronomy systems sparse-regular arrays could however be very interesting. The implications and mitigations of the effect of the grating lobes will be discussed in this chapter.

The analysis presented in this chapter assumes no taper is used: the nominal amplitude of each element in the array after calibration is set to 1 . For most of the analysis this is the worst case situation, albeit with the highest array sensitivity. Side lobes can be reduced by (amplitude) tapering the elements of the array at the expense of directivity (sensitivity). This might be relevant, e.g. the first side lobe of a circular array can be reduced from $-17.7 \mathrm{~dB}$ to $-30 \mathrm{~dB}$ with a Gaussian aperture taper at the cost of only $1 \mathrm{~dB}$ sensitivity [41]. In AA's, a taper can be applied at any time in the calibration process.

\subsection{Introduction}

Sparse-regular arrays can be considered for the implementation of AA's in a cost effective manner for frequencies up to $1.4 \mathrm{GHz}$, with many millions of antenna elements. Regular systems have a number of advantages for calibration, signal processing, and construction cost in comparison with random arrays. Sparse-regular arrays however exhibit strong grating lobes. As discussed below, dense regular arrays address many of these issues, but at the cost of a high element count (and associated RF front end and processing requirements).

The impact on astronomical observations of signal in the grating lobe can be suppressed by:

- Station rotation, a powerful technique used in LOFAR high band: each station can be given a different orientation and therefore a different beam on the sky, significantly reducing the impact of signals in side- and grating lobes.

- Time averaging: tracking a source will move the grating on the sky, reducing coherent distortion from strong sources in the grating lobe.

- Chromatic dispersion: grating lobes will point at different locations on the sky for different frequencies and therefore will be averaged down over frequency.

An accurately calibrated array will have low side lobes and combined with the grating lobe suppression techniques, a high dynamic range imaging capability can be achieved with a regular sparse array. 


\subsection{System}

In [45] a subset of the performance criteria for an SKA2 AA mid frequency band system (AAMID) is discussed, in particular highlighting requirements of relevance for the antenna arrays. Cryogenically cooling large AA systems is unlikely to be cost effective, therefore a relatively high (for radio astronomy telescopes) system noise temperature needs to be accepted. This drives the total effective area of the system and the resulting number of antennas. Dense AA systems, demonstrated in the modest size prototypes, will be able to meet the required sensitivity. However a dense array, with antenna spacing of $\lambda / 2$ at the high end of the band, will have up to 100 dual pol antennas per square meter, resulting in a high total antenna element count.

Sparse arrays, with a $\lambda / 2$ antenna spacing at the low end of the frequency band, will have a much lower antenna count, reducing system cost and power consumption, at the cost of a lower sensitivity at the high end of the band [43]. For the following analyses of sparse-regular arrays it is assumed that a sensitivity slope $\left(\propto \lambda^{2}\right)$ over the frequency band is acceptable. Higher red shift (lower frequency) sources are further away and therefore weaker, requiring a higher sensitivity and the sky noise increases for lower frequencies, again requiring a higher sensitivity for detection.

In order to avoid grating lobes but also to smoothen the station gain when grating lobes enter the visible space antenna placement can be randomized. The SKA1-Low telescope, as well as the LOFAR low band array uses this concept. An impact analysis of the sparse-random station design of SKA1Low is presented in [46]. Even though the far out station side lobes are in the -30dB range, a very low Far Side-lobe Source Noise level is achieved for typical observations. SKA1-Low is however relatively small in antenna count: 512 stations and 256 elements per station, giving a total of 131,072 elements. Individual antenna placement is already challenging for 100,000 antennas, but is certainly not tractable for millions of antennas. A regular structure will ease production and deployment considerably.

A typical sparse-regular array station design is given in Table 3 . To reach the sensitivity $\left(\mathrm{A}_{\text {eff }} / \mathrm{T}_{\text {sys }}\right)$ of $10,000 \mathrm{~m}^{2} / \mathrm{K}$ approximately 150 to 250 of these stations would be required.

Table 3 Typical AAMID station parameters

\begin{tabular}{ll}
\hline \hline Parameter & Description \\
\hline Station diameter & $38 \mathrm{~m}$ \\
Nelements & 12825 \\
Configuration & Regular, circular \\
Antenna spacing & $\lambda / 2$ at $500 \mathrm{MHz}: 0.3 \mathrm{~m}$ \\
\hline
\end{tabular}

Rotation of the orientation of the station grid between stations provides a powerful mechanism to mitigate the grating lobes in the imaging or tied array beamforming process. Since tied array beam forming and correlation are done in the voltage domain, the sum of all stations includes positive and negative side lobes which ensure even better suppression than simple addition of the power beam patterns. Unlike LOFAR, were the station grid is rotated but the antennas themselves are back rotated such that the $\mathrm{x}$ and $\mathrm{y}$ polarizations of all antennas are parallel, full station rotation is proposed in this analysis. This requires a polarization rotation correction before station beams can be cross correlated; the stations themselves are however identical which not only simplifies array production but also station modelling and calibration. The polarization correction is not needed when left and right circularly polarized antennas are used. 


\subsection{Sparse-regular array response}

A sparse-regular array is nothing different from any phased array aperture and array analysis is given in many antenna text books. Below some of the theory of [53] and [41] is used with a focus on a linear array of $\mathrm{N}$ elements. The linear array can be easily extended to a 2-dimensional array.

With $k$ the wave number $(2 \pi / \lambda), d$ the spacing between the adjacent array elements, $\theta_{d}$ the desired direction, and assuming that element $n$ is at location given by $\boldsymbol{r}_{n}=\left(x_{n}, y_{n}, z_{n}\right)=(0,0, n d)$ for a linear array, the array factor becomes:

$$
A F=\sum_{n=0}^{N-1} w_{n} e^{-j \boldsymbol{k} \cdot \boldsymbol{r}_{n}}=\sum_{n=0}^{N-1} e^{-j k n d \sin \theta_{d}} e^{-j \boldsymbol{k} \cdot \boldsymbol{r}_{n}}
$$

with weights to be selected

$$
w_{n}=e^{j k n d \cos \theta_{d}},
$$

and with the definition of the wave vector:

$$
\boldsymbol{k} \cdot \boldsymbol{r}_{n}=k n d \sin \theta
$$

Substituting this in the array factor equation

$$
A F=\sum_{n=0}^{N-1} e^{j k n d\left(\sin \theta-\sin \theta_{d}\right)}=\sum_{n=0}^{N-1} G^{n},
$$

with $G$ defined as

$$
G=e^{j k n d\left(\sin \theta_{d}-\sin \theta\right)},
$$

and the sum formula

$$
\sum_{n=0}^{N-1} G^{n}=\frac{1-G^{N}}{1-G}
$$

The array factor then becomes

$$
A F=\frac{1-e^{j k N d\left(\sin \theta-\sin \theta_{d}\right)}}{1-e^{j k d\left(\sin \theta-\sin \theta_{d}\right)}}
$$

When interested in magnitude only and using the following general formula for the sin function

$$
\sin x=\frac{e^{j x}-e^{-j x}}{2 j}
$$

the magnitude of the array factor reduces to

$$
|A F|=\frac{1}{N}\left(\frac{\sin \left(k N d\left(\sin \theta-\sin \theta_{d}\right)\right) / 2}{\left.\sin \left(k d\left(\sin \theta-\sin \theta_{d}\right)\right) / 2\right)}\right)
$$

The grating lobes are given by those angles $\theta_{\mathrm{g}}$ which make the denominator zero

$$
k d\left(\sin \theta_{g}-\sin \theta_{d}\right)= \pm n \pi,
$$


and

$$
\sin \theta_{g}-\sin \theta_{d}= \pm n \frac{\lambda}{d}
$$

Note that when the denominator is zero the numerator is also zero. The value of the array factor is indeterminate when both the denominator and the numerator are zero. However, by applying L'Hopital's rule (differentiating numerator and denominator separately) it is found that $|\mathrm{AF}|$ is maximum when $\sin \theta= \pm n / \lambda$, resulting in a maxima in the direction:

$$
\theta_{g}=\sin ^{-1}\left( \pm n \frac{\lambda}{d}+\sin \theta_{d}\right)
$$

Grating lobes enter the visible region, the region for which $-1<\cos \theta<1$, when

$$
\frac{d}{\lambda} \geq \frac{1}{1+\sin \theta_{d}}
$$

For a typical sparse array with an antenna spacing of $d=\lambda$, equivalent to the examples in Section 3.4, grating lobes enter the visible space at $\theta_{\mathrm{d}}=0$, zenith pointing, and are therefore always present. If the $\theta_{\mathrm{d}}$ is constrained to $45^{0} \mathrm{scan}$, an element spacing of $\mathrm{d}=0.85 \lambda$ would still avoid grating lobes to appear. Expanding the analysis in two dimensions [41], the array factor also has maximum when

$$
\sin \theta_{p q} \cos \varphi_{p q}=\sin \theta_{d} \cos \varphi_{d}+p \frac{\lambda}{d_{x}}
$$

and

$$
\sin \theta_{p q} \cos \varphi_{p q}=\sin \theta_{d} \cos \varphi_{d}+q \frac{\lambda}{d_{y}}
$$

for $p= \pm 1, \pm 2, \ldots$ and $q= \pm 1, \pm 2, \ldots$ with $d_{x}$ and $d_{y}$ the respective $\mathrm{x}$ and $\mathrm{y}$ element spacings. The locations of the grating-lobes appear with equal spacing on a rectangular grid in a plane with uvcoordinates $u=\sin \theta \cos \varphi$ and $v=\sin \theta \sin \varphi$.

\subsection{Station rotation}

The first order impact assessment of sparse-regular arrays focusses on the array patterns in which a number of simplifications have been taken:
a) All antennas are equal and have $120^{\circ}$ beamwidth
b) No antenna coupling
c) $10 \%$ normal distributed amplitude errors and $10 \%$ phase errors
d) Uniform amplitude weighting
e) $0.3 \mathrm{~m}$ element spacing: $\lambda / \mathrm{d}=1$ at $1 \mathrm{GHz}$

Station beams are calculated with Xarray [54]. In Figure 12 a station beam, pointed at $45^{\circ} \theta$ (elevation) and $45^{\circ} \varphi$ (azimuth) is plotted. The station is rotated $20^{\circ}$ in Figure 16 . The simulation is at $1 \mathrm{GHz}$ with the array parameters from Table 3. Clearly, three grating lobes are visible in both stations simulations and the gratings lobes rotate with the station rotation, as expected from array theory. 


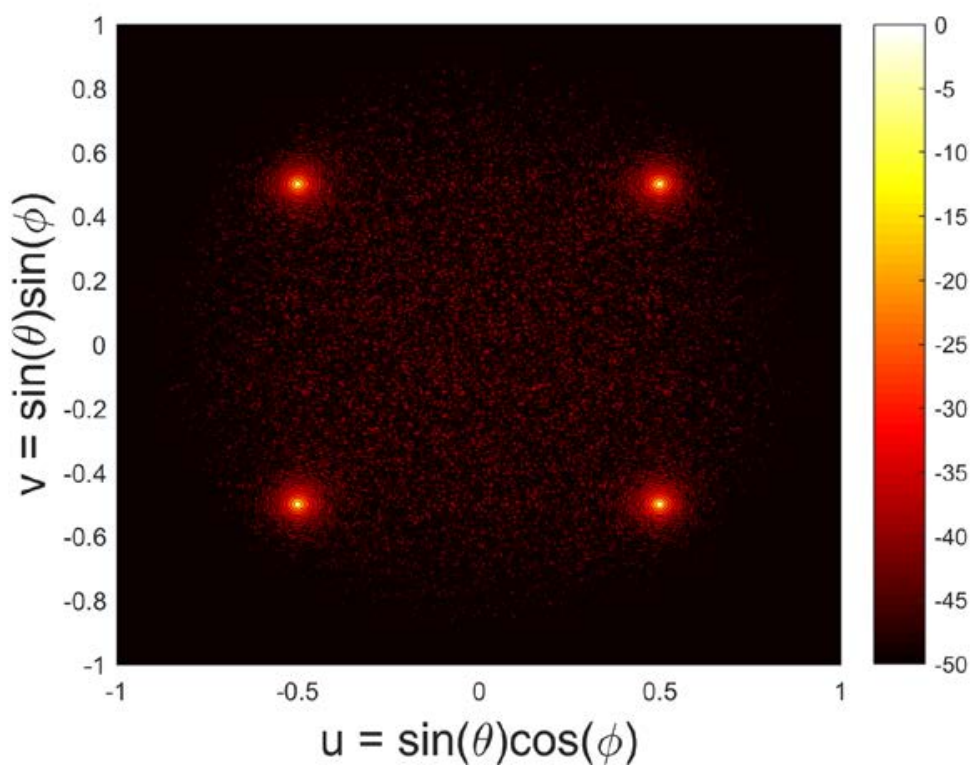

Figure 15 Array factor calculation for $45^{\circ}$ elevation and $45^{\circ}$ azimuth scan at $1 \mathrm{GHz}$ of the typical station (colour scale in $\mathrm{dB}$ )

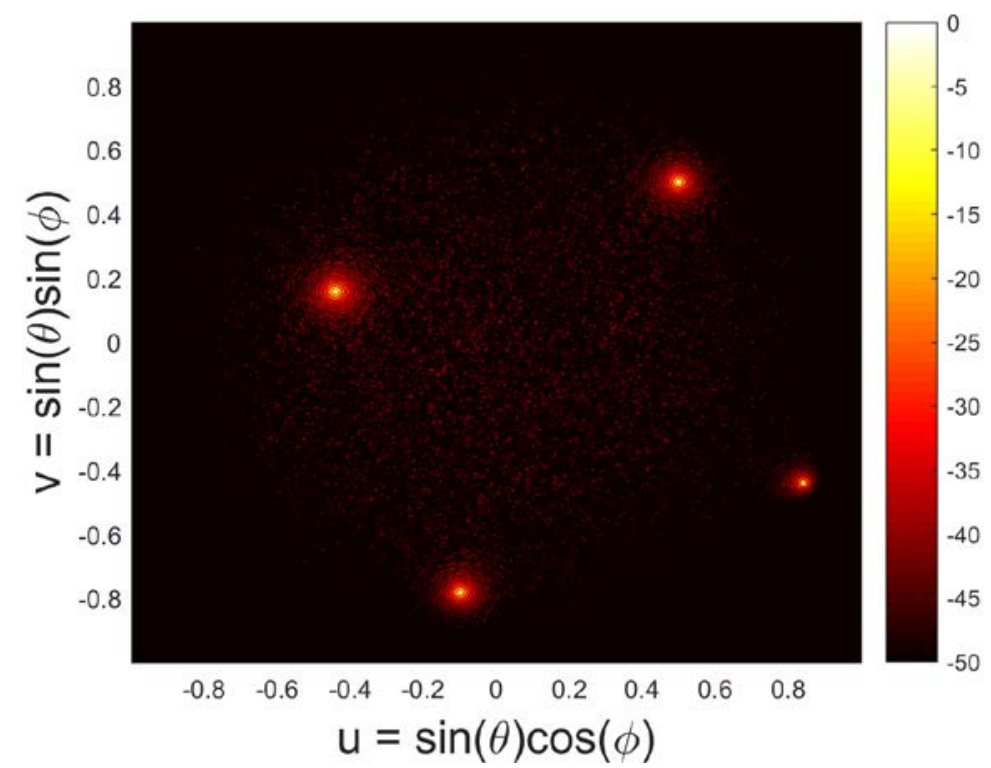

Figure 16 Array factor calculation for $45^{\circ}$ elevation and $45^{\circ}$ azimuth scan at $1 \mathrm{GHz}$ with the station rotated $20^{\circ}$ (colour scale in dB) 


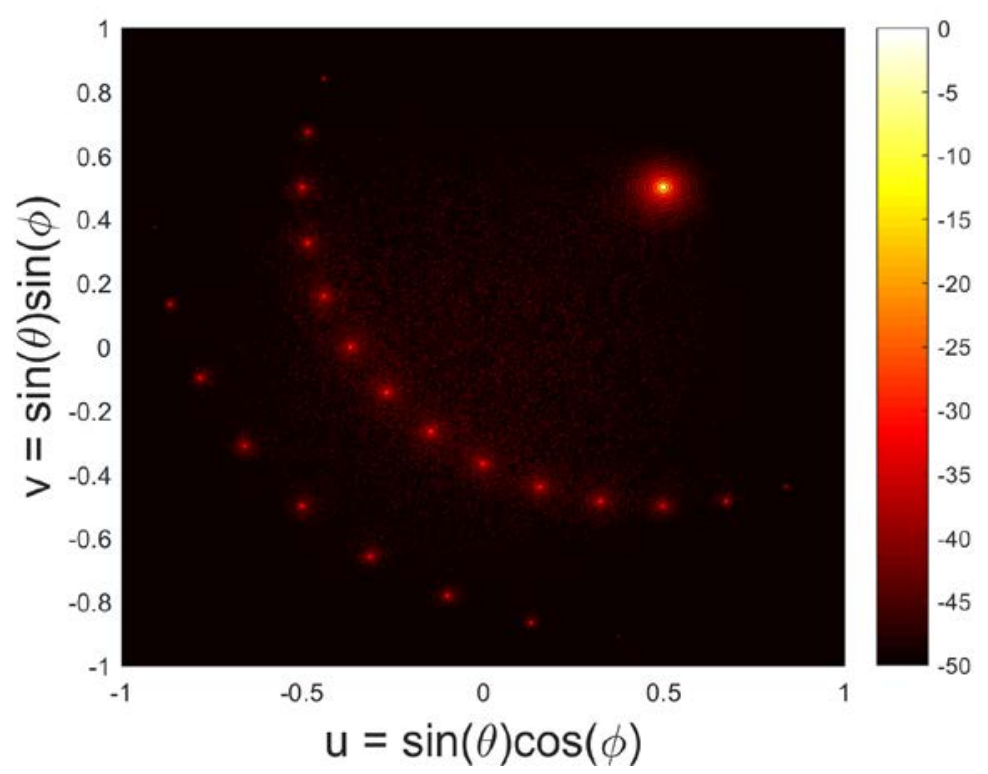

Figure 17 Summed correlations of 9 stations (colour scale in $\mathrm{dB}$ )

The effect of the grating lobes will be reduced if the outputs of the two stations of Figure 15 and Figure 16 are cross correlated by taking the square root of the multiplied voltage patterns. To illustrate this further, simulations have been done with 9 stations with $0,10,20,30,40,50,60,70$, 80 degree rotation. Cross correlations of all combinations, $1 / 2 n(n-1)$ with $n$ the number of stations, gives 36 correlations. When summing the cross correlations (Figure 17), the grating lobes are still clearly visible but they are $\sim 30 \mathrm{~dB}$ lower compared to the main lobe.

Correlated power from far out lobes is lower than $-50 \mathrm{~dB}$ with the set element phase and amplitude calibration (10\% in both). In the Southern Hemisphere, in the absence of very strong sources like Cas A and Cygnus A, this attenuation is sufficient to suppress strong sources below the source detection limit of an individual snapshot.

The simulations have been done on 9 stations only. When extended to e.g. 256 stations, a larger fraction of the imaged sky will be filled with grating lobe responses. In contrary to the sparse-random solution in SKA1-Low, the grating lobes responses will be distinct and the locations will be known. This provides the option to discard specific correlations (visibilities) in the imaging step when grating responses would detect too much unwanted signal from strong sources outside the area of interest.

\subsection{Time dispersion of grating responses}

Earth rotation $(0.25 \% \mathrm{~min})$ will move the grating away from strong sources. Repointing of the array, required to keep-up with earth rotation, will therefore have an effect on grating lobes responses since the repointing will move grating lobes to another location on the sky while the main lobe will continue to follow the source.

This effect is dependent on the (latitude) location of the array on the earth, the location of the source and the frequency. In an extreme case, for celestial pole sources like Polaris in the North, repointing of the array is not required. Still, due to earth rotation, the grating lobes in this observation will move on the sky. 
In order to estimate the time dispersion effect to first order, a simulation has been done with the typical station at $1 \mathrm{GHz}$. For the rotation, movement perpendicular the earth rotation axis of $\frac{2 \pi}{24 \text { hour }}=$ $0.0727 \mathrm{mrad} / \mathrm{sec}$ or $0.0042^{\circ} / \mathrm{sec}$ has been taken. Typically two effects reduce the correlated power in the grating lobe, firstly, the main lobe needs to be repointed to track the source and secondly, the grating position with respect to the main lobe changes. In Figure 18 the time has been calculated for the grating lobe to move by a beamwidth. The beamwidth depends on the station diameter and the projected angle of the beam. A beamwidth of $\lambda /\left(\cos \left(\theta_{\mathrm{d}}\right) \mathrm{D}_{\text {stat }}\right.$ with $\mathrm{D}_{\text {stat }}$ the station diameter has been taken. Only the earth rotation has been considered in this plot. From Figure 18 it can be concluded that the typical station, with a diameter of $38 \mathrm{~m}$, will receive signals through the grating lobe from the same source for up to 200 seconds. A typical integration time for a radio astronomy system is 10 seconds, therefore up to 20 visibilities might need to be discarded if the noise in the grating lobe is degrading the image. This is not insignificant but due to the frequency and proposed station size much less than e.g. in a LOFAR high band station. The LOFAR high band stations have a $30 \mathrm{~m}$ diameter and operate at maximum 250 $\mathrm{MHz}$ and therefore have a large station beam when compared to an AAMID station of $38 \mathrm{~m}$ at higher frequency.

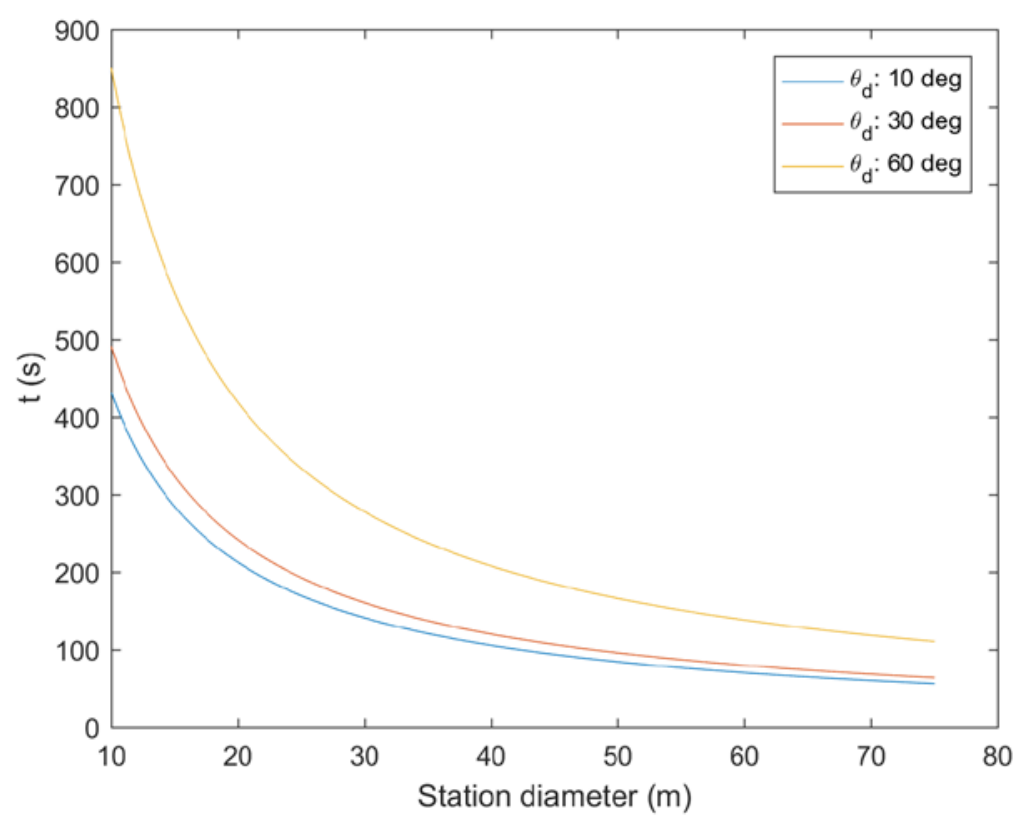

Figure 18 Time for a grating lobe at $1 \mathrm{GHz}$ to move a station beamwidth, depending on station diameter for 3 different pointing angles $\theta_{\mathrm{d}}$

\subsection{Frequency or chromatic dispersion of grating responses}

Similar to the time dispersion a frequency or chromatic dispersion reduces the impact of the energy in the grating lobes. The position of the grating with respect to the main lobe is determined by the antenna element spacing and the observation wavelength. A grating lobes displacement of the size of the station beam, $\theta_{B}$, will be

$$
\theta_{g}-\theta_{g}^{\prime}=\theta_{B}
$$

Considering the first grating lobe, $\mathrm{n} \pm 1$, and the nominal beamwidth given by $\lambda / \mathrm{d}(\mathrm{N}-1)$, the displacement of the grating lobe to move by a beamwidth $\theta_{\mathrm{B}}$ will be: 


$$
\sin ^{-1}\left( \pm \frac{\lambda}{d}+\sin \theta_{d}\right)-\sin ^{-1}\left( \pm \frac{\lambda^{\prime}}{d}+\sin \theta_{d}\right)=\frac{\lambda}{d(N-1)^{\prime}}
$$

with $\lambda$ the nominal wavelength and $\lambda$ ' the off-set wavelength. In Figure 19 a simulation is plotted of the delta frequency for the grating lobe to move a full beamwidth. Typically only one $10 \mathrm{MHz}$ slot will be affected, assuming (high) noise from unresolved sources. The simulations were done with a linear array, but can be expanded in more dimensions.

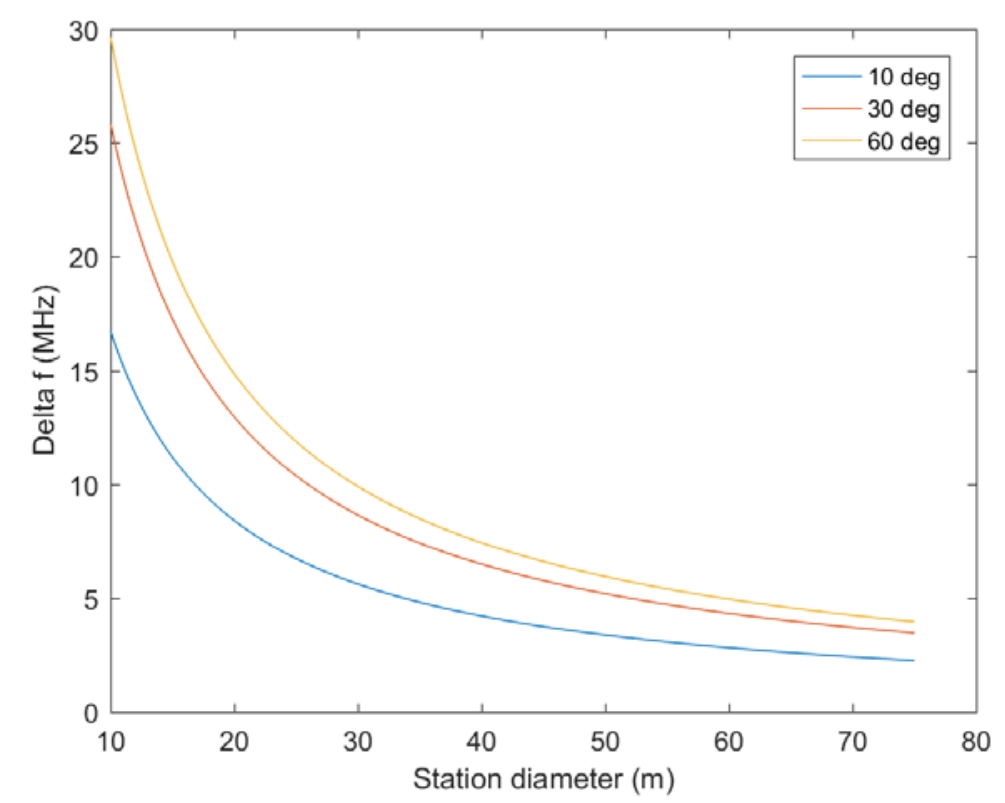

Figure 19 Frequency shift for a grating lobe at $1 \mathrm{GHz}$ to move a station beamwidth, depending on station diameter for 3 different pointing angles $\theta_{\mathrm{d}}$

\subsection{Discussion}

Let's assume a typical example to understand the positive effects of time and frequency dispersion. For continuum science a bandwidth of $100 \mathrm{MHz}$ can be useful. Since the energy of the grating influences $\sim 10 \mathrm{MHz}$ bins, a reduction of the effect of a factor of 10 or $10 \mathrm{~dB}$ will be achieved. The total integration time for a typical science case cannot be given due to the wide range and possible very long integration for very weak sources, however if we want to assess the data in a practical manner, 1 hour could be a good assumption. Given that pointings remain at a certain direction for about 200 seconds (from Figure 18 for a $38 \mathrm{~m}$ station), a reduction of $3600 / 200=18$, or about $13 \mathrm{~dB}$ is achieved. The reduction of the grating lobes due to time and frequency dispersion is, with these typical numbers, limited to 20-25dB. For high dynamic range imaging significantly lower side lobe and grating lobe suppression is needed. Station rotation is therefore required and will provide an additional $\sim 30 \mathrm{~dB}$.

In the array simulations in Section 3.4, a 10\% Gaussian error in amplitude and 10\% in phase has been considered. A much better calibration has been achieved for the LOFAR high band, which is a regular array, using array redundancy [55]. In this work a $1 \%$ amplitude and $1 \%$ phase errors are reported using the redundant baselines. The AAMID stations considered in this work will have many redundant baselines due to the regularity. However single element sensitivity in AAMID will be smaller (smaller element size) and when positioned in the Southern Hemisphere, South Africa, less strong 
sources will be available for calibration. In [56] and [57] self-holography is proposed as a calibration method for AAMID. In this work errors in the range of a couple degrees, less than $1 \%$, are achieved after a number of iterations. Element calibration of this quality will reduce far-out side lobes to very low levels.

The calibration accuracy determines very strongly the level of the far-out side lobes in a regular array structure. Therefore lower side lobes can be achieved if a good calibration can be realized. This is different from random arrays, in which case side lobe levels are determined by the antenna position, if the signal chain calibration is reasonable.

\subsection{Imaging analysis}

The simulations in the previous paragraph indicate that a sparse-regular station design could provide a satisfactory system performance. To support this, a full system performance analysis is required, this falls outside the scope of this dissertation however in [58] a full station analysis has been performed which was focussed on the lower frequencies but is relevant for the AAMID case as well. In this work the array station temperature has been evaluated for 6 different array configurations with 4 different inter-element separations of $0.5 \lambda, 0.8 \lambda, 1 \lambda$ and $2 \lambda$. The station array pattern was computed for arrays with 10,000 antenna elements using array pattern multiplication, assuming all element patterns are identical and excluding mutual coupling. The array temperature was evaluated as the beam tracked a cold patch of the sky over four and a half hours. For the sky model the Haslam $408 \mathrm{MHz}$ survey has been used assuming $\mathrm{T}_{\text {sky }}=\mathrm{T}_{408}\left(\mathrm{f} / \mathrm{f}_{408}\right)^{\beta}$ [59], with the spectral index $\beta$ to be -2.5 (Figure 20). The 6 configurations, regular, triangular, sparse random, concentric rings, thinned and fully random are actually not very different in array noise temperature. In Figure 21 only the regular case has been reproduced; an analysis at $100 \mathrm{MHz}$ for the 3 different element separations with uniform weighting and with Taylor weighting. Figure 21 shows the $T_{\text {array }}$ which are typically below $1000 \mathrm{~K}$ with the exception of the observations where the grating lobe points at the Galactic plane. Random array configurations don't exhibit the peak shown but have a slightly higher average $T_{\text {array }}$.

In this work it is demonstrated that in a single station a doubling of the $T_{\text {array }}$ occurs when the grating lobe receives noise from the Galactic plane. For many time slots (pointings) the regular array actually has a lower $T_{\text {array }}$ than the random station. If a low $T_{\text {sys }}$ is required, station beams with grating lobes pointing at the Galactic plane can be discarded in the processing at the cost of losing some stations and therefore $\mathrm{A}_{\text {eff. }}$ Since a random array lay out will always have the Galactic plane noise in the side lobes, albeit lower, in each of the stations, a system with random array configurations does not have this freedom. A random array configuration will not have grating lobes but random side lobes at the level of $-30 \mathrm{~dB}$ in a careful design. Besides the high grating lobes, far-out side lobes can be much lower than $-30 \mathrm{~dB}$ in a regular array. In this simulation the high station noise is about 5 degrees, or 20 minutes wide and is done with $80 \mathrm{~m}$ diameter stations. For AAMID, with a $38 \mathrm{~m}$ station diameter, the effect will be about half at $450 \mathrm{MHz}$ (half station diameter, 4 times the frequency), and less for higher frequencies. 


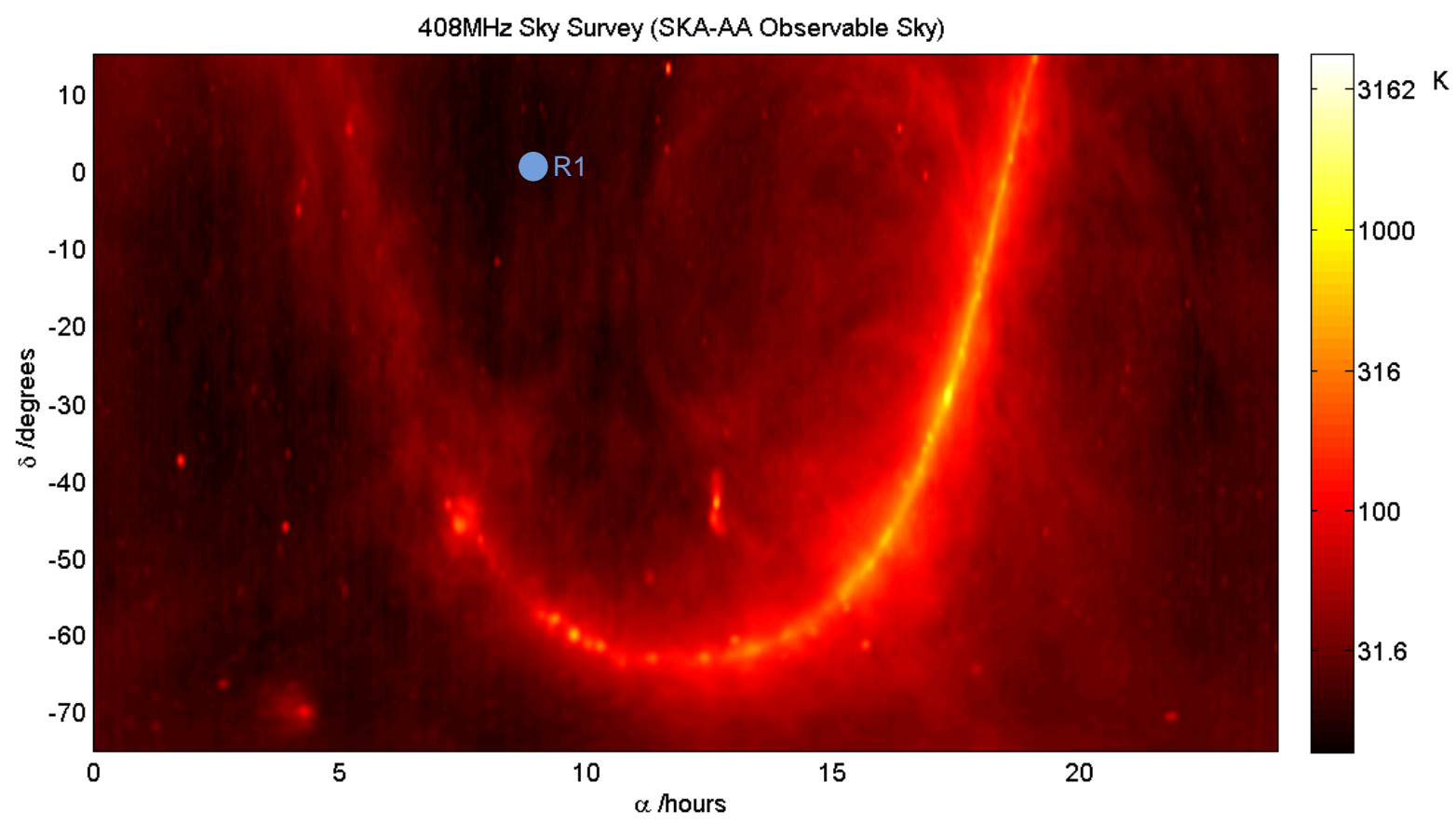

Figure 20 Observable sky in brightness temperature for AAMID based on the Haslam survey [59]. Cold region R1 is used in Figure 21 (R1: $09^{\mathrm{h}} 07^{\mathrm{m}} 12^{\mathrm{s}} 00^{\circ} 00^{\prime} 46^{\prime \prime}$ )

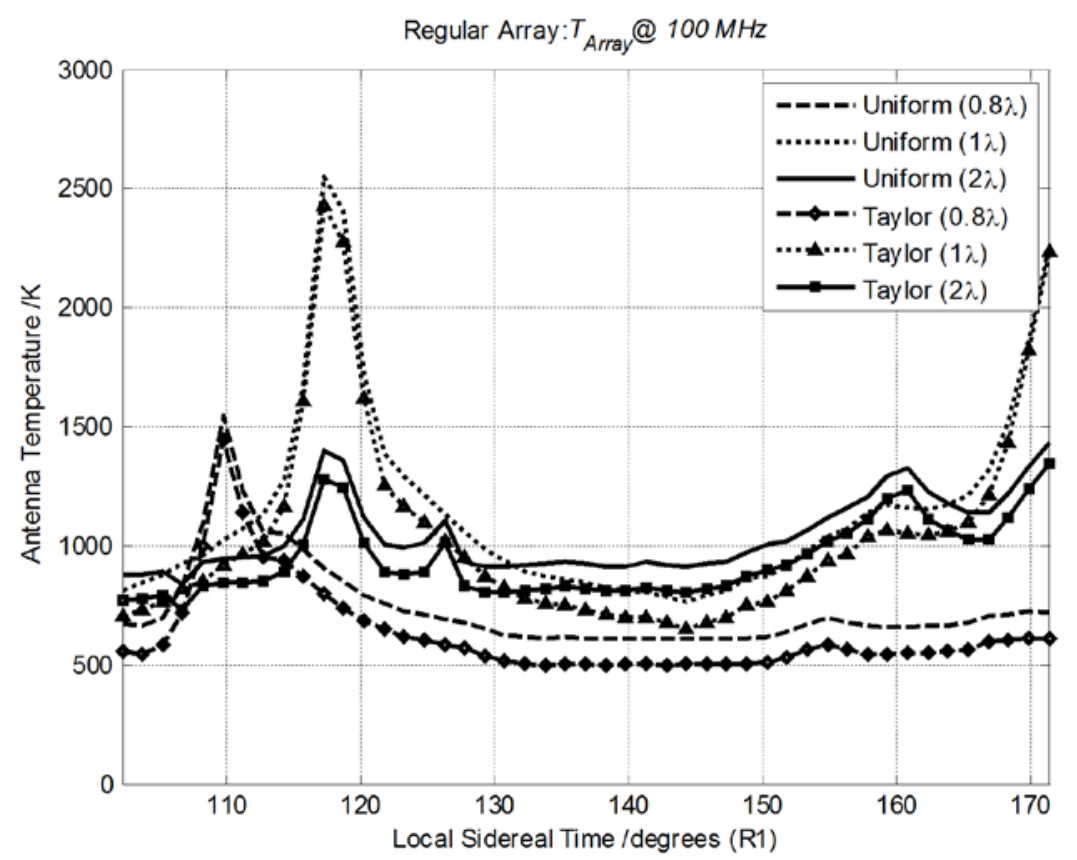

Figure 21 Array temperature computed at 100MHz for R1 (reproduced from [58])

For a full system analysis a tool developed by Oxford University, OSKAR, can be used [60]. In [61] OSKAR has been used to analyse SKA1-Low up to $600 \mathrm{MHz}$. In this work the authors conclude that 
the sparse-random rotated stations actually perform better at higher frequencies, attributed to the smaller FoV and reduced flux from sources at higher frequencies. This indicates that an AAMID system with high side lobes, in the form of grating lobes, can be considered, although a more detailed analysis is required.

\subsection{Station implementation considerations}

The typical station (Table 3) and the simplifications (Paragraph 3.4) considered in this chapter are hiding effects that are likely to occur in a real system. Firstly, element patterns will not be fully rotational symmetric, e.g. non-ideal linear polarised antennas will have different patterns in the $\mathrm{E}$ and $\mathrm{H}$ plane, but even circular polarised antennas will have limited rotational symmetry. Stations will therefore not be constant in gain $\left(\mathrm{A}_{\text {eff }}\right)$ when rotated. Only when the station is dense, (isolated) element pattern effects have limited impact on the station pattern: the station $\mathrm{A}_{\text {eff }}$ in a dense array is determined by the station area and not an addition of individual element gains. Secondly, mutual coupling which will have a rotational dependence when the elements are place on square grid or any other non-rotational grid. A change in mutual coupling will affect the system noise temperature (see Paragraph 5.3.1) and the station gain. A rotated station will therefore have a different station gain and noise temperature in a certain observation direction when compared to station with a different rotation. Note that these effects will occur in non-rotated AA's system as well due to geometric different station locations, which require different beam directions, albeit significantly smaller.

Complex cross correlations between unequal stations will have an impact on the sensitivity or signal to noise ratio of the correlator output. The system noise temperature, $T_{s y s}$, in Paragraph 2.1 needs to be replace by $\sqrt{T_{\text {station } 1} T_{\text {station } 2}}$ with $T_{\text {station } 1}$ and $T_{\text {station } 2}$ the system noise temperatures of station 1 and 2 when 2 stations are correlated. Likewise, the total $A_{\text {eff }}$ will be a summation of $A_{\text {eff1 }}$ and $A_{\text {eff2. }}$. The variations in correlations (visibilities) due to these direction dependent effects will need to be taken into account in the calibration and imaging steps.

The station rotation itself and the accuracy of it will impact the above considerations, however, this effect will be constant and can be calibration for. Anyhow, station rotation steps will not be very useful when smaller than the station beamwidth, when grating energy will not be reduced. This means that for the typical station in this chapter with a diameter of $38 \mathrm{~m}$ and a beamwidth of $\lambda / D$ at $450 \mathrm{MHz}$ of $\sim 0.018$ or $\sim 1$ degrees, only rotation steps of 1 degree or larger should be considered.

Alternative to the round station, a square station can be considered. In Figure 22 a beam pattern calculation of a squared station is given, with the parameters of the typical station, filled out to 16384 elements. The effects of station rotation will be stronger with a squared station and far-out side lobes are higher, however, manufacturing might be easier and station beamforming will be computational more efficient (see Chapter 4). 


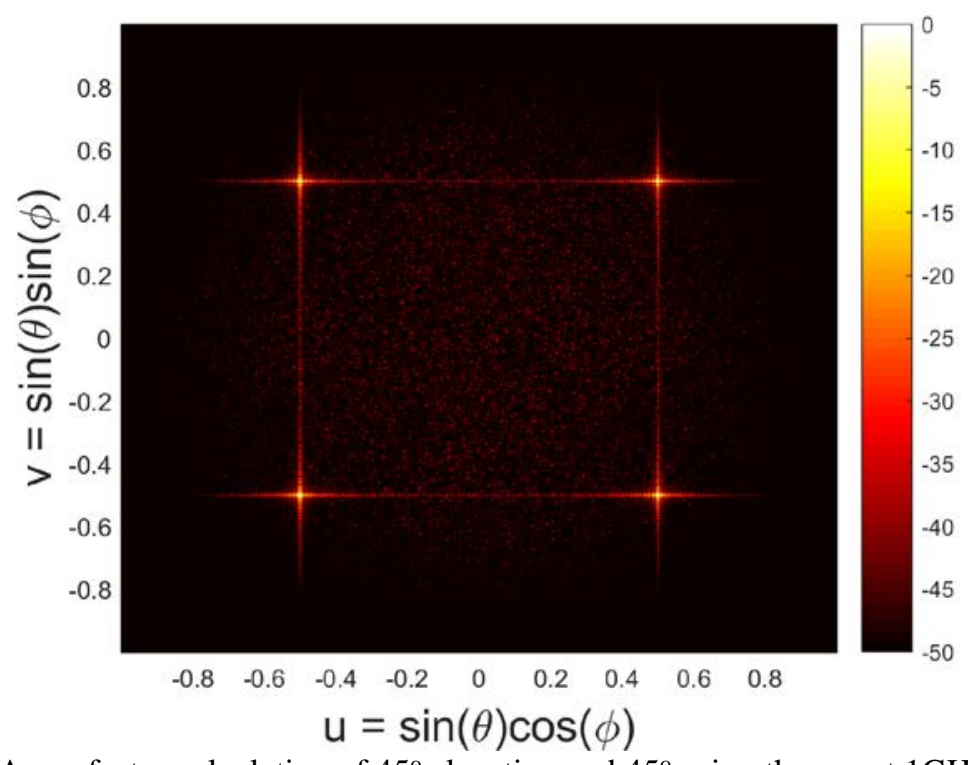

Figure 22 Array factor calculation of $45^{\circ}$ elevation and $45^{\circ}$ azimuth scan at $1 \mathrm{GHz}$ of a square station (colour scale in $\mathrm{dB}$ ) with $16384\left(2^{14}\right)$ elements, $38 \mathrm{~m}$ diameter and one $\lambda$ element spacing.

\subsection{Conclusion}

Station rotation has been used in the LOFAR high band array [49]. In LOFAR the stations are rotated but the antennas are all kept on an identical North-South and East-West orientation. The rotation of the antenna grid has a similar effect as discussed in Section 3.4: grating lobes will be dispersed. This approach has the advantage of a simplified polarization handling, but all stations are different in construction; each antenna array requires a different 'antenna element rotation' step which complicates site work. Further, the station beam model for the LOFAR stations are all different due to the rotation, which complicates modelling and calibration. If the complete station is rotated, as proposed in this dissertation, array construction will be not be complicated with a rotation mechanism and a single station beam model can be used.

It can be concluded from the impact assessment of grating lobes, that the sparse-regular array concept can be considered as an option for AAMID. 


\section{Signal Processing}

The design of the signal processing system for a radio telescope is complex and the detailed design of it, for an aperture array system with very many elements, falls outside the scope of this dissertation. However, in order to reach an understanding of the solution space in terms of operations per second and data rate, this chapter will outlay the basic approach based on a selected reference system.

As discussed in the introduction chapters, beams on the sky can be formed through beamforming, i.e. summing element signals after a specific delay or phase shift, which points the sensitivity of the array in the required direction. This requires a computational load proportional to the number of beams and the number of elements. Beamforming can also be seen as an equivalent of the Discrete Fourier Transform (DFT), summation of an input data sequence of $x_{i}$ of length $N$. DFTs can be performed much more efficiently with a Fast Fourier Transform when $\mathrm{N}$ is of length $2^{\mathrm{n}}$, where $\mathrm{n}$ is any positive integer, when the array elements are placed on a regular grid. Lengths less than this can be extended with zeros to the next $2^{\text {n }}$. Computing a DFT will require $\mathrm{N}^{2}$ multiplies and additions, while an FFT will only cost $\mathrm{Nlog}_{2} \mathrm{~N}$ multiplies and additions. Normally FFTs are used to take a time domain signal and separate it into its different frequency components. In this case, the FFT will separate the incoming signal into bins corresponding to different angles of arrival generating $\mathrm{N}$ beams with $\mathrm{N}$ elements. The spacing and direction of the $\mathrm{N}$ antenna beams are fixed and equally spaced in direction, ranging over the full $+/-90$ degrees elevation and 360 degrees azimuth. The operations in this chapter could either be integer or floating point arithmetic. If the latter is required, the operations per second equal the commonly used compute load or capacity of Floating Point Operations per Second (FLOPS).

\subsection{Reference System}

The system analyses in Chapter 2 considered system implementation options. In this chapter a reference design, out of the ones considered, is used to detail the amount of processing involved. The analysis will concentrate on the station processing. The, possibly very large, output data rate and generated beams need to be processed by an imaging system. In the classic radio interferometer the station beams are processed in a correlator, which generates the visibilities by cross correlating station beams, with some duration of integration, followed by a gridding and imaging step.

Table 4 Reference Station Parameters

\begin{tabular}{|c|c|c|}
\hline Parameter & Quantity & Description \\
\hline $\mathrm{N}_{\text {elements }}$ & $2^{14}=16384$ & $\begin{array}{l}\text { \# antenna elements per station, equals } 51.2 \times 51.2 \mathrm{~m} \text { size station } \\
\text { in a square configuration }\end{array}$ \\
\hline $\mathrm{d}$ & $0.4 \mathrm{~m}$ & Antenna element pitch, $\lambda / 2$ at $375 \mathrm{MHz}$ \\
\hline $\mathrm{N}_{\text {pol }}$ & 2 & \# polarizations \\
\hline $\mathrm{N}_{\text {tap }}$ & 16 & $\begin{array}{l}\text { \# taps FIR. Typical number, equals } 60 \text { dB dynamic } \\
\text { range/suppression }\end{array}$ \\
\hline$\Delta \mathrm{f}_{\text {signal }}$ & $1 \mathrm{GHz}$ & Total radio frequency band (450 - $1450 \mathrm{MHz}$ ) \\
\hline$\Delta \mathrm{f}_{\text {band }}$ & $1 \mathrm{MHz}$ & Sub bandwidth coarse channels \\
\hline$\Delta \mathrm{f}_{\text {channel }}$ & $1 \mathrm{KHz}$ & Sub bandwidth fine channels \\
\hline $\mathrm{N}_{\text {band }}$ & 1000 & A practical implementation might use 1024 \\
\hline $\mathrm{N}_{\text {beam }}$ & 262144 & $\begin{array}{l}\text { Maximum for full visible sky coverage: } 2^{4} \text { (sparsity factor) } \times 2^{14} \\
\text { (\# antenna elements) }\end{array}$ \\
\hline
\end{tabular}


The computational requirements are derived in terms of operations per second and bandwidth requirements in terms of bytes per second. It is assumed that the effective sample width is 8 bits complex, equalling two bytes. Given the RFI interference and dynamic range considerations, 8 bits should be sufficient [106]. Complex additions are counted as two real valued operations, complex multiplications are counted as six operations. It is assumed the word size stays constant throughout the processing, requiring appropriate truncation.

To give some perspective to the numbers in Table 4, SKA1-Low has 131,072 antenna elements and $300 \mathrm{MHz}$ RF bandwidth. All antenna signals in SKA1-Low are digitized. If 256 stations would be built for AAMID, the total output bandwidth would be about a factor of 100 larger (32 times more antennas and three times more bandwidth). If Moore's Law would continue, doubling the integrated circuit capacity every 18 months, a two orders of magnitude improvement would be achieved in 10 years. Moore's Law is levelling off but even if it would only achieve doubling the capacity in 2.5 years, a two orders of magnitude capacity improvement would be realised in 16 years. The International Roadmap for Devices and Systems organization publishes a roadmap with a 15-year horizon [62], indicating that significant technology improvements are expected. It should be noted that SKA1-Low only generates one full bandwidth beam per station. More beams or multiple FoV's are generated in SKA1-Low but at the expense of bandwidth of each of the generated beams.

Signal processing designs are most efficiently done in powers of 2 . Therefore a station size of $2^{14}$ $=16384$ elements is selected for the calculations in this chapter. If a round station is preferred, $2^{14}$ grid points can be used of which only $\pi\left(2^{6}\right)^{2} \approx 12868$ would be filled with antenna elements. The FFT would remain the same size, with zeros at $\sim 3516$ points. The analyses in Chapter 3 are based on round stations. The sensitivity of a square station would not be constant over the observation due and cross correlations between rotated stations would complicate the back end processing.

\subsection{Calibration and Channelization}

In radio astronomy systems the need for two types of calibration can be distinguished; instrument calibration and atmospheric calibration. Errors in both influence the complex voltages received from the source in the same way. For synthesis, dish based, radio telescopes, instrument calibration is relatively straightforward and well understood: the mechanical structure provides a first order pointing. However in AA systems, with low gain single element beams, a reasonable level of receive channel calibration is required before a station beam can be formed. In LOFAR coaxial cables between the antennas and the processing units are all phase matched and buried at installation, therefore at system start-up the difference between antenna channels is small and beams can be formed easily. Since the phase-matched solution used in LOFAR (and also MWA) is a complication and therefore costly additional step in the production of the telescope, it is unlikely that this approach can be used in AAMID due to the large amount of elements. In SKA1-Low, where antennas are connected with RFoF with no a priori knowledge of the transit delay or phase (see the discussion in section 5.4.4), no functional beam can be formed at start-up. Calibration of the 256 elements in these stations is therefore a crucial step

Second to the delay calibration, the complex differences between receiver channels are typically frequency dependent. Components from a single manufacturing batch might have similar behaviour and for low frequencies differences tend to be small but for a wide band high frequency system each frequency bin requires a different correction factor. This means that calibration of the elements can only be done after the frequency select filter, i.e. the channelization process. 
In the channelization processing step, every frequency sub-band is split into $\mathrm{N}_{\text {band }}$ narrower frequency channels by trading time resolution for frequency resolution. This is performed through a poly-phase filter consisting of an $\mathrm{N}_{\text {band }} \mathrm{N}_{\text {taps }}$ finite impulse response sub-filters (FIR) and an $\mathrm{N}_{\text {band }}$ real to complex Fourier transform (FFT) that is applied to the outputs of the sub-filters. The FFT step converts the polyphaser output to a sequential stream of complex channelized samples. The FFT requires $2.5 \operatorname{Nog}_{2} N$ operations per sample [63] [65]. The number of sub-bands generated, $\mathrm{N}_{\text {band, }}$, is half the number of points in the FFT: $N=2 N_{\text {band }}$. Together the channelization of an AA station will require

and

$$
\begin{gathered}
R_{F I R}=N_{\text {elem }} N_{\text {pol }} 2 N_{\text {tap }} 2 \Delta f_{\text {signal }}, \\
R_{F F T}=N_{\text {elem }} N_{\text {pol }} 5 N_{\text {band }} \log _{2}\left(2 N_{\text {band }}\right) \Delta f_{\text {band }}
\end{gathered}
$$

$$
R_{P}=R_{F I R}+R_{F F T}
$$

operations per second. With the number of samples per second

$$
N_{\text {sps }}=N_{\text {elem }} N_{\text {pol }} 2 \Delta f_{\text {signal }}
$$

With the numbers of the reference design, both the FIR and the FFT step are about equal in size, 2.0 $10^{15}$ and $1.810^{15}$ operations per second respectively.

\subsection{Beam Forming}

Consider the conventional beamformer

$$
y(t)=a^{H} x(t)
$$

with $a$ is the vector of weights ("steering vector") for the desired beam and $x(t)$ is the vector of antenna outputs of the station. The vector $a$ is e.g. selected to maximize gain in a given direction but can also be used for channel calibration, for nulling or specific weighting functions. For multi beaming (6.5) can be simply extended to

$$
y(t)=B x(t)
$$

with $B$ the beamformer matrix $\left[a_{1}, a_{2} \ldots a_{N}\right]^{H}$ and $a$ the desired steering vectors for $\mathrm{N}$ beams. The weighting in (4.5) and (4.6) needs to be followed by a summation to form a station beam

$$
y_{b}(t)=\sum B x(t)
$$

The station beamformer uses a complex gain function to implement the time delay in the frequency domain and to apply various calibration parameters. When $a$ is selected, calibration and nulling has no additional computational cost. For each of the $N_{\text {beam }}$ beams, beamforming involves a complex multiply-add operation (eight real-valued multiply and add operations) per sample resulting in a compute rate of

$$
R_{b}=8 N_{\text {beam }} N_{\text {elem }} N_{\text {pol }} N_{\text {band }} \Delta f_{\text {signal }}
$$


Equation (4.8) is an approximation valid for $N_{\text {elem }} \gg 1$ [63] and assumes a flat beamforming approach where each beam is formed separately. A hierarchical beamforming could be considered. This is in principle identical to the established analogue beamforming and is a direct reduction of the compute load [64]. For a 2-stage beamformer we need

$$
R_{b-2}=8\left[\left(N_{a 1} N_{b 1}\right) \frac{N_{\text {elem }}}{N_{a 1}}+N_{\text {beam }} \frac{N_{\text {elem }}}{N_{a 1}}\right] N_{\text {pol }} N_{\text {band }} \Delta f_{\text {signal }},
$$

operations. In this we have $N_{a 1}$ the number of antenna elements combined in the first stage beam forming and $N_{b 1}$ the number of beams after the first stage beamforming. Each of $1^{\text {st }}$ stage antenna beamforming groups forms $N_{b 1}$ beams, which correspond to the number of directions in the sky. When $N_{b 1}$ is equal to 1 , only subsequent beams can be formed in one direction (or FoV), similar to an analogue beamformer. $2^{\text {nd }}$ stage processing for each station beam is a constant amount for a given $N_{b 1}$. Each station beam can be formed out of the number of $1^{\text {st }}$ stage beamformed antennas, which is the fraction of the total number of antennas $N_{b 1} / N_{a 1}$. If $N_{b 1}=1$ (one FoV) and $N_{a 1}=2^{4}$, then the 2-stage beamforming only uses $7 \%$ of the operations in comparison with a single stage beamforming. The 2stage beamformer is more efficient for a larger number of FoV's as well, up to $N_{b 1}=N_{a 1}$, when the first stage does not reduce the to-be-processed data for the second stage anymore. In section 6.5 the processing load for a 2-stage beamformer is compared with a conventional beamformer (4.8), where for the 2-stage $N_{a 1}$ is 32 and $N_{b 1}$ is 8 has been chosen.

\subsection{FFT Beam Forming}

When many independent FoV's or beams are needed an alternative beamforming method can be considered. Equation (4.7) can also be executed as a spatial Fast Fourier Transform (FFT). The FFT method of beamforming is computationally very efficient and allows for multiple directional signals to be simultaneously received. An FFT on $N$ antennas will generate $N$ beams, all useful except for the low elevation beams. Very low elevation beams will have low sensitivity due the projection effect on $A_{\text {eff, }}$ which follows $\cos \theta$, with $\theta$ the polar angle from zenith.

A spatial FFT beamformer can be seen as the digital equivalent of the Butler matrix [66]. A Butler matrix consists of hybrid couplers and fixed-value phase shifters. The number of outputs is equal to the number of inputs, generating $n$ beams from $n$ input signals. As with the Butler matrix, antennas need to be placed on a regular grid for the FFT to work

The computational load of an FFT scales with $N \log _{2} N$, with $N$ the number of input signals and is computationally more efficient if the required number of beams, $M$, is larger than $\log N$ since beamforming scales with $M N$. However, the spacing and direction of the $\mathrm{N}$ beams are fixed and equally spaced in direction. In keeping with the characteristics of the FFT, the peak of any given antenna beam lies on the null of the sidelobes of all the neighboring antenna beams. For the FFT beamforming the following processing load applies

$$
R_{f f t}=6 N_{\text {pol }} N_{\text {band }} \Delta f_{\text {band }} N_{\text {elem }} \log _{2} N_{\text {elem }}
$$

by analogy with (4.8). In (classic) beamforming, the calibration coefficients, amplitude and phase, can be included in the steering vector $a$. Once determined, no extra operations are needed apart from the beamforming itself. This is, however, not the case for the FFT beamformer, which requires the calibration step as an additional processing step. 
The default considerations of FFT processing assume a $\lambda / 2$ antenna pitch, in which case the signals from $N$ elements form the $N$ orthogonal (first nulls coincide) beams. This situation does not apply to highly dense arrays nor to sparse arrays. In the dense situation, the beams start to overlap more strongly, since the number of generated beams remains constant and beamwidth increases with $\lambda$, leading to oversampling. This might not be a direct concern since the operator can opt for the use of fewer beams. In the sparse case however, under-sampling leads to non-contiguous sampling of the sky. The most straightforward solution for this is to extend the array with a sparsity factor by zero padding the array [67], at the expense of more signal processing. The sparsity factor s equal to $\lambda_{0} / \lambda$, with $\lambda_{0}$ the wavelength at which the antenna pitch $d$ is $\lambda / 2$, needs to be an integer and for efficient FFT processing the resulting matrix needs to be a power of 2 [68]. This reduces the options to process the reference design to $s=1$, $s=2$ and $s=4$, which increases the amount of processing for a square array by a factor of 1,4 or 16 . Depending on the amount of required overlap between contiguous beams, the frequency band can be split up in three parts, e.g. 450-666 MHz with $s=1,666-986 \mathrm{MHz}$ with $s=2$ and 986 - $1450 \mathrm{MHz}$ with $s=4$ - given the antenna pitch suggested in Table 4 and a factor of 1.48 frequency steps. The processing load for these bands increases by $\mathrm{s}^{2}$, from 1 to 16 . If an array would be designed with a larger antenna element sparsity, e.g. $s=8$, a factor of $2^{6}, 64$ times, higher FFT load needs to be considered. Note that the matrix increase has the effect of an increase of $N_{\text {elem }}$ in (4.10); the increase in processing load is therefore equal to $s^{2} N_{\text {elem }} \log \left(s^{2} N_{\text {elem }}\right)$.

For radio astronomy systems, contrary to telecommunication, beam orthogonality is not necessarily required or desirable. In telecommunication systems beam orthogonality is defined as beams which are sufficiently independent, with spill-over at a sufficiently low level. For radio astronomy systems some beam overlap might actually be desired for smooth image generation. Where in traditional AA systems every beam can be formed arbitrary, FFT beamforming generates a fix grid of beams on the sky and therefore limits the flexibility and observer control.

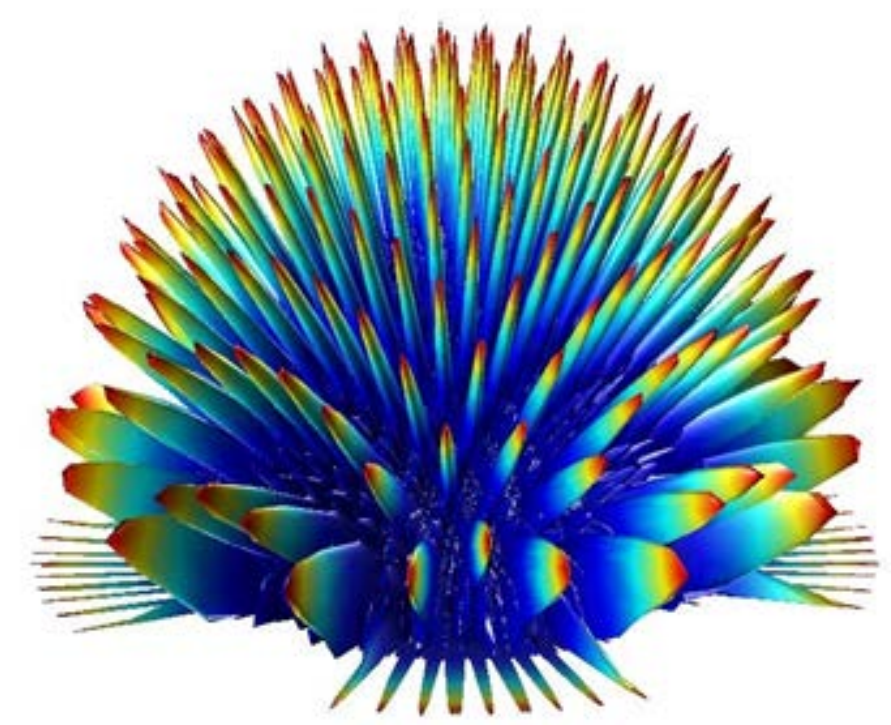

Figure 23 Visualisation of FFT array beams of a sparse regular array (reproduced from [74])

In Figure 23 a simulation of an FFT beamforming of a sparse array is given to illustrate the effect. In this simulation the FFT is not oversampled causing the beams to be separated. 


\subsection{System optimization}

In order to assess the possible advantages of FFT spatial beamforming the requirements for the number of beams needs to be assessed. For a square station the beam size, $\Omega_{b}$, can be approximated by

$$
\Omega_{b}=\frac{\lambda^{2}}{D^{2}}
$$

with $D=d \sqrt{N_{\text {elem }}}$. The number of beams required to produce a total instantaneous FoV of an AA system of $\Omega_{F}$ is

$$
N_{b}=\frac{\Omega_{F}}{\Omega_{b}}=\Omega_{F} \frac{D^{2}}{\lambda^{2}}
$$

With a FoV requirement of $200 \mathrm{deg}^{2}$, the number of beams required for the reference system of Table 4 is given in Figure 24. It is clear that the number of beams required and therefore the processing load is not constant and increases with frequency. Alternatively, a constant survey speed (2.2) could be required. Since the sensitivity of a sparse array relates to the individual antenna gain or element $A_{\text {eff, }}$ the total array $A_{\text {eff }}$ will have, to first order, a $\lambda^{2}$ dependency. Since $A_{\text {eff }}$ is squared in the survey speed, this results in a $\lambda^{4}$ relation. The reduction of $A_{\text {eff }}$ can be compensated by generating more beams (with a $\lambda^{2}$ dependency). For illustration, taking the $A_{\text {eff }}$ at the lowest frequency, $450 \mathrm{MHz}$ in Figure 24, as the reference, the required number beams for a constant survey speed, with a $\lambda^{6}$ dependence, results in 40,000 beams at $1450 \mathrm{MHz}$. With a beam size of $\approx 0.1 \mathrm{deg}^{2}$ this is a good fraction of the visible sky $\left(10,000\right.$ of $\left.20,000 \mathrm{deg}^{2}\right)$. In this calculation it is assumed that all beams have the same sensitivity: projection losses are ignored which is valid in this comparison since projection loss does not depend on the frequency. Still, it is clear that the $\lambda^{6}$ dependence is not favourable for efficient sparse array processing.

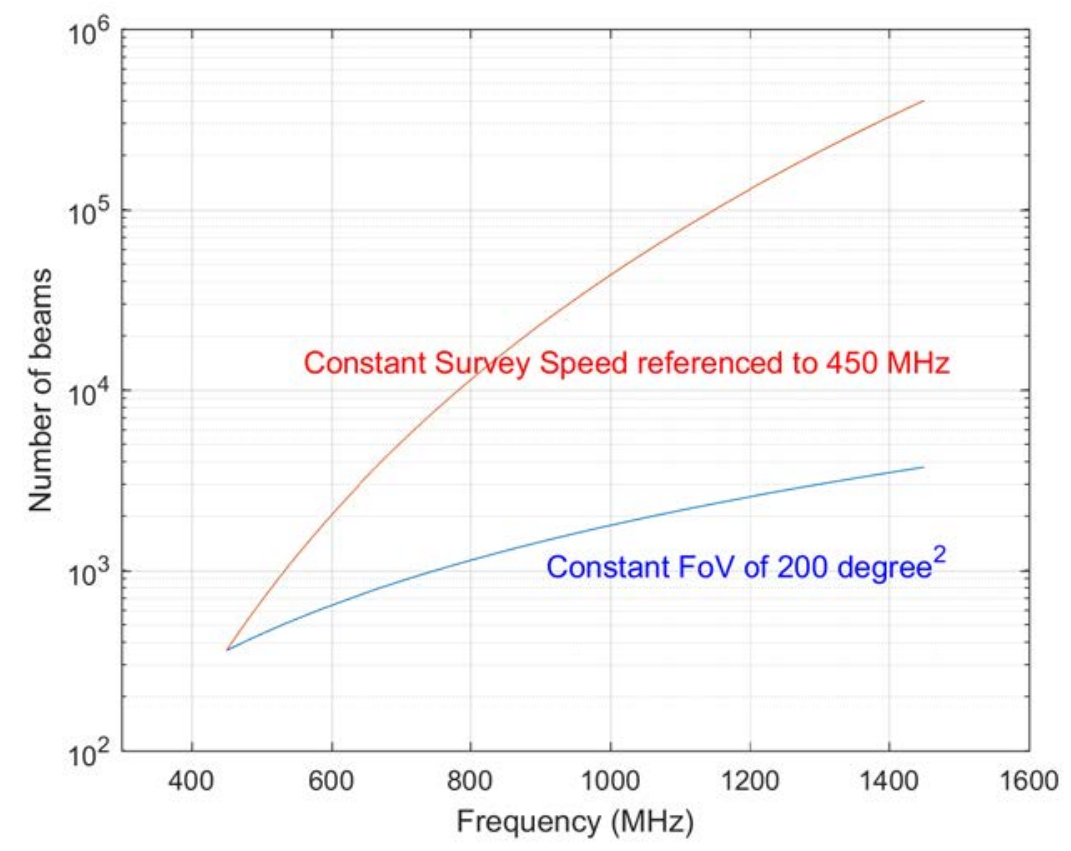

Figure 24 Required number of stations beams for a constant FoV (blue) and for a constant survey speed referenced to $450 \mathrm{MHz}$ (red) 
The reference system in this chapter, with a sparsity of $s=4$ at the maximum frequency, has the advantage described in Chapter 2 (higher sensitivity) but also the discussed drawback of the narrower beam requiring more beams to fill the required FoV. This is expressed in Figure 25: a dense array requires 257 beams to fill 200 deg $^{2}$ at $1450 \mathrm{MHz}$ and the reference design used in the chapter requires 3730 beams $(\lambda / \mathrm{d}=2)$. As discussed above, this drawback is even more severe for the survey speed.

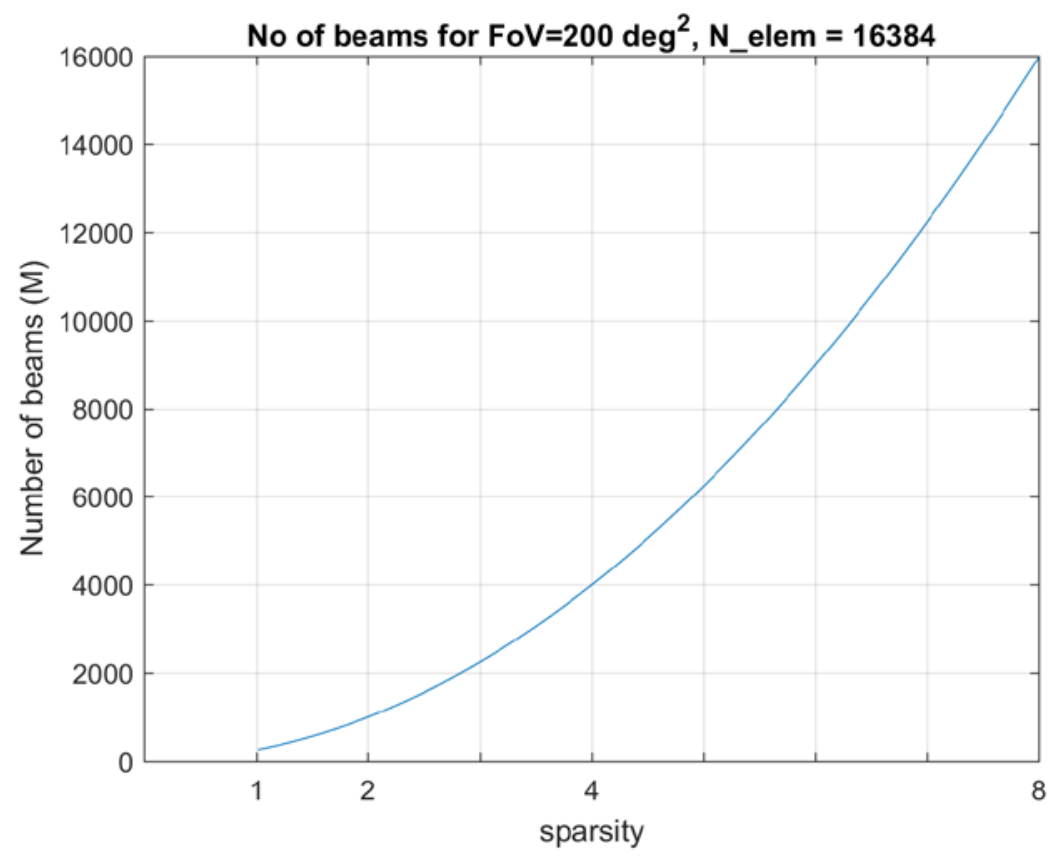

Figure 25 Number of beams required for a $200 \mathrm{deg}^{2} \mathrm{FoV}$ at $1450 \mathrm{MHz}$ for a square station with $2^{14}$ elements in relation to the sparsity of the array at $1450 \mathrm{MHz}$ (from dense to very sparse)

In Figure 26 the operations per second for the processing of the reference station are plotted against the number of beams: equations (4.3), for the channelization, (4.8) for the beamforming, (4.9) for the two stage beamforming and (4.10) for the spatial FFT with 16 times oversampling. The channelization is independent of the number of beams. Since the FFT will generate all possible beams, $16 N_{\text {elem }}$ in this case, it is plotted as a straight line to illustrate the intersection with the beamforming options. For the 2-stage beamforming a first stage of 32 elements is selected, similar to a typical analogue beamformer.

In Figure 26, the operations per second for the FFT beamforming of a dense array are plotted labelled with "FFT". The operations per second for the beamforming, single stage or 2-stage, is independent of the element pitch. Therefore, if oversampling the FFT is not required, FFT processing would already be more efficient if more than 10 beams are required. To what level oversampling the FFT is indeed required in the case of a sparse configuration is contentious and involves further study [69].

From Figure 26 and Figure 25, it can be concluded that in order to process the required $200 \mathrm{deg}^{2}$, FFT processing is significantly more efficient than single stage beamforming. The difference is less with the 2-stage beamformer and if the amount of independent FoVs would be reduced to two only, the required operations per second for the 2-stage beamforming is nearly equal to the oversampled FFT for 3730 beams (not plotted in Figure 26). Even so, the FFT would generate more (all) beams. 


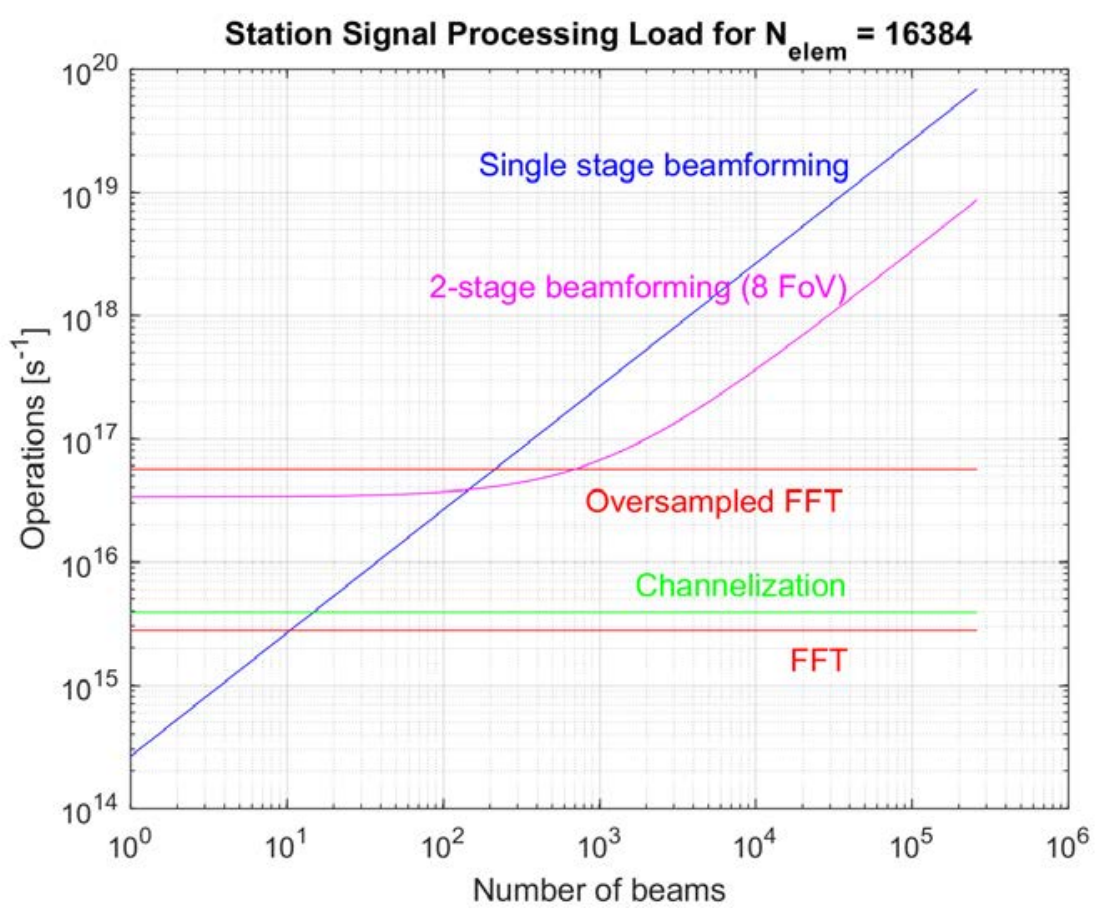

Figure 26 Operations per second for the station processing of a regular station. 'FFT' is applicable to a dense array. 'Oversampled FFT' is applicable to the reference sparse array.

\subsection{Array configuration}

The analysis in this chapter uses square stations. Round stations will have better and smoother side lobe performance but for the FFT $\left(2^{\mathrm{n}}\right)$ signal processing an overhead needs to be included. The zero padded area for a round station will be

$$
Z_{p}=(2 n)^{2}-\pi n^{2}
$$

which is $\sim 21 \%$. Creating a circular array will therefore save this percentage of antenna hardware at the expense of signal processing hardware (signal processing will remain $2^{\mathrm{n}}$ based). In case of a 1:1 cost ratio for collecting area versus station processing, building a square array would cost a bit more in total but for many science cases all elements can be used, therefore the potential of shape optimization in the antenna hardware is not efficient. The specific station beam pattern optimization can still be achieved in processing by weighting.

\subsection{Conclusion}

In the assessment of the processing load of the reference design and in the comparison of the options, only indicative conclusions can be drawn, since the following aspects have been neglected and require more detailed investigation:

a) Signal transport between the processing nodes

b) Signal transport to correlator/imager

c) Signal storage, needed if one operations requires more than one cycle

d) Matrix handling, e.g. matrix transpose or corner turn

The calculated compute load plotted in Figure 26 should therefore be considered as the minimum need.

In comparison with the largest radio astronomy AA in operation (2019); LOFAR installed a GPU 
cluster for the correlation of station data with a capability of 360 Tera FLOPS [70]. SKA1-Low projects the need for 8 Peta FLOPS to perform the beamforming of the 512 stations (0.15 Peta FLOPS per station) [71] [72] and hundreds of Peta FLOPS for the image processing. The compute load for the station processing of one station of the reference design in this chapter is 56 Peta FLOPS. Although this is significantly more than the beamforming in SKA1-Low, the total compute load of an AAMID telescope with this station reference design, including correlation and imaging, is not inconceivable. 


\section{Aperture Array Station Realization}

The proposed system architecture does not strongly depend on the detailed implementation. For most system elements, multiple options can be considered, with only modest effect on performance. The review of options in this chapter is intended to demonstrate the achievability of the proposed AAMID telescope and to give guidance on research of the system elements. The antenna element is however very specific, not only does the array performance strongly depend on the antenna element, also the system cost is highly affected by the antenna choice. The proposed system architecture intends to at least mitigate strong cost drivers.

Signal processing firmware and data processing imaging algorithms, which will be a very significant challenge for a possibly all sky instrument, are outside the scope of this dissertation.

\subsection{Introduction}

The antenna types currently investigated by the Mid Frequency Aperture Array consortium either assume a dense array or a sparse random array implementation. The antenna types considered for the dense array are Vivaldi, ORA (Octagonal Ring Array) and DDA (Dense Dipole Array) [78] [79]. In order to get good performance up to $1.4 \mathrm{GHz}$, a half $\lambda$ spacing around $1.2 \mathrm{GHz}$ is used in these dense designs. The sparse array antenna under investigation for AAMID is a Log Periodic Dipole (LPD) antenna with a typical half lambda spacing of $0.6 \mathrm{GHz}$. In contrast with the above regular dense antennas, which benefit from coupling and to a large extend have broadband performance due to the inter element coupling, the sparse LPD antenna cannot be used on a regular grid because of unacceptable behaviour due to coupling, creating anomalies; frequencies were the active reflection coefficient is close to 1. In Figure 27, a simulation of a regular array of LPD antennas is compared with an array with random placement [80]. From this simulation (for SKA1-Low) it is clear that the sparse-regular array exhibits these anomalies. The antenna element spacing in this work is $\sim 1.5 \mathrm{~m}$ and is therefore sparse above $100 \mathrm{MHz}$.

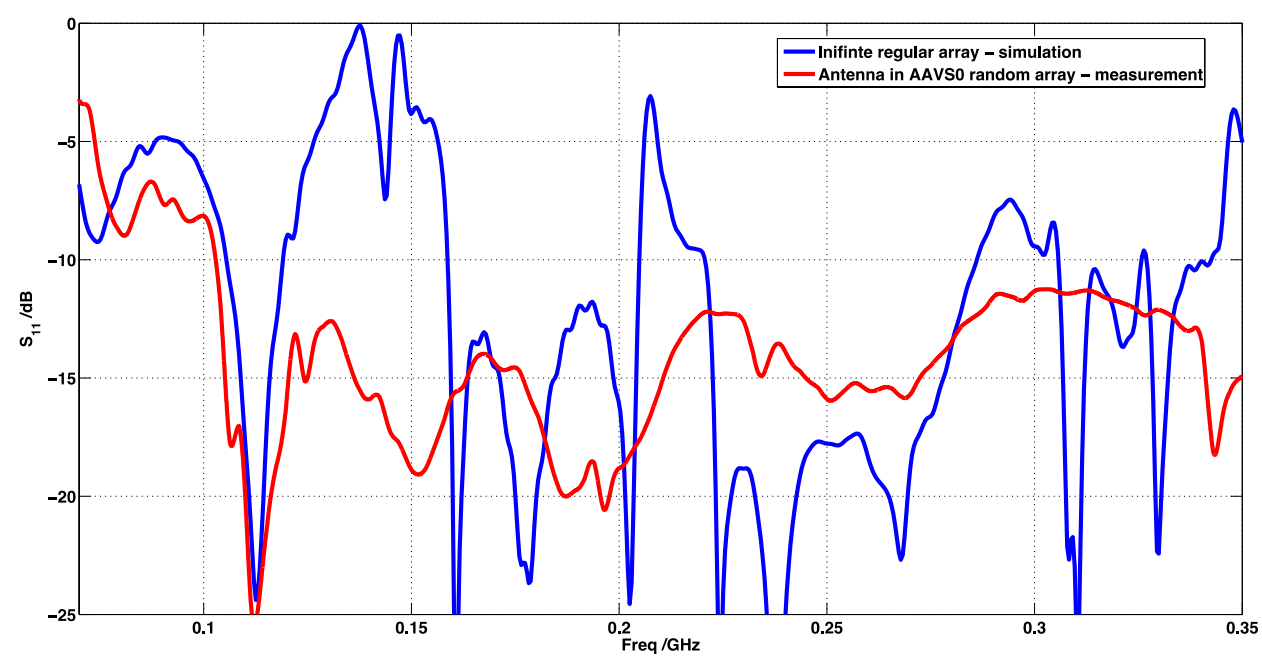

Figure 27 Reflection coefficient simulation of a regular array of Log Periodic antennas (blue curve) and the same antenna in a random orientation (red curve) [80]. 
Anomalies, also call blind scan angles, are a typical concern for sparse regular arrays. Options for alternative antenna concepts or modifications to the above will be needed in a sparse regular implementation.

Array design criteria include:

a) Smooth impedance. Cryogenic Low Noise Amplifier (LNA) cooling, such as used in reflector antennas, is expensive, not only in terms of construction cost but also for power consumption and maintenance. An AA system, with a large number of receivers, should therefore consider the use of room temperature LNA's. Recent developments demonstrate receiver noise temperature less than 25 Kelvin, but only when a good noise match with the antenna is achieved [81][82][83][84][85] [86][87][88]. Section 5.3.3 includes an assessment of the cooling options.

b) Low inter element coupling in order to reduce anomalies.

c) Benign beam pattern for easy calibration. Recent developments in SKA1-Low emphasized this issue (to be published).

d) Antenna gain: The SKA requirements don't call for a full hemispheric scan range and due to the foreshortening effect sensitivity below 60 degrees off Zenith are anyhow not very effective, therefore some antenna gain would improve most of the observations.

e) Wide bandwidth. A bandwidth in the order of 3.5 to 1 is needed which is significantly more than a patch or a dipole antennas but relatively modest compared to typical broadband concept. Besides the above examples, antennas like sinusoidal or spiral antennas will be considered.

f) Low cost fabrication. In order to create sufficient sensitivity up to 10 million antennas might be needed. It is therefore crucial to design an antenna with low production and deployment cost. When done properly, the system cost should be dominated by the electronics and signal processing.

The current investigated dense antennas typically suffer impedance deterioration and blind scan angles when used in the regular sparse regime. Different regular layouts might mitigate some of the problems with regular sparse arrays: a Vivaldi array placed on a diamond-like configuration instead of a square grid can be considered [89]. Placement of antennas slightly off grid have been considered as well. It needs to be investigated if the FFT processing can still be used in the latter case. An indicative investigation in [90] on dense irregular arrays suggested this can be of interest. This, however, falls outside the scope of this dissertation.

\subsection{Antenna array}

A sparse regular array might suffer from issues caused by mutual coupling. Due to the regularity of the array, signals coupling between antenna elements can create problems like:

a) Anomalies, frequencies for which the array becomes completely blind (near perfect reflection of incoming plane waves from the array surface), independent of scan direction of the array. This phenomenon is believed to be related to surface waves in the array

b) Blind scan angles - scan directions at specific frequencies with a high reflection

c) Beam shape ripples

A detailed analysis of antenna arrays in the sparse-regular regime has been reported in the dissertation from Klopper [91]. This work reveals an interesting correlation between the incursion of grating lobes into visible space and the degradation of the active reflection coefficient, both related to the regular antenna spacing. This research confirmed issues with antenna elements which rely on coupling to 
generate a broad bandwidth like the Vivaldi antenna. Performance of these antenna arrays can be problematic when used in the sparse-regular frequency regime (see also Figure 31). The best solution identified in the work from Klopper is a pyramidal sinuous antenna element. In Figure 28, the simulated active reflection coefficients for three frequencies, 450, 950 and $1450 \mathrm{MHz}$ and scan angles to $30^{\circ}$ elevation for the array are plotted. The element spacing is quite large, $d=\lambda$ at $450 \mathrm{MHz}, 0.67 \mathrm{~m}$, which contributes to the smooth behaviour due to reduced coupling with this large element separation. With respect to the sparsity defined in Chapter 4, it relates to a sparsity of 6.4 at $1450 \mathrm{MHz}$. The reference impedance in these simulation is $300 \Omega$. The relevance of the active reflection coefficient will be discussed in section 5.3.1.
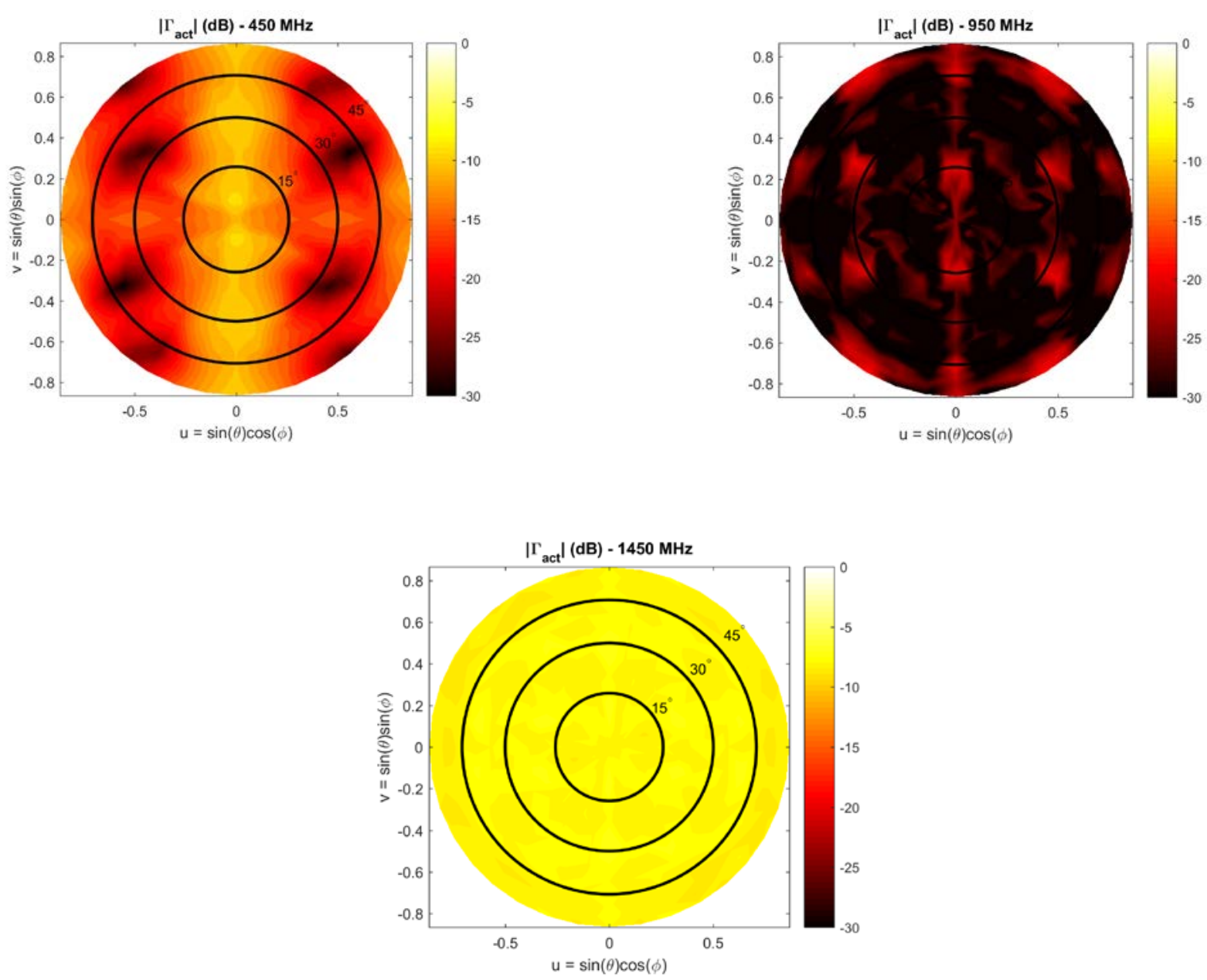

Figure 28 Active reflection coefficient simulation of a pyramidal sinuous array with an element spacing $\mathrm{d}=\lambda$ at $450 \mathrm{MHz}(0.67 \mathrm{~m})$ for 450,950 and $1450 \mathrm{MHz}$ for scans to $30^{\circ}$ elevation angles. Reference impedance is $300 \Omega$.

An alternative method to reduce the array element count while maintaining a good impedance is thinning the array. This has been explored in [92]. In this work, Vivaldi antenna elements have not been removed but left open. The red crosses in Figure 29 are the element positions while the black circles are the active antennas, effectively creating a sparse array in which the active elements are on a grid, allowing FFT signal processing. In Figure 29 only elements in the x-direction have been removed, expanding the thinning in the y-direction will reduce the number of active elements by a factor of 4 . Simulations confirmed that the thinning has no effect on the $\mathrm{A}_{\text {eff }}$ in the lower frequency range, while as expected for higher frequencies $A_{\text {eff }}$ will be reduced with the same factor as the number of elements left out. The justification for this solution is that the actual tile cost is dominated by the receivers and not 
by the antennas (see discussion in Chapter 6) and therefore complies with the goal of cost reduction. In the proposed concept, although elements are still on a grid, the removal of elements is done in a semirandom fashion, effectively creating an irregular on-grid array that suppresses grating lobes. FFT signal processing can be applied to this array concept, since all the remaining antennas with receivers are located on regular grid positions.

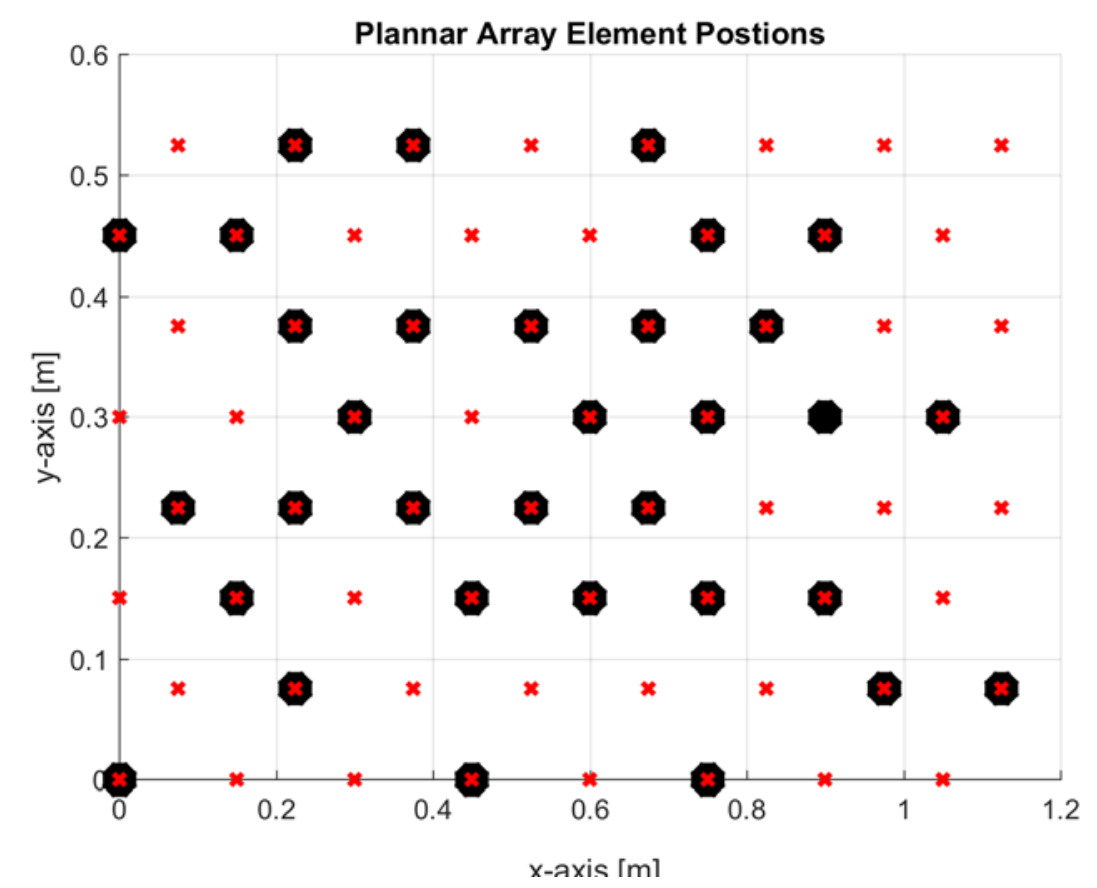

Figure 29 Thinned sparse-regular array concept, x direction thinned only. Red crosses are element positions, black circles are active antennas.

\subsection{Low Noise Receiver}

The sensitivity of a radio telescope has a linear relation with the system temperature. A low system temperature is therefore important. In this paragraph, we briefly analyse the options for a low cost, low noise receiver. From the noise model developed by Pospieszalski [93], the minimum noise temperature of a field effect transistor chip can be expressed by

$$
T_{\min }=2 \frac{f}{f_{T}} \sqrt{r_{t} T_{g} g_{d s} T_{d}}
$$

where $T_{\min }$ is the minimum noise temperature, $f$ is the frequency, $f_{T}$ is the intrinsic cut-off frequency of the transistor, $r_{t}$ is the total resistance including parasitic resistances of gate and source and the intrinsic gate resistance, $g_{d s}$ is the drain-to-source conductance, and $T_{g}$ and $T_{d}$ are equivalent gate and drain temperature, respectively. $T_{g}$ is approximately equal to the physical temperature of the device. Equation (5.1) is an approximation and only valid under the conditions given in [93]. When the device is cooled to very low physical temperatures, (5.1) reduces to the following 


$$
T_{\min }=4\left(\frac{f}{f_{T}}\right)^{2} r_{t} g_{d s} T_{d}
$$

For a complete model, more information is needed than the limited set of parameters used in the equations above. However, it already gives a good indication of the control mechanisms. To achieve a good noise temperature the following needs to be considered:

- A high $f_{T}$ is needed. This usually is outside the control of the circuit design, be it an integrated circuit (IC) design or a receiver design with to off-the-shelf packaged transistors. A high $f_{T}$, although very often not needed for consumer products is a by-product of the miniaturization, since smaller devices have smaller parasitic capacitors and shorter transit times. A $f_{T}$ of hundreds of $\mathrm{GHz}$ is very well possible in modern CMOS processes.

- A low $r_{t}$ is needed. An integrated circuit designer has some control over this: short and many multiple parallel gates will reduce the gate resistance.

- A low $r_{d s}$, high gain device. This parameter is controlled by the process parameters by means of doping profiles etc. A very high gain device is more vulnerable to process variations and instabilities and therefore often not chosen by process designers.

- A very straight forward method of improving the minimum noise temperature is reducing $T_{g}$, the physical temperature of the device. Cooling the transistor not only reduces the channel noise but also has an effect on the $g_{d s}$ and the $f_{T}$. Both parameters improve by about 10 to $30 \%$ when the field effect transistor is cooled from $300 \mathrm{~K}$ to $50 \mathrm{~K}$ [94].

Low noise amplifier design and prototyping for room temperature operation has been a focus of attention very early on in the AA research [81][82][83][84][85][86][87][88].

\subsubsection{Low Noise Array}

It is well understood how the source impedance of an LNA determines the noise temperature of the receiving system [96] [97]. For a single element system, this impedance does not depend on the scanning range, however for an AA, the active reflection, or scan impedance, should be used as the source impedance. For the noise temperature of an array, $T_{N}$, we get

$$
T_{N}=T_{\min }+4 r_{n} T_{0} \frac{\left|\Gamma_{a c t}-\Gamma_{o p t}\right|^{2}}{\left|1+\Gamma_{o p t}\right|^{2}\left(1-\left|\Gamma_{a c t}\right|^{2}\right)},
$$

with $T_{\min }$ the minimum noise temperature, $\Gamma_{o p t}$ the complex optimal noise impedance and $r_{n}$ the normalized noise resistance parameter, together forming the three noise parameters of the LNA, and with $\Gamma_{a c t}$ the array active reflection coefficient and $T_{0}=290 \mathrm{~K}$. The active reflection coefficient of the $i^{\text {th }}$ element of an array with $N$ elements can calculated from

$$
\Gamma_{a c t, i}=\frac{1}{\omega_{i}} \sum_{j=1}^{N} \omega_{j} S_{a n t, j, i},
$$

with $\omega_{i}$ the complex weighting of the $i^{\text {th }}$ element, $\omega_{j}$ the complex weighting of $j^{\text {th }}$ element and $S_{\text {ant }}$ the S-parameter matrix of the antenna array. From (5.4) it is clear that the $\Gamma_{a c t}$ depends on the intrinsic antenna impedance or reflection coefficient $\left(S_{a n t, i, i}\right)$, on the coupling between antenna elements $\left(S_{a n t, j, i}\right.$ 
with $i \neq j$ ) and the complex weighting of all elements $\omega$. The complex weighting or beam steering will be different for every scan direction and the active reflection coefficient will therefore not be constant. Only when the coupling between the antenna elements of the array is negligible, (5.4) reduces to $S_{\text {ant }}, i, i$.

In the case of a large array in which all array elements have equal properties, (5.3) completely describes the equivalent array input noise temperature. From (5.3) it can be concluded that to minimize $T_{N}$, the active reflection coefficient at the input of the LNA should be made equal to $\Gamma_{\text {opt: }}$ the LNA's should be designed for noise matching to the active instead of the passive reflection coefficient. However, since each beam has a unique set of weights, the active reflection coefficient depends on the beam steering, resulting in a noise figure which is influenced by this beam steering. From (5.3) a high sensitivity of $T_{N}$ to $\Gamma_{\text {act }}$ variation can be expected when $\Gamma_{\text {act }}$ is close to one.

What does this mean in practice? In many antenna array designs, a $-10 \mathrm{~dB}$ limit is set for the worst acceptable active reflection coefficient, however, achieving this for a broadband regular sparse array is likely to be very difficult. A relevant measurement has been performed on a small 64-element active Vivaldi array with $0.1 \mathrm{~m}$ element pitch [98]. This array exhibits a high noise temperature for specific pointing directions in the sparse regime. In Figure 30 the noise temperature is plotted for $1.75 \mathrm{GHz}$. Simulations of the array, without active circuitry, in ANSYS HFSS, reveals the source of the high noise temperatures. In Figure 31 the active reflection coefficient at $1.73 \mathrm{GHz}$ is plotted, showing an active reflection coefficient close to zero. At $1.75 \mathrm{GHz}$ the active reflection coefficient has restored to -10 $\mathrm{dB}$. It is assumed that the small frequency difference is due to either simulation inaccuracy or construction deviations.

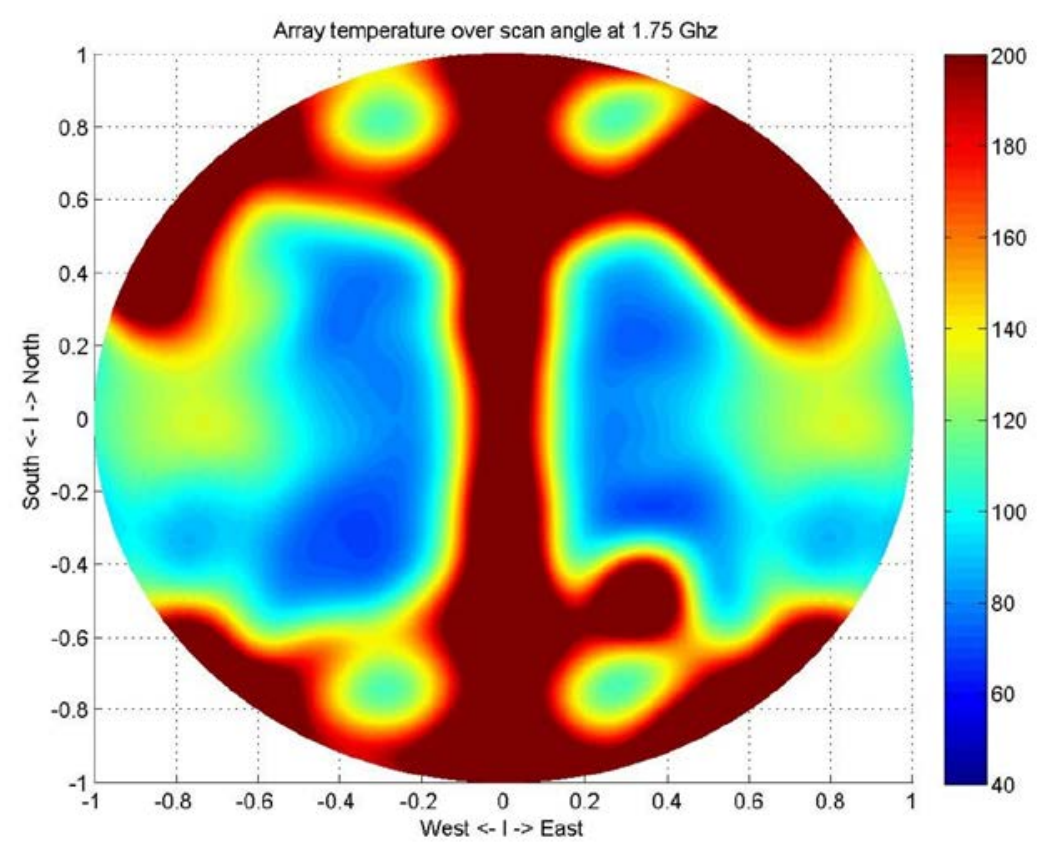

Figure 30 Noise temperature measurements of a small active Vivaldi array [98] as a function of scan angle. South-North in $\sin (\theta) \sin (\varphi)$, West-East in $\sin (\theta) \cos (\varphi)$. Colour scale in kelvin. 


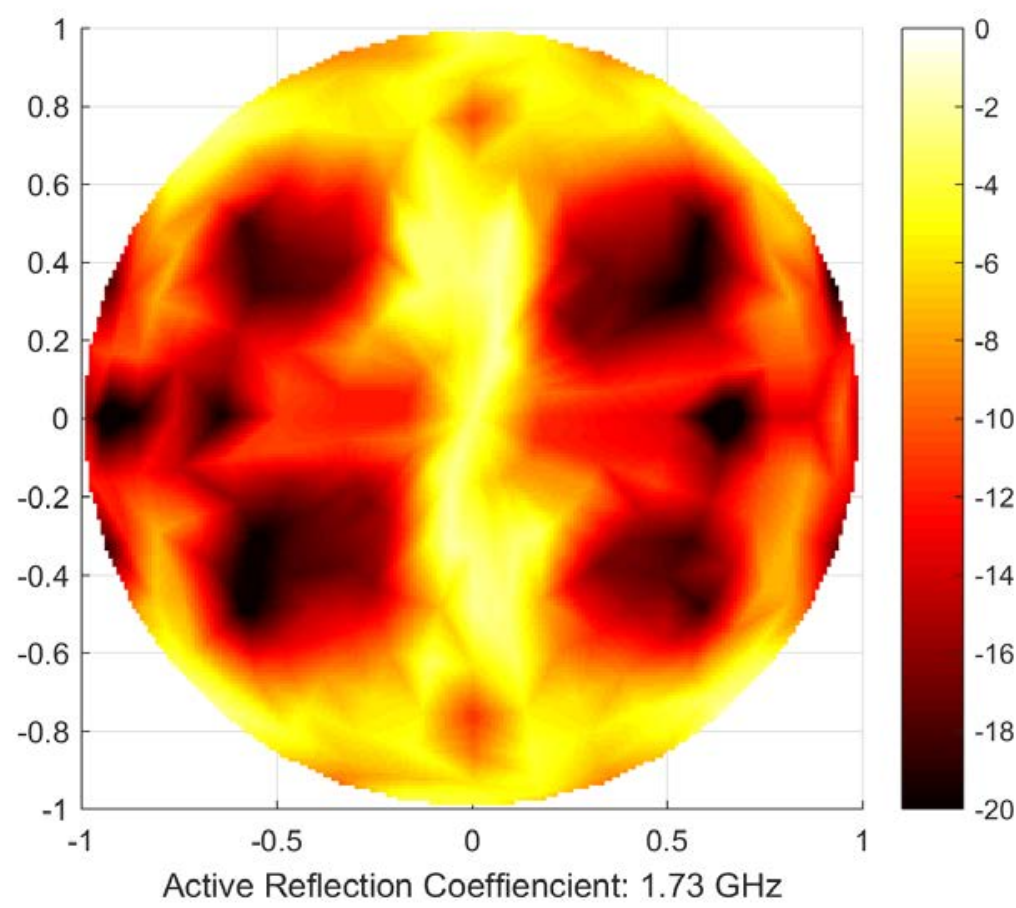

Figure 31 Active reflection coefficient simulation of a 64-element Vivaldi array with $0.1 \mathrm{~m}$ antenna pitch as function of scan angle. Scale in $\mathrm{dB}\left(\Gamma_{\mathrm{act}}\right)$

Modern low noise transistors, with a low noise figure but also with a low $\mathrm{r}_{\mathrm{N}}$, are becoming available. A basic assessment of the performance of a transistor used in APERTIF, a SKYworks metamorphic HEMT, SKY67151, is plotted in Figure 32. Optimum source impedance and noise circles are plotted for this component. The red inner circles are the impedance circles where the noise remains below 22 $\mathrm{K}$ for this component.
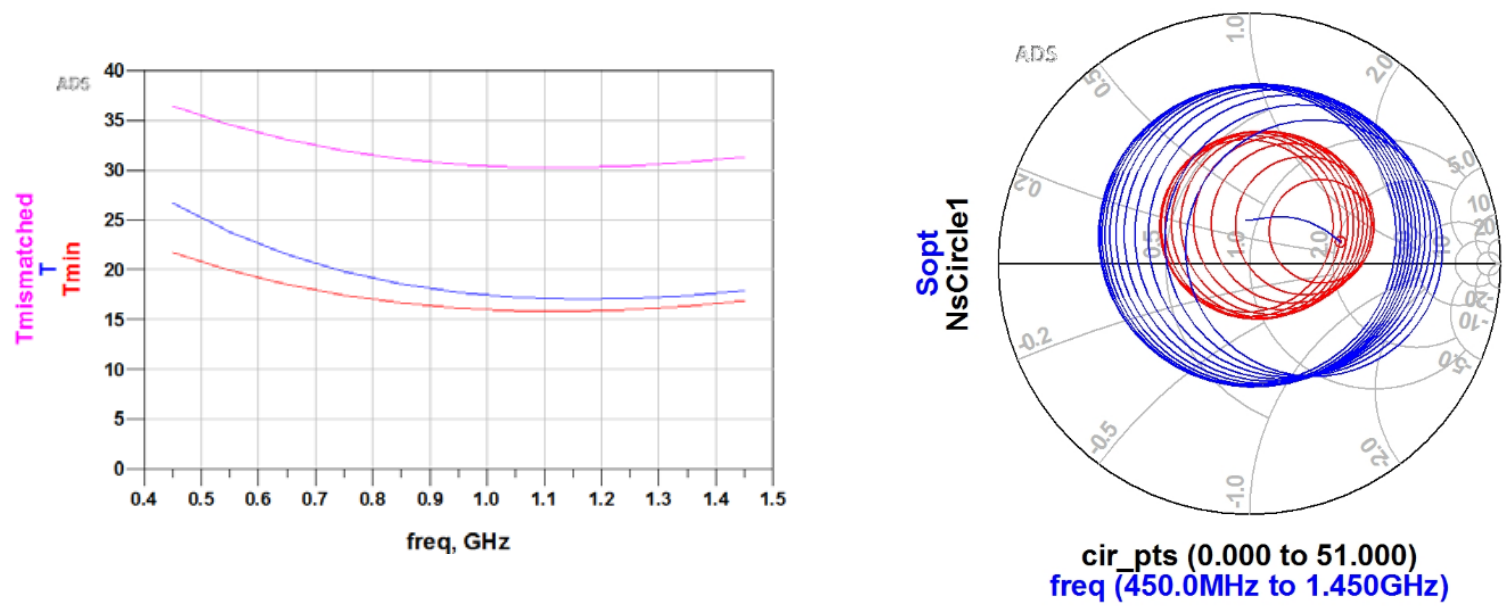

Figure 32 Noise temperature and noise circles simulation for the SKY67151 HEMT

The blue curves are the source impedances which limit the extra noise, above the $\mathrm{T}_{\min }$, to $15 \mathrm{~K}$. Assuming a sky noise $(\sim 6 \mathrm{~K})$ and second stage noise $(10 \%, \sim 5 \mathrm{~K})$ and small losses between the antenna 
and the LNA, the total system temperature would still be below $50 \mathrm{~K}$ if the source impedance would be within the $+15 \mathrm{~K}$ blue noise circles. In terms of impedance, a relatively large deviation from the optimum reflection coefficient, in this case a magnitude of 0.5 or $-6 \mathrm{~dB}$, still is within the $+15 \mathrm{~K}$ circle. When the active reflection coefficient phase can be tuned, a magnitude of 0.7 or $-3 \mathrm{~dB}$ is still fine.

\subsubsection{Active Antenna}

Noise temperatures of radio astronomy low noise receivers can be characterised by measuring the low noise amplifier in a dedicated measurement set-up. These set-ups are normally designed and calibrated for a $50 \Omega$ standard impedance, and therefore the logical impedance of choice for antenna and low noise amplifier is also $50 \Omega$. This restriction limits the design space unnecessary but, when abandoned, other measurement approaches are needed. One option is to test the active antennas, antennas with integrated LNA's, is given in Figure 33. This approach uses RF absorbing material in two states, at room temperature, providing a hot, $290 \mathrm{~K}$, source and at cryogenic temperature with liquid Nitrogen, providing a cold $78 \mathrm{~K}$ source. From the two measurement, hot noise power and cold noise power, the noise temperature of the LNA can be calculated [95].

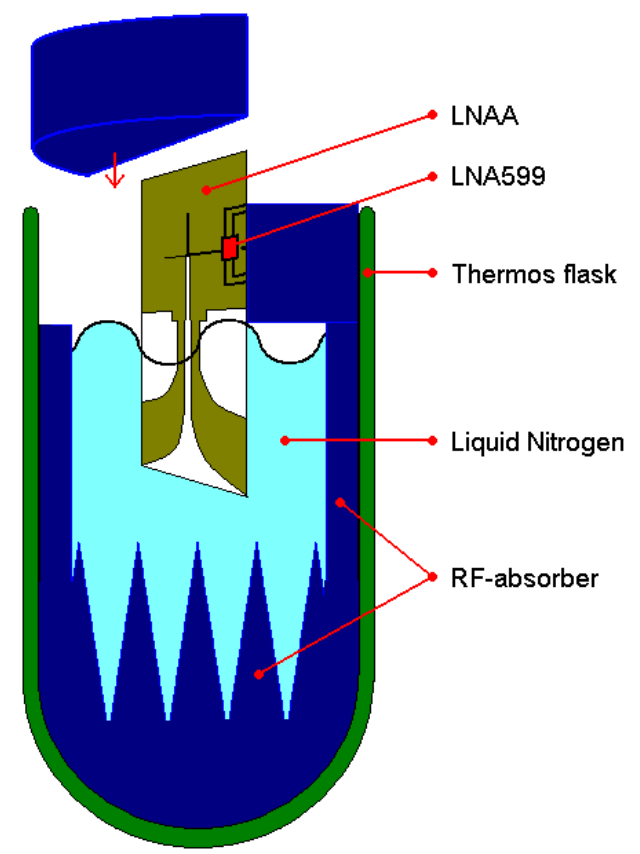

Figure 33 Artist impression of the active antenna test set up [95]

\subsubsection{Cooling options}

Traditional dish based radio telescopes use cryogenic cooling for the low noise amplifier. Bringing the temperature of the LNA down to $20 \mathrm{~K}$ or even lower reduces the noise temperature of the LNA significantly, however at significant expenses in size and operating cost. Very low noise receivers are not very critical in the frequency regime where the sky noise is high and dominating the system temperature. Array telescopes in the lower frequency regime, up to $350 \mathrm{MHz}$, are therefore non-cooled receivers. Phased array feed systems, with 100 to 200 antenna elements for each reflector, are also realized with ambient temperature low noise amplifiers. Although low noise amplifiers have improved, 
these systems exhibit a higher noise temperature when compared with traditional cryogenically cooled front-ends. Since a reduction in system noise temperature can be directly translated into a reduction in element count, in order to achieve a certain sensitivity, cooling can be considered for future AA systems, even when the element count is high.

\section{Thermo Electric Cooling}

A modest reduction of the LNA physical temperature, and therefore noise temperature, can be achieved when the transistor is placed on a Peltier element or Thermo-Electric-Cooler (TEC). In [100] a $\Delta \mathrm{T}$ of 60 degrees is achieved with a cooling power of $61 \mathrm{~mW}$ and a TEC power consumption of $500 \mathrm{~mW}$. The Coefficient of Performance (COP) is strongly dependent on the type and current setting of the TEC. E.g. the device used in this work achieves a $\Delta \mathrm{T}$ of 35 degrees with a power consumption of just 150 $\mathrm{mW}$, a much better COP than when a high $\Delta \mathrm{T}$ is needed. To avoid condensation on the LNA, the chip is placed in a low vacuum package, eliminating condensation issues but also reducing cooling heat loss through air convection. Still, half of the cooling power, $30 \mathrm{~mW}$, is needed for the heat loss due to the 6 gold bond wires needed to connect the device with input and output RF and DC power.

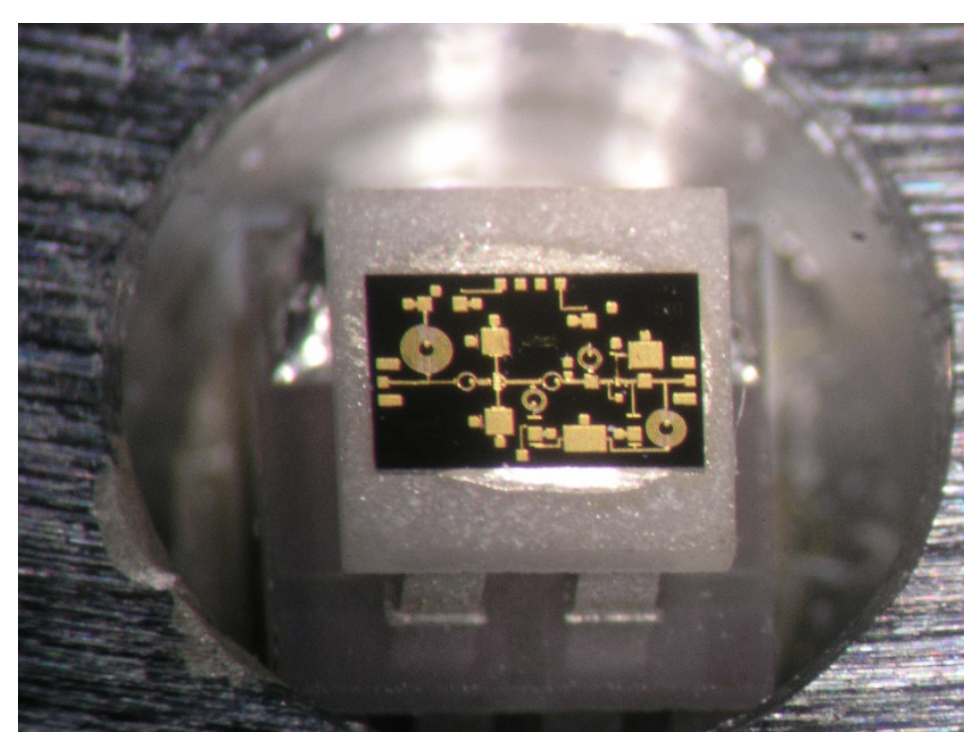

Figure 34 GaAs Low Noise Amplifier mounted on a Peltier element

\section{Micro cooling}

Alternatively to large cryogenic Helium coolers, like GM or Stirling coolers, Nitrogen micro coolers have been developed [99]. In this concept high pressure Nitrogen (80-120 bar) flows through micro channels in a Silicon substrate before expanding in the tip, cooling that area, and being transported back to a separate compressor. The LNA is placed on the cold tip (Figure 35). PCB's of low loss RO4003 substrate are providing the input and output signal traces and power for the LNA. The cooling power is limited but the compact size of the vacuum chamber is attractive for distributed multiple element systems. Tests of this system revealed a particular issue: in order to limit the energy loss from the cold tip, a minimum length of the connecting substrate needed to be taken, with a direct hit on the signal connection loss and therefore on the noise temperature. 


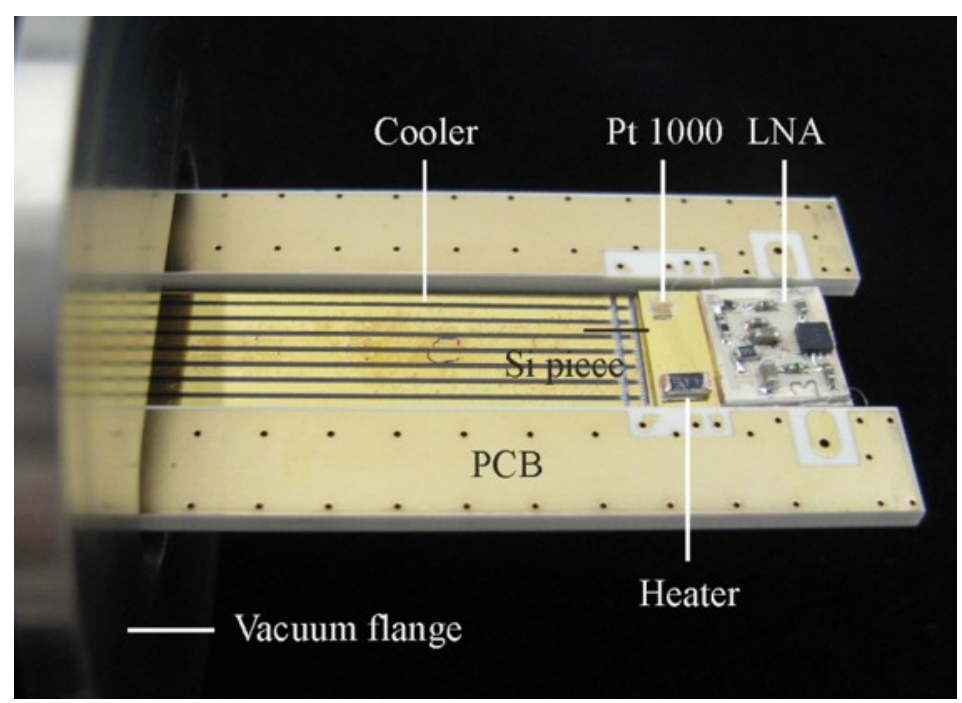

Figure 35 Micro cooler

Table 5 Comparison of cooling methods and noise temperature

\begin{tabular}{l|c|c|c}
\hline \hline Parameter & $\begin{array}{c}\text { No temperature control } \\
{[101]}\end{array}$ & $\begin{array}{c}\text { Peltier cooler } \\
{[101][100]}\end{array}$ & $\begin{array}{c}\text { Micro cooler } \\
{[99]}\end{array}$ \\
\hline Temperature & $\begin{array}{c}298-358 \mathrm{~K} \\
\left(25-85^{\circ} \mathrm{C}\right)\end{array}$ & $\begin{array}{c}253 \mathrm{~K} * * * \\
\left(-20{ }^{\circ} \mathrm{C}\right)\end{array}$ & $77 \mathrm{~K}$ \\
\hline Connection loss & $0 \mathrm{~K}$ & $0 \mathrm{~K}$ & $-11 \mathrm{~K} * *$ \\
\hline $\begin{array}{l}\text { Noise Temp delta } \\
\text { (at } 358 \mathrm{~K})\end{array}$ & $-7 \mathrm{~K} *$ & $+1 \mathrm{~K}$ \\
\hline $\begin{array}{l}\text { Change from } 17 \mathrm{~K} \text { noise } \\
\text { temperature at } 1 \mathrm{GHz} \text { at }\end{array}$ & $+11 \mathrm{~K}$ & $-7 \mathrm{~K}$ & \\
\hline \hline
\end{tabular}

*30\% noise temperature reduction has been achieved in [100], albeit with $110 \mathrm{~K}$ noise temperature of the set-up under test at $308 \mathrm{~K}$, reducing to $80 \mathrm{~K}$ noise temperature at maximum cooling power to $258 \mathrm{~K}$. [101] has been used to calculate the reduction with a TEC $(\sim 0.1 \mathrm{~dB} / 7 \mathrm{~K}$ for a $\Delta \mathrm{T}$ of 60 degrees).

**27 K noise temperature reduction has been achieved, albeit with $79 \mathrm{~K}$ noise temperature of the set-up under test at $294 \mathrm{~K}$, reducing to $52 \mathrm{~K}$ noise temperature at $77 \mathrm{~K}$ case device temperature. This percentage reduction has been applied to [101].

$* * *$ Depends on the amount of cooling power, which relates to the size of the Peltier and the available energy

Table 5 temperature control options are compared, using $T=\left(F_{n}-1\right) T_{0}$, with $F_{n}$ the linear noise factor and $T_{0}=290 \mathrm{~K}$. Listed in the footnotes, re-calculations have been applied to the data taken with different LNA's and different set-ups in order to compare the results. This impacts the accuracy of the concluding numbers. The results are nevertheless interesting: the TEC is an interesting option for LNA cooling, with limited power, physical space, maintenance and cost impact. Instead of actively cooling the device passive cooling and careful design of the tile packaging can reduce the $\Delta \mathrm{T}$ between the environment (up to $45^{\circ}$ ) and the transistor. Sun loading, even in the Netherlands, can increase LNA temperatures up to $30^{\circ}$ above environmental temperatures [107] if the design is not optimised. Further prototyping is needed to confirm these results. 


\subsection{RF station architectures}

A sparse array will have significantly fewer antenna elements compared with a dense array of the same physical area. Nevertheless, a high level of integration and production automation is required to construct, install and maintain a station with e.g. 16,384 antenna elements. Labour in the field should be minimized: a plug and play solution will reduce cost and installation risk. In this section three implementations are compared, all three assuming environmentally shielded tiles will be constructed off site. The tile size is then best chosen to fit in a standard shipping container. These have a $2.35 \mathrm{~m}$ inside width and assuming some packaging material needs to be included, the tile size should not be larger than $\sim 2.2 \mathrm{~m}$. This is an unusual design constraint for a radio astronomy system, however construction and transportation cost can quickly inflict the viability of an otherwise good solution. For comparison, SKA1-Low antenna transportation will require $45440 \mathrm{ft}$ containers at a cost of $€ 5 \mathrm{M}$, a significant fraction of the station cost [102]. For the AAMID telescope about 20 tiles of $2.2 \mathrm{~m}$ square and $0.5 \mathrm{~m}$ height would fit in the $40 \mathrm{ft}$ container (internal size $2.35 \times 12 \times 2.35 \mathrm{~m}$ ) resulting in a manageable but not insignificant 13 shipping containers for each station of 256 tiles. In section 5.5.2., the shielding of the tiles will be discussed.

The implementation options considered are based on the adoption of the following criteria:

a) Signal data will not be reduced at station level. Existing AA telescopes beamform data at station level which reduces the data rate but at the same time restrict the capabilities of the telescope.

b) A tile consist of 64 antennas. With the size constraint of $2.2 \mathrm{~m}$, this means an antenna pitch of $0.275 \mathrm{~m}$ or $\lambda / 2$ at $545 \mathrm{MHz}$.

\subsubsection{Remote digitization}

The most basic tile implementation is sketched in Figure 36. The amplified antenna signal is converted in to a modulated optical signal. This Radio over Fibre (RFoF) signal can then be multiplexed on a single fibre if different wavelengths are used in the RFoF conversion units. Due to the low optical losses of the fibre cables the processing units can be far away from the stations and processing of many, if not all, stations can be combined in one processing unit. In [103] a maximum RFoF length of $40 \mathrm{~km}$ has been evaluated for SKA1-Low. The impact of calibration stability of these long fibres will be discussed below. This implementation does not require any control logic at the tile level, only power needs to be provided. All complexity, control, clocks etc. is remotely located. Although this implementation could be considered with coax cables as well, omitting the need for RFoF, station processing needs to be close to the station to avoid the impact of signal losses and/or expensive cables. 
Tile

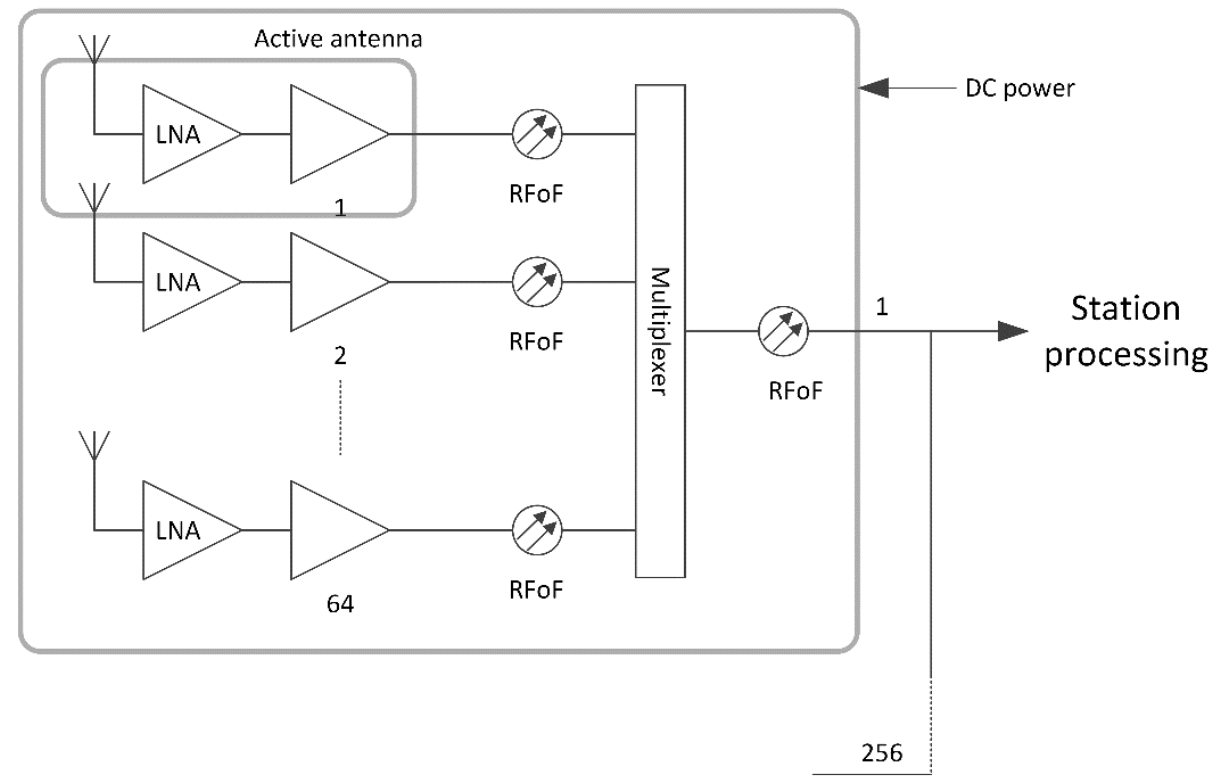

Figure 36 Remote digitization

\subsubsection{Local direct digitization}

Loss of analogue signal is minimized if the Analogue to the Digital Conversion (ADC) is done very close to, or in the antenna. The output data of this active antenna will be a digital data stream on an optical fibre, see Figure 37. The given data rates are based on $1 \mathrm{GHz}$ RF bandwidth and $2.5 \mathrm{GSamples} / \mathrm{s}$ with 8 bits. Higher data rates will be needed if 8 bits turns out not to be enough to handle gain variation, RFI and quantization noise. The SKA site in the Karoo is a radio quiet protected zone and measurements have confirmed this [106]. The highest level of radio energy is received from aircraft radar and aircraft communication, which is not insignificant but only intermittent. It should be noted that an AA system, with wide antenna beamwidths, does not have a first level of RFI power level reduction, which a dish would have when pointed away from the RFI. 
Tile

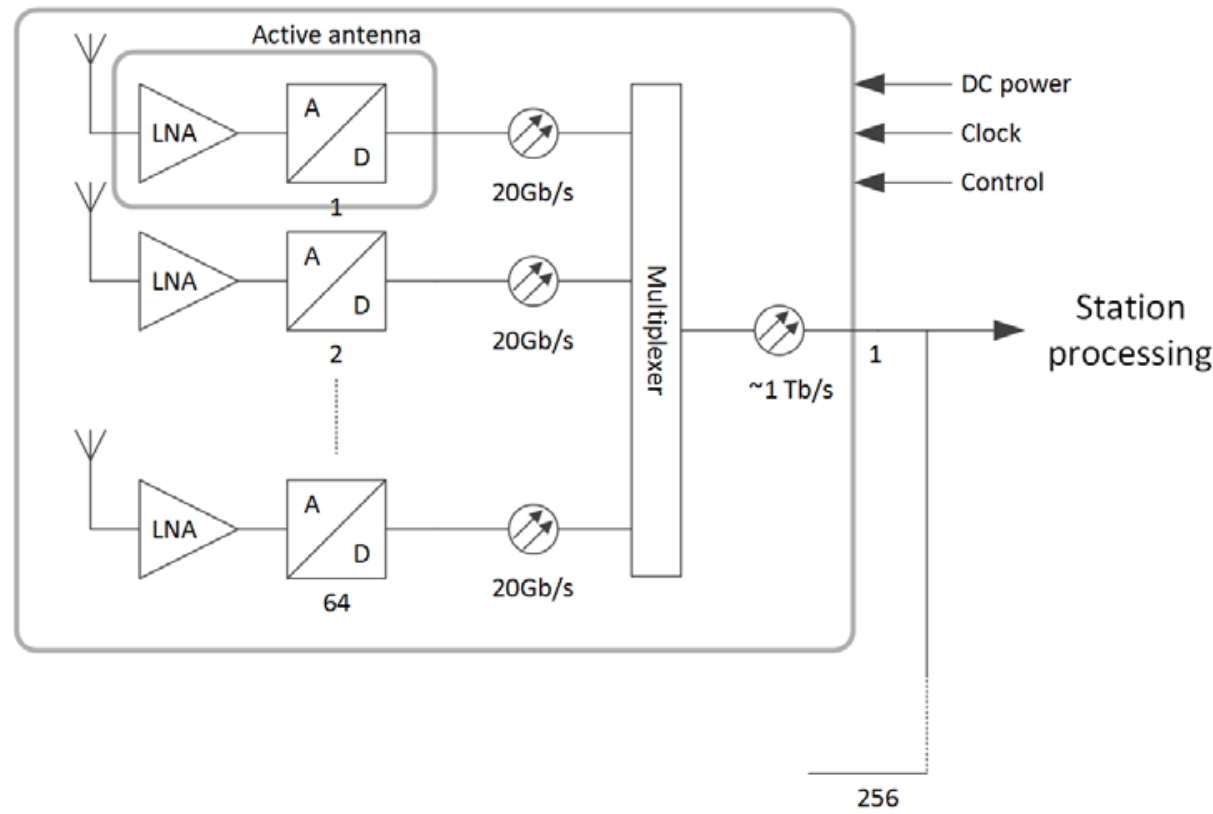

Figure 37 Local direct digitization

\subsubsection{Digitization of groups of antennas}

Instead of sampling very near to the antennas (short) cables carry the RF signals to a digitizer box. This box can have an arbitrary number of inputs but practical considerations on cable length, losses, cost and performance (e.g. freq. ripple) constrain the length of the cable. If the cable length is restricted to 10 $\mathrm{m}$, a maximum of 256 antennas could be processed in one processing unit. In Figure 38, a number of 16 antennas is assumed. In comparison with direct digitization, the complexity of clock stabilization is reduced with the number of combinations. 
Tile

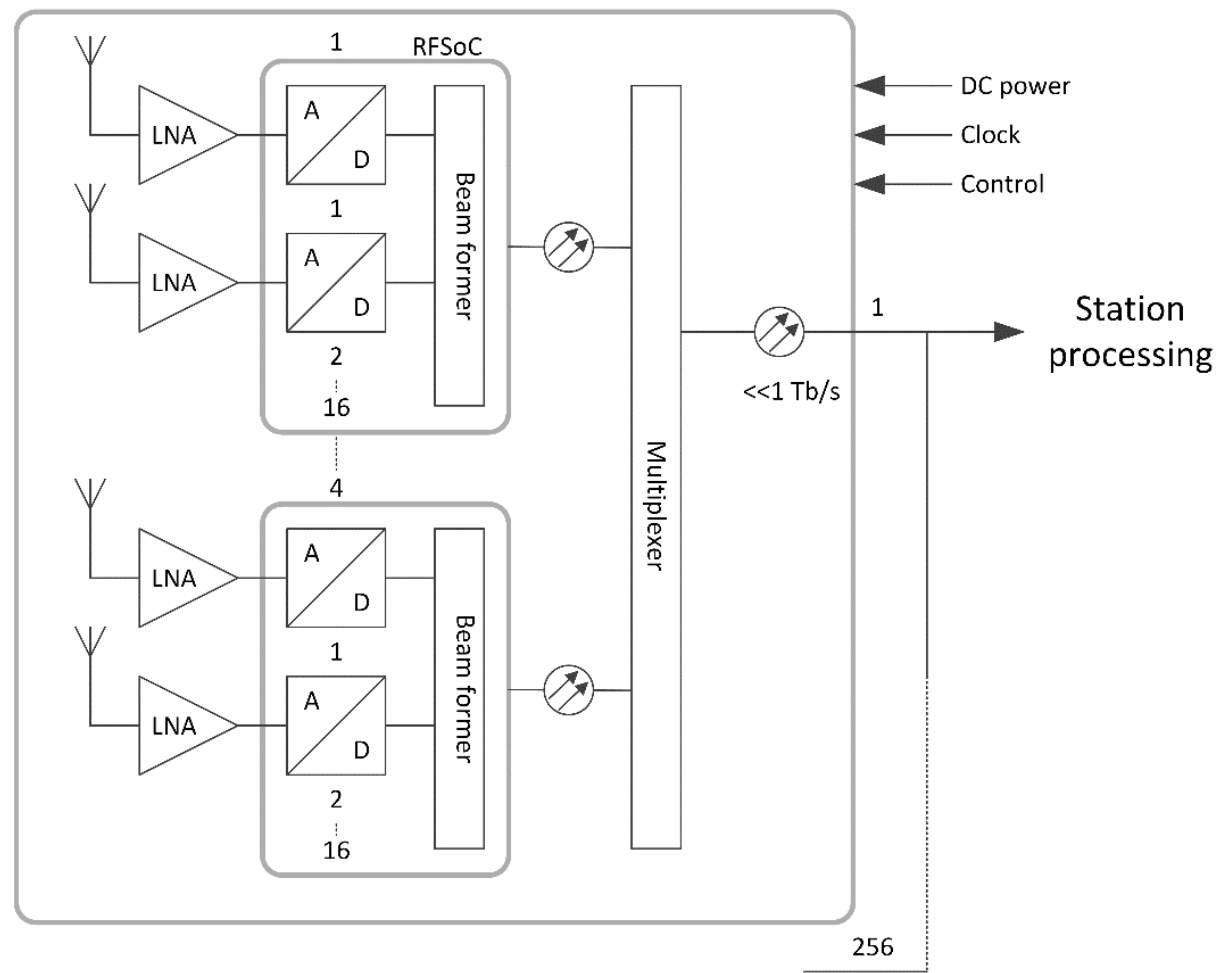

Figure 38 Digitization of groups of antennas

\subsubsection{RFoF stability consideration}

Stability of the transit phase and amplitude of the RFoF links is important for the calibration stability of the system when signals are not digitized close to the antenna. This is not different from systems with coax cables, however very long cable lengths can be considered in a fibre solution and therefore effects might be more severe. Two temperature effects play a role in the RFoF links, the time delay in the fibre and the wavelength of the laser. Experiments with the RFoF solution in SKA1-Low can be used to analyse these effects for AAMID [104]. For the phase variation (in radian), we have

$$
\Delta \varphi=2 \pi f\left[(n \alpha+\beta)\left(\frac{L_{0} \Delta T}{c}\right)\right]
$$

with $\alpha$ the linear thermal expansion coefficient $\left(\mathrm{m} / \mathrm{m} \mathrm{K}^{-1}\right), \beta=\Delta n / \Delta T$ the thermal coefficient of the refractive index $\left(\mathrm{m} / \mathrm{m} \mathrm{K}^{-1}\right)$. However, fibre cable suppliers don't provide these numbers. Based on a literature search and verification experiments in [104] a typical value $\alpha$ of $\sim 0.56 \times 10^{-6} \mathrm{~K}^{-1}$ and $\beta$ of $\sim 1.2 \times 10^{-5} \mathrm{~K}^{-1}$ can be assumed for a single mode fibre. With $\mathrm{n}$ the refractive index of the core (typically 1.47) and c the speed of light, a phase variation can be estimated for a given cable length $\left(L_{0}\right)$ and temperature variation $(\Delta \mathrm{T})$. For a frequency $\mathrm{f}$ of $1.45 \mathrm{GHz}$, a temperature variation of 5 degrees and a fibre length of $100 \mathrm{~m}$, the phase moves nearly $\sim 11^{\circ}$. Since the effect is linear, a longer fibre of e.g. 10 $\mathrm{km}$ and a small $\Delta \mathrm{T}$ of $1 \mathrm{~K}$ already results in a phase change of $\sim 220^{\circ}$. From this it is clear that for very long fibre links, precautions need to be taken, either by temperature stabilizing the cable, or by 
sufficiently frequent calibration. SKA1-Low accepts small phase errors in 600 seconds calibration intervals. AAMID might consider a faster calibration interval, at computational cost.

The wavelength of the laser is temperature dependent. A typical number for a laser is $0.1 \mathrm{~nm} / \mathrm{K}$. This as-such is not an issue for the amplitude modulation of the RFoF communication of RF signals, however the fibre $\Delta \tau$ is wavelength dependent and therefore a wavelength shift will result in a different transient time, the group delay. The effective group delay variation $\Delta \tau$ (ps) can be expressed with

$$
\Delta \tau=\Delta \lambda D(\lambda) L
$$

in which $\Delta \lambda$ the variation of the wavelength of the laser $(\mathrm{nm})$ and $D(\lambda)$ the chromatic dispersion characteristic of the fibre $(\mathrm{ps} / \mathrm{nm} \cdot \mathrm{km})$ from

$$
D(\lambda)=\frac{S_{0}}{4}\left[\lambda-\frac{\lambda_{0}^{4}}{\lambda^{3}}\right]
$$

with $S_{0}=$ Zero dispersion slope $\left(\mathrm{ps} / \mathrm{nm}^{2} \mathrm{~km} \lambda\right)$ and $\lambda_{0}$ is the zero dispersion wavelength of the fibre. A typical number for S0 is 0.087 and for $\lambda_{0}$ is 1313 [105]. With the numbers used above, $1.45 \mathrm{GHz}, 100$ $\mathrm{m}$ cable and 5 degrees $\Delta \mathrm{T}$, the phase variation, $\Delta \varphi=2 \pi \mathrm{f} \Delta \tau$, is only $0.0035^{\circ}$ and therefore negligible.

Also for long fibre lengths of $10 \mathrm{~km}$ the effect is small. It should be noted that the laser might be more exposed to temperature variations when placed close to the antenna.

\subsection{Station Implementation}

\subsubsection{Antenna production techniques}

In general, an antenna consists of electrically conducting material, which should have low ohmic loss to limit added antenna noise or reduced antenna efficiency. The material could be sheet metal, printed metal, or just wires. The optimal low cost antenna array production technique strongly depends on the antenna type. A vertical radiator, like the Vivaldi, requires very different production techniques when compared to planar structures, like a patch or flat dipole, and the antenna cost is only a part of the complete array cost. The cover or radome is preferable an integral part of the solution and the connection to the electronics, the low noise amplifier and subsequent parts, can be an important cost driver. First AA prototypes, OSMA and THEA, used Printed Circuit Boards (PCB's) to produce the antenna, LNA and beamformer on a single 8 layer board. The combination of antenna and electronics, similar to modern wireless devices, is good for signal integrity, low loss and simple production. However the conflicting requirements, large low loss antenna and multiple layer high density electronics, resulted in a high total cost. 


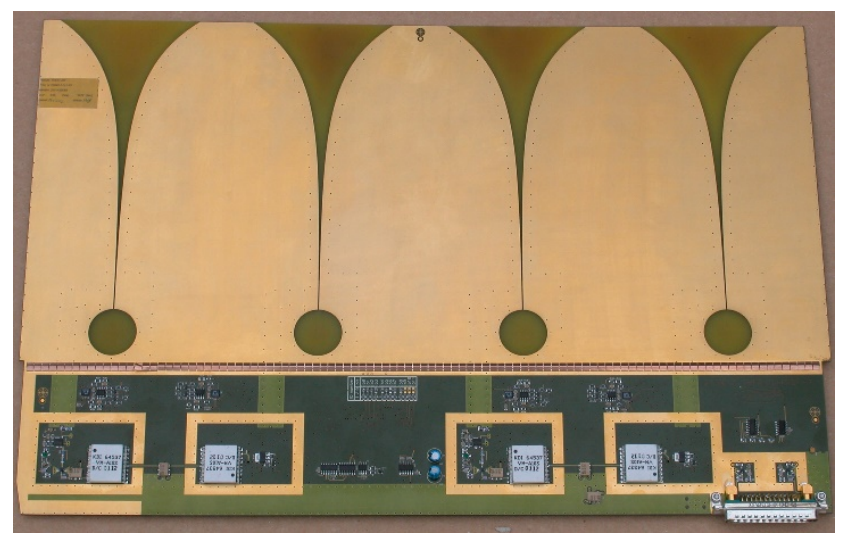

Figure 39 Four element antenna and beamformer board used in THEA

The THEA boards (see Figure 39) were produced with Rogers RO4003 ${ }^{\mathrm{TM}}$, a low loss substrate material, and gold plated to further reduce the loss. The $0.5 \times 0.3 \mathrm{~m}$ board cost is about $€ 400$ including electronics, of $€ 100$ per element. Various cost reduction techniques have been explored of which cutting the antennas out of sheet metal resulted in a cost for the antenna of less than $€ 10$ per element. This technique has been used in APERTIF. Connecting the electronics to the antenna requires special attention, in particular around the signal pick-up area were the gap between the PCB and the metal needs to be tightly controlled. Very low cost antenna material is used in RFID tags. These are typically screen printed on a thin polyester foil with conducting silver ink, the only costly part of the process. This production technique was used for the production of Vivaldi antennas. Screen printing the antennas on $50 \mu \mathrm{m}$ foil takes about a second per antenna. The subsequent electrolytic plating step is slower, 5 seconds per antenna, for growing $\sim 5 \mu \mathrm{m}$ copper on the antennas. These are typical numbers for standard equipment and although this is fast, 1000 antennas would only take an hour, producing 10 million antennas would still require 10,000 hours: more than 2 years on a single machine, or less when multiple machines are used. Cost per antenna, foil, silver ink, copper, labour and machine depreciation, would be less than $€ 0,50$. This is equivalent to the cost of the (smaller) RFID labels of a couple of cents.

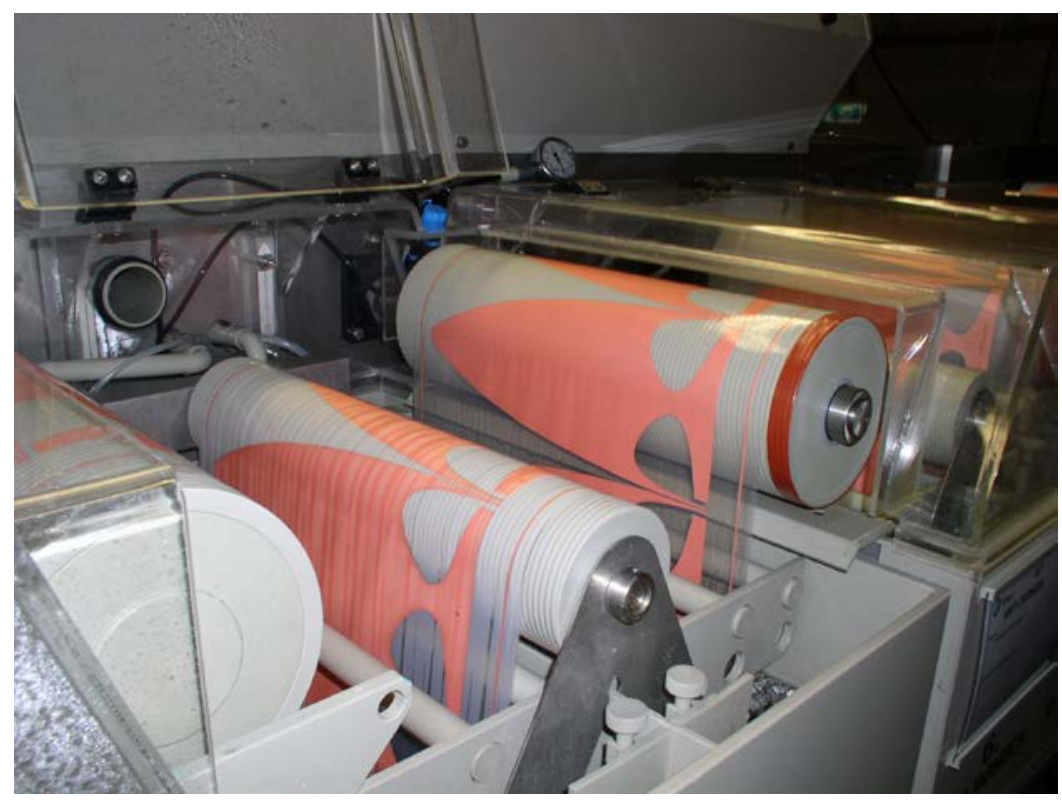

Figure 40 Copper plating screen printed Vivaldi antennas 
The foil based antenna however needs mechanical support to keep them in position. For this, EPS blocks are proposed. The folded antennas, see Figure 41, need to be electrically connected antennas for this antenna to work, which is established with special designed paperclip style clamps.

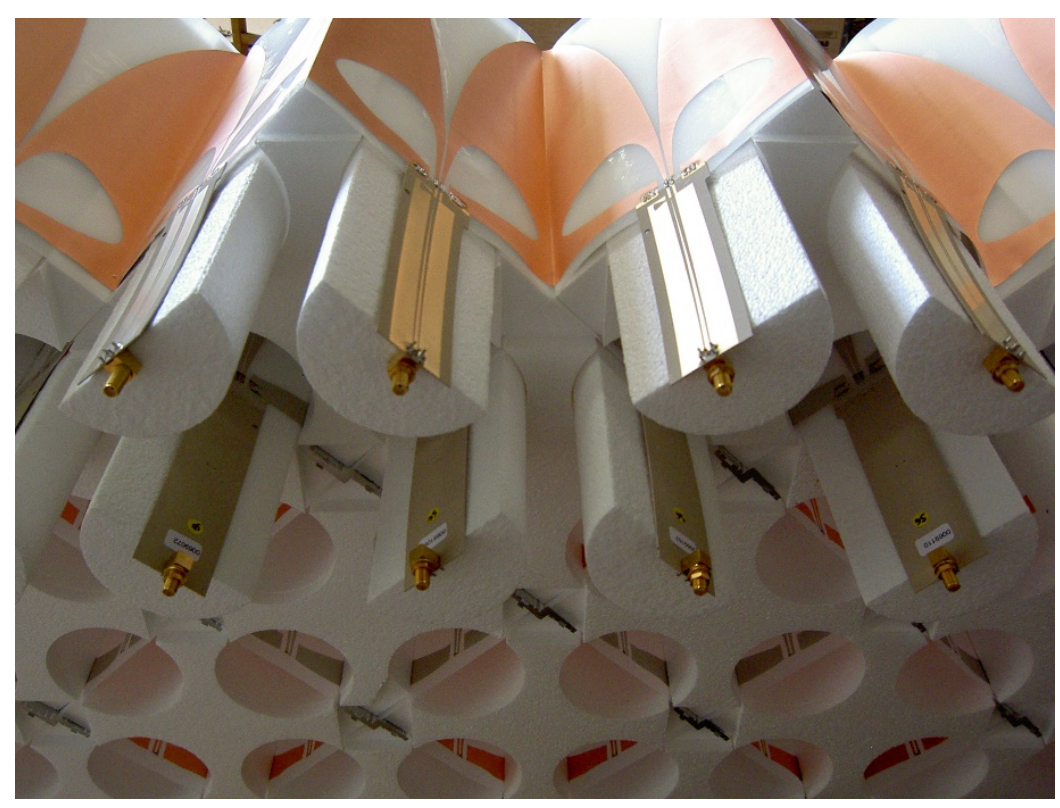

Figure 41 Foil based Vivaldi antennas in an EPS array

The foil production method is considerable cheaper than etch based production methods, currently used for DDA and ORA prototypes, but can be applied to these flat antenna types as well.

The above calculation highlights the importance of low cost fast production techniques. Only 5 seconds per antenna adds up to a long production time.

\subsubsection{Radome}

A significant cost and performance driver for AAs is the shielding from the environment, rain, sun loading, dust, but also rodents and insects. Low loss, preferably with a low dielectric constant, needs to be achieved. Two approaches can be considered; global coverage in which a full station is covered, and local coverage in which a tile or just one antenna is shielded. THEA, with an inflatable tent (Figure 42) and EMBRACE, with an EPS dome, used the global approach. This approach is easier to set up and to work under, however is difficult to scale to large stations and expensive. Therefore recent studies focus on local shielding. In SKA1-Low, only the antenna electronics are encapsulated; a small unit in the top of the metal wire antenna. For AAMID environmental prototypes (Figure 43) have been constructed to evaluate various concepts, ranging from fully enclosed boxes of EPS or Polyethylene to open structures with a tarp or plastic sheet covering the array. The dry and hot South African Karoo, the designated SKA2 location, turned out to be relatively benign for the low cost shielding concepts, no significant dust collection or damage by rodents or insects could be observed after three years of field testing. 


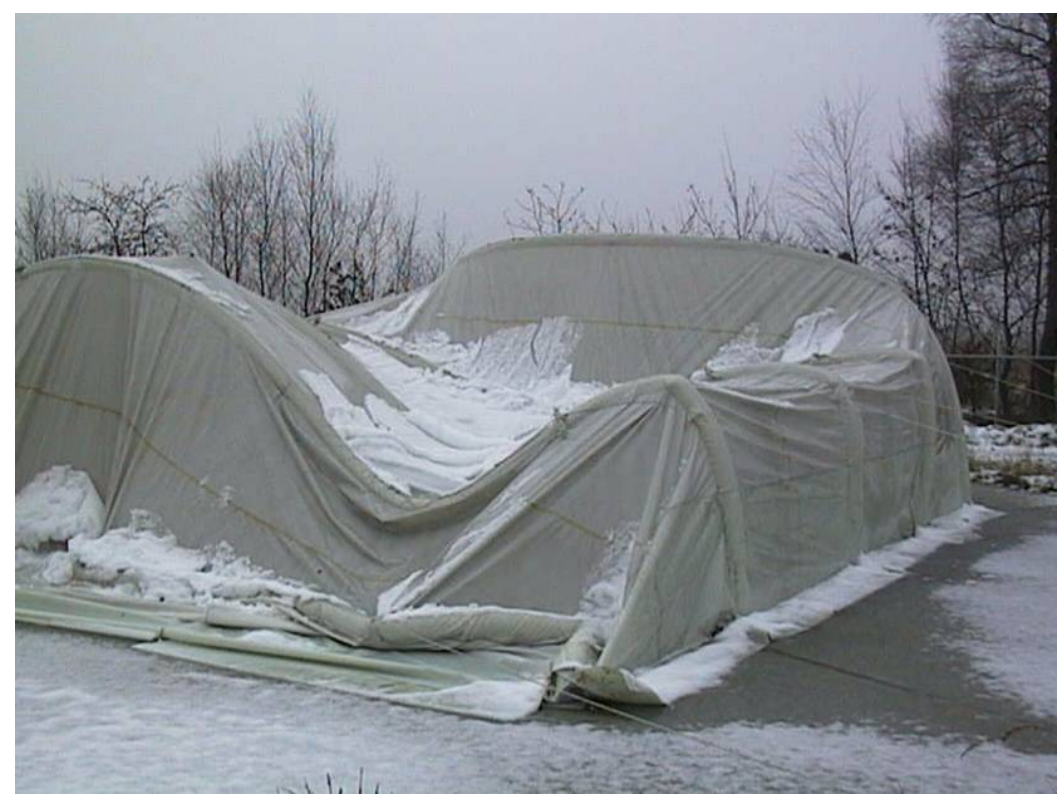

Figure 42 Global THEA Radome, after a snow blizzard

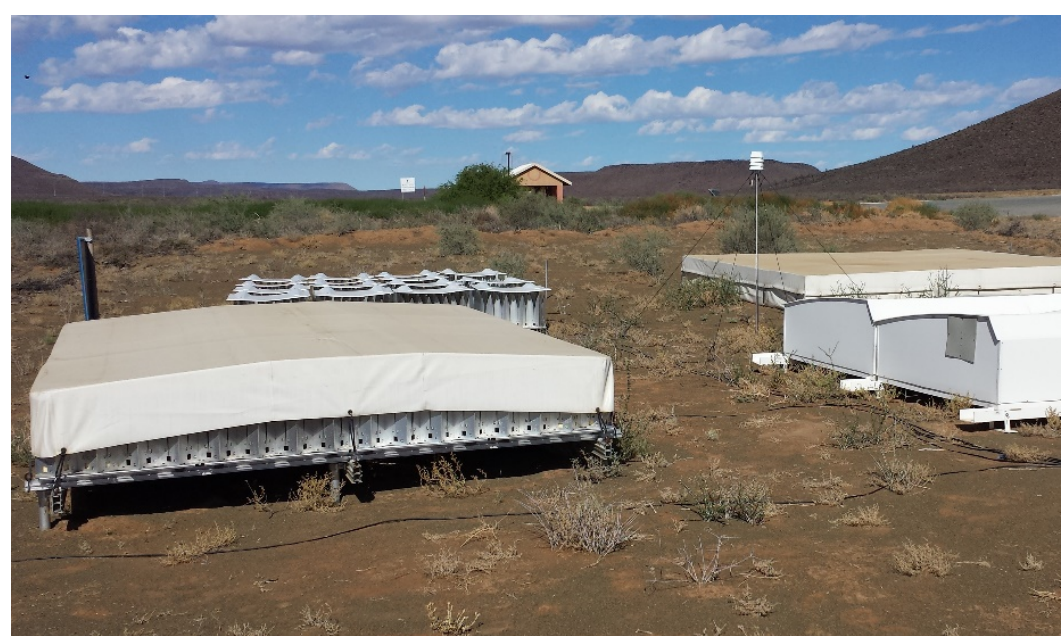

Figure 43 Local shielding, environmental proto types at the SKA site in the Karoo, South Africa

\subsection{Signal Processing}

Low cost and low power Analogue to Digital Conversion (ADC) is crucial for the feasibility of an alldigital aperture array telescope with millions of antenna elements. A full assessment of the availability and the roadmap for ADC's falls outside the scope of this dissertation. One development is, however, of particular interest for the AAMID telescope, which is the release of Radio Frequency System on Chip (RFSoC) components [108] [109]. These components combine 16 ADC with digital signal processing and would fit nicely in the architecture proposed in Figure 38. However, cost and power consumption needs to be reduced by at least one order of magnitude. Research on ADC's specific for the SKA indicates that low power and low cost is indeed possible with future CMOS technology [110]. 


\subsection{Conclusion}

For the realization of the AAMID stations many possibilities are considered by the research teams and this chapter provides a limited selection only. Many solutions are available for each element, be it the antenna, the radome, the data transmission or any other part of the system. Many of these solutions can be realized for good performance and low cost. The presented subset of solutions presented in this chapter is an indication of this, but clearly further work is required. 


\section{Costing}

Design, production, installation and operation costs assessment of AA radio telescopes is significantly more complicated than of classic dish telescopes for two reasons. Firstly, the community has limited experience in AA systems and secondly, the small (by industry standards) number of antenna elements. The number of elements, e.g. $10^{5}$ for LOFAR or even $10^{7}$ for an AAMID telescope is still small compared to high volume telecommunication equipment. Therefore, typical cost of 0.10 Euro for each $\mathrm{mm}^{2}$ silicon chip area or mobile phone production cost of less than 100 Euro does not apply, although these systems can be more complex than a radio astronomy receiver. The number of elements is however high enough to create serious issue if the unit price, installation or repair/modification costs are not estimated correctly. In [111], Bregman assesses the system design of LOFAR with a focus on the optimal ratio between front-end and back-end costs. In short, high spending on antennas in the field can only be justified if the back-end is capable of processing the output of the antennas and a cost ratio of 1:1 might be the right optimum. In [112] this is brought a step further with parametric design models and scientific figures of merit to generate an optimal solution. This method is applied to LOFAR and assessed for SKA1-Low. The use of these models is not common practice; both LOFAR and SKA1Low have been designed top down from basic requirements to detailed design with limited feedback loops. The complexity of cost assessment gets more complicated with frequency dependent design parameters as discussed in Chapter 3, sparse or dense, number of FoVs, number of beams etc.

\subsection{AA production cost}

Detailed production cost assessment of two realized systems, LOFAR and EMBRACE, have led to the cost relation depicted in Figure 44 [113]. The cost in $€ / \mathrm{m}^{2}$ has two components. Firstly the construction of the mechanical part, which has been found to scale linear with the element pitch because the elements will in general be larger and higher with increased pitch. Secondly, the electronics, which scales with $1 /$ pitch $^{2}$. The accuracy of this assessment is limited and is strongly related to a particular chosen architecture but the trend is clear: a smaller antenna pitch leads to higher cost.

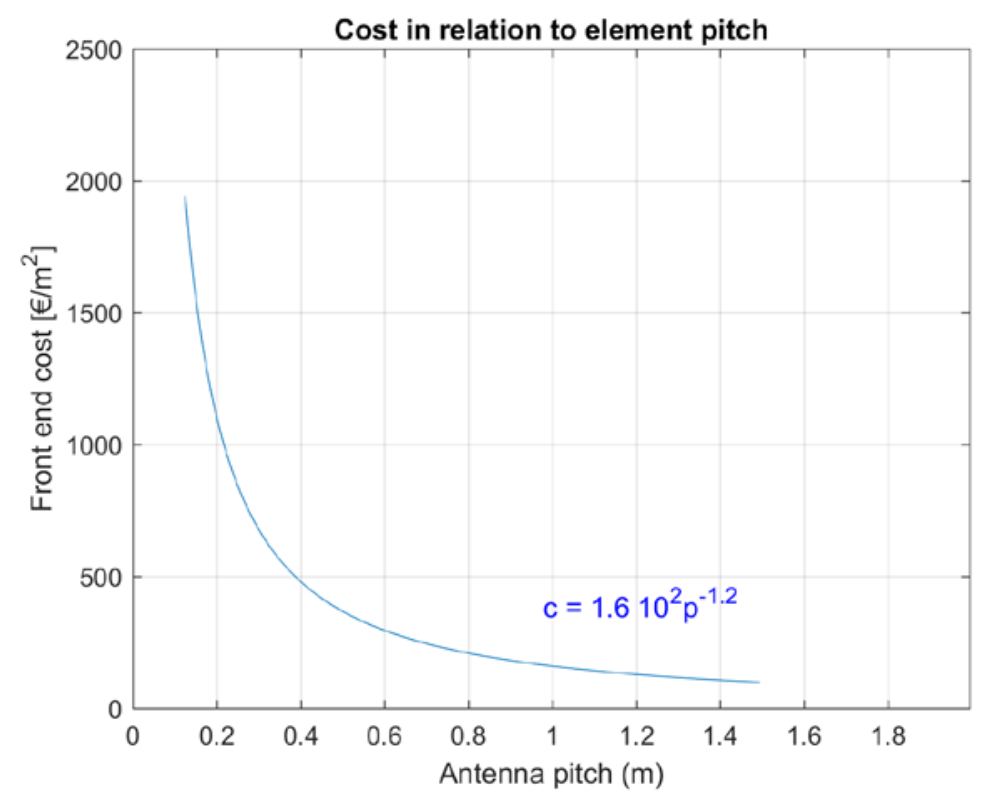

Figure 44 Front end cost dependence on the antenna element pitch based on LOFAR and EMBRACE 
The designs used in Figure 44 are tile based structures, meaning the elements and the tile form a single entity. When the antenna elements are mechanically separate items, like in SKA1-Low, the elements can be distributed at will (within reason) for the same element cost. In this case the square meter cost will not follow the pitch ${ }^{2}$ relation closely. Still, since accurate costing is very complicated, trend figures like Figure 44 can be useful.

\subsection{Sparse-dense optimization}

In this phase of system design for AAMID, it is difficult to determine the optimal design solution since no accurate costing is possible. Technology trends and international roadmaps can give an indication, however, the design space is large, and only indicative requirements are available. In [112] it is argued that at the time when LOFAR was designed, the SKA1-Low could not have been costed with any level of accuracy due to two orders of magnitude size increase of e.g. the correlator. Further, the authors argue that SKA1-Low should be redesigned given today's (2019) costing. A mature costing is only available close to production, or worse, only known when orders are placed. The fact that radio astronomy systems are nearly always one-offs with state-of-the art technology strongly contributes to this issue. To solve this catch-22 situation an iterative design method is proposed in [112].

It has been argued in this dissertation that an AAMID system should be all-digital in order to facilitate the full capabilities of an AA system. This will only be possible when the cost of digital signal processing will be sufficiently low. Further, in section 2.4 it has been argued that a sparse system will benefit from higher $A_{\text {eff }}$ for lower frequencies due to the $\lambda^{2}$ increase for the lower frequencies, at the cost of the need for processing more beams (Figure 24). The optimum solution depends on the cost ratio of the front-end, the antennas and receivers, and the signal processing. To visualize the optimization issue, three different frond-end/back-end ratios and the resulting normalized averaged $\mathrm{A}_{\text {eff }}$ costs are plotted in Figure 45. In this figure the following assumptions have been taken:

a) $200 \operatorname{deg}^{2} \mathrm{FoV}$ is needed for the complete frequency band.

b) The total number of beams to generate $200 \mathrm{deg}^{2}$ for every $10 \mathrm{MHz}$ are used for the costing of the signal processing.

c) The average $A_{\text {eff }}$ is calculated from the integral of a simplistic $A_{\text {eff }}$ curve: constant where the array is dense and reducing with $\lambda^{2}$ where the array is sparse. With the dense/sparse transition at twice the antenna spacing. The average is taken for the $450-1450 \mathrm{MHz}$ frequency band. $\mathrm{A}_{\text {eff }}$ of a regular array will have a significant ripple around the dense to sparse transition [43].

d) Array projection $(\cos \theta)$ effects are ignored.

e) The total of the front-end and back-end costs are normalized to the dense situation with the antenna element pitch $\mathrm{d}=0.1 \mathrm{~m}$.

f) Processing cost is based on beamforming, normalized to the number of beams. FFT processing, most efficiently done with powers of 2 , will give a similar trend but due to the $2^{\mathrm{n}}$ steps will not be as smooth as the curves plotted in Figure 45.

g) Receiver costs have not been scaled to antenna spacing.

A sparse array will require more beams to fill the $200 \mathrm{deg}^{2}$. The sensitivity of the sparse array will be higher for frequencies where the array is sparse. The optimum is therefore not straightforward and related to the ratio of the cost of antenna and receiver hardware and the signal processing hardware. 


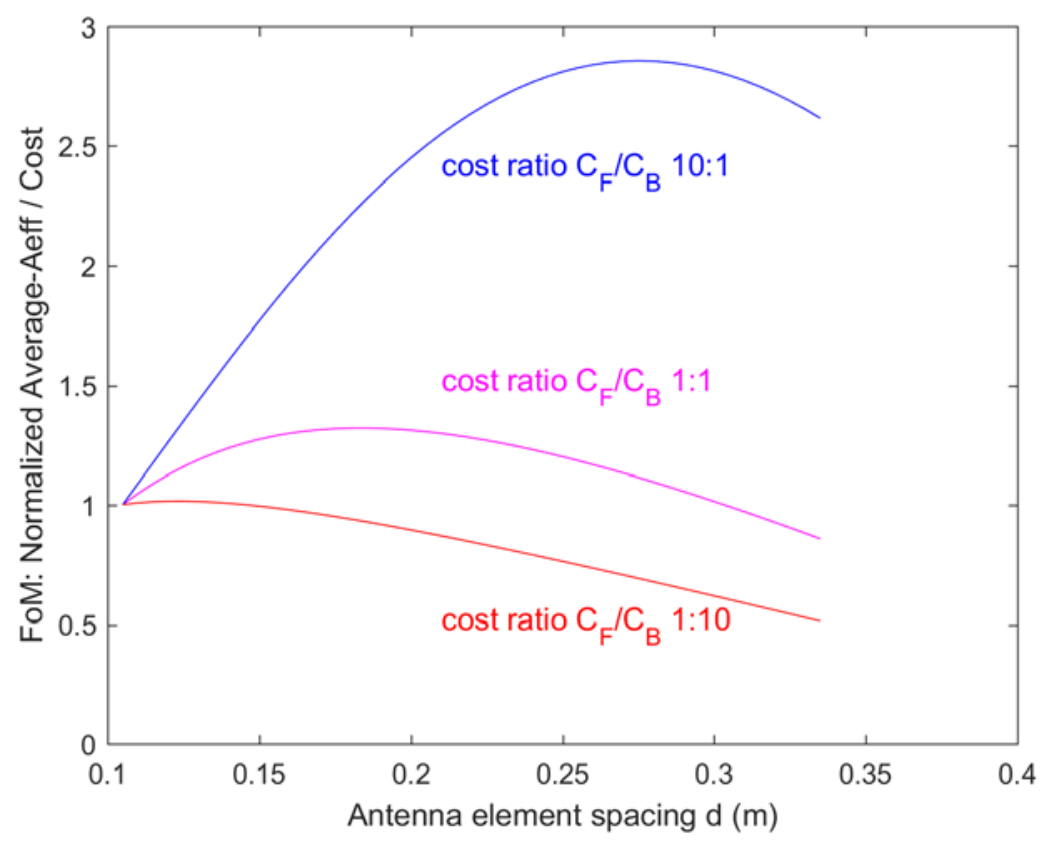

Figure 45 Normalized average $A_{\text {eff }}$ / cost for an AA system with 200 deg$^{2}$ FoV for different antenna element spacings (d) and for three different front-end back-end cost ratios.

For the average $A_{\text {eff, }}$ the following is used

$$
\overline{A_{e f f}}=\frac{N_{a}\left(\int_{\lambda_{\max }}^{\lambda_{p}} \frac{1}{4} \lambda_{p}^{2} d \lambda+\int_{\lambda_{p}}^{\lambda_{\min }} \frac{1}{4} \lambda^{2} d \lambda\right)}{\left(\lambda_{\max }-\lambda_{\min }\right)},
$$

with $N_{a}$ the number of antenna elements, $\lambda_{\max }$ the wavelength at $450 \mathrm{MHz}, \lambda_{\min }$ the wavelength at 1450 $\mathrm{MHz}$ and $\lambda_{p}$ the $\lambda / 2$ spacing of the antenna elements ( $2 d$, with $d$ the element pitch). For the calculation of $A_{\text {eff }}$ in the sparse regime an antenna gain of $5 \mathrm{~dB}$ is chosen. See also equation (2.7). Higher gains are possible, at the cost of scan range. For the signal processing load, the total number beams needed to fill 200 square degrees is calculated following

$$
M_{t o t}=\sum M_{\Delta}
$$

with $M_{\Delta}$ the number of beams needed for every $10 \mathrm{MHz}$ slot for the 450 to $1450 \mathrm{MHz}$ bandwidth. For the total cost $C T$ the following has been used

$$
C T=N_{a}\left(C_{F}+\frac{M_{t o t}}{M_{t o t z}} C_{B}\right)
$$

with $C_{F}$ the cost of the receivers, including antenna structure, amplifiers, ADC's and signal transport, $C_{B}$ the signal processing cost and $M_{\text {totz }}$ the number of beams for $\mathrm{d}=0.1$. The FoM, average $\mathrm{A}_{\text {eff }}$ divided by the total cost then becomes

$$
F O M=\frac{\overline{A_{e f f}}}{C T} .
$$


The FoM is then normalized to start with ' 1 ' when $\mathrm{d}=0.1$; the dense situation.

The calculations used in Figure 45 are unconventional for radio astronomy systems. An average sensitivity does not comply with specific science cases and a constant FoV might not be needed. Also the AA system performance used is only indicative for any real system. However, the conclusions are interesting. When signal processing costs are high, the F/B 1:10 regime, a dense system would be preferred and when signal processing costs are low, a sparse system would be beneficial.

\subsection{Conclusion}

The costing analysis in this chapter is indicative only. However since AA's key advantage over a reflector based system is the possibility for a large FoV, the cost impact of processing this FoV is very relevant. The processing should be sufficiently low in cost to justify a sparse array. Given the proposed FoM based on a normalized average $A_{\text {eff, }}$ benefits can be high for a sparse array if the processing cost is indeed low. When the ratio between front-end and back-end cost is in the range of 1:1 a modestly sparse array will give a slightly higher averaged- $\mathrm{A}_{\text {eff }} /$ cost figure compared to the dense situation. Considering the added complexity of dealing with grating lobes and processing the extra beams in the correlator and imager, this advantage quickly evaporates. 


\section{Conclusions and Recommendations}

Systems engineering practices are very important in the guidance of the design of large scale projects. Starting from performance requirements, cost limitations, schedule and risk management, large scale systems can be successfully designed and realized. It has been argued that radio astronomy instrumentation - working at the forefront of new technology - undefined and often conflicting requirements, unclear funding, and schedule limitations, are an exception to the rules. Possibly worse, that big science and engineering projects, cannot be successful on all fronts. In [114] Crosby argues the importance of understanding multiple dimensions of project complexity, including the challenge of international collaborations. The AAMID telescope, as part of SKA2, is no exception to this, a large number of factors need to be considered, but when done in a structured fashion it can be very successful. This dissertation zooms in on a possible solution for the station design providing guidance in the form of a simple and quantitative description of the performance vs cost trade-off as a function of array sparsity. However, this work and two decades of research by large international teams have not given the community a "one stop shop" solution - yet.

\subsection{Conclusion}

The research for the AAMID telescope has been diverse, covering a wide solution space. This led to very important insights but not to a single telescope design. This dissertation is not different to this. The sparse-regular solution is a new alternative, with interesting advantages but also drawbacks. Radio astronomy instrumentation is just entering the era of instantaneous-all-sky field of view for the low frequency instruments, e.g. LOFAR and SKA1-Low, which digitize signals of all antenna elements. But even in these instruments, data is quickly reduced to a restricted number of beams, utilizing only a subset of the available data. It has been argued in this dissertation that two conditions need to be fulfilled before an AAMID deployment can be considered: it has to have the right performance at an acceptable cost. However obvious these conditions, the right performance is unclear in this phase of the project, in particular how much of the potential of AA's should be utilized is unclear. E.g. the argumentation for many fields of view is suggestive and almost based on reductio ad absurdum logic: conceiving an instrument at the cost of AAMID that only supports one or two science cases at once is nearly absurd given the all-sky intrinsic capability of the antenna elements. This logic then leads to an all-digital system and to realize this at an acceptable cost (550 million Euros for the stations [115]), an appropriate system design is required and the available technology needs to advance sufficiently. From the latter point it can be concluded that the AAMID telescope in its first conception as part of SKA1, was just too early.

In this dissertation, two design aspects have been explored which would bring a very attractive, with many FoVs, AAMID telescope within reach. Firstly, a reduction of the element count, and secondly, fast Fourier Transform signal processing. The reduction of the element count by sparsing the array maintains a good sensitivity at the low end of the frequency band, with a reduced sensitivity at the high end, but results in an increased processing cost if used as a survey telescope. The cost FoM proposed in this dissertation, average sensitivity divided by system cost, indicates that sparsing the array, although technically feasible, is only attractive if the signal processing cost is significantly lower than the antenna and receiver cost. The second aspect explored, the signal processing by FFT, indicates that this would indeed be very attractive, requiring a fully digital array with the antennas placed on a regular grid. When digital processing cost stabilizes at the level of the receiver cost, a dense-regular alldigital telescope would be the design of choice for a survey telescope. 


\subsection{Recommendations}

It is impossible to summarize the research on AAMID in the scope of this dissertation; the focus has been on the exploration of one particular solution. Still, the recommendations below expend a bit further than the presented research. Future research could focus on:

a) Array signal processing research using FFT beamforming.

b) Sparse or thinned arrays.

c) Array calibration. A regular array will require good calibration to realize superior performance.

d) Integrated circuit design, to reduce the receiver cost.

e) All-digital data storage. This is considered for LOFAR [116], but would be very attractive for AAMID as well.

It has been argued that a large AAMID prototype system, possibly set-up as an observatory, is needed to advance the technology [117]. A modest size AAMID system consisting of a small array of stations would already be of scientific interest, in particular for transient detection and cosmology. If this system would have $\sim 2500 \mathrm{~m}^{2}$ total collecting area and would process $200 \mathrm{deg}^{2}$, survey performance would already exceed survey telescopes like ASKAP [117]. It could contribute to the final goals of AAMID if such a system can be realized with future technology in mind. In others words, compromises, because of technology availability, are best avoided. Therefore, with the logic proposed in the conclusions of this dissertation, this should be an all-digital system. 


\section{Bibliography}

[1] SKA Radio Telescope: www.skatelescope.org

[2] M. Klein Wolt et al., Netherlands-China Low-Frequency Explorer (NCLE), https://www.ru.nl/astrophysics/radbout-radio-lab/projects/netherlands-china-low-frequencyexplorer-ncle, accessed august 2019

[3] J. G. Bij de Vaate, S. A. Torchinsky, A. J. Faulkner, Y, Zhang, A. Gunst, P. Benthem, M. van Bemmel, G. Kenfack, SKA Mid Frequency Aperture Arrays Technology for the Ultimate Survey Machine, URSI General Assembly, Beijing, China, Aug. 2014

[4] S. Yahya, P. Bull, Mario G. Santos, M. Silva, R. Maartens, P. Okouma, B. Bassett, Cosmology performance of SKA HI galaxy surveys, Monthly Notices of the Royal Society, Volume 450, March 2015

[5] K. G. Jansky, Electrical Disturbance Apparently of Extraterrestrial Origin, Proceedings of the Institute of Radio Engineers, Vol. 21, Issue 10.,1933

[6] K. G. Jansky, Directional Studies of Atmospherics at High Frequencies, Proceedings of the Institute of Radio Engineers, Vol. 20, Issue 12.,1932

[7] P. J. Duffett-Smith, A. Purvis and A. Hewish, A statistical study of faint radio sources at 81.5 $\mathrm{MHz}-\mathrm{I}$. The data, Monthly Notices of the Royal Astronomical Society, Volume 190, Issue 4, April 1980

[8] M. van Haarlem et al., LOw Frequency ARray, Astron. \& Astrophys. 556, A2 (2013) doi: 10.1051/0004-6361/201220873

[9] S. J. Tingay, et al., The Murchison Widefield Array: the Square Kilometre Array Precursor at low radio frequencies, Publications of the Astronomical Society of Australia, 30, e007 doi:10.1017/pasa.2012.007

[10] J. E. Noordam, J. L. L. Voûte, Design aspects of a Tile Telescope; A possible approach to a Square Km Array Interferometer (SKAI), ASTRON memo, 3 May, 1994

[11] J. E. Noordam, R. Braun, A. G. de Bruyn, EURO16: Proposal for an Array of 16 Low Cost 100 Meter Radio Telescopes, ASTRON memo, August 13, 1991

[12] J. G. Bij de Vaate, SSM96, April 2003, ASTRON SKA System meeting minutes

[13] C. Jackson, SKA memo 29, April 2002, available at www.skatelescope.org

[14] A. van Ardenne, B. Smolders, G. Hampson, Active adaptive antennas for Radio Astronomy; results of the R\&D program towards the Square Kilometre Array, Proceedings of SPIE, Vol. 2015, 2000

[15] G. Hampson, M. Goris, A. Joseph, F. Smits, The Adaptive Antenna Demonstrator, IEEE Digital Signal Processing Workshop, Bryce Canyon, Utah, USA, 1998

[16] G. Hampson, B. Smolders, A. Joseph, H Heutink, A. Doorduin and K. Dijkstra, One Square Metre of a Million, European Microwave Conference, Munich, Germany, Oct. 1999

[17] J. G. Bij de Vaate, S.J. Wijnholds, J.D. Bregman, Two Dimensional 256 Element Phased Array System for Radio Astronomy, Phased Array Systems and Technology 2003, Boston, 
USA, Oct. 2003

[18] J. G. Bij de Vaate, G. W. Kant, W. A. van Cappellen, S. van der Tol, First Celestial Measurements: Results of the Thousand Element Array, URSI GA, Maastricht, the Netherlands, August 2002

[19] J.G. Bij de Vaate, G.W. Kant, The Phased Array Approach to SKA, Results of a Demonstrator Project, European Microwave Conference, Milan, Italy, Oct. 2002

[20] S. J. Wijnholds, G. de Bruyn, J.D. Bregman, J.G. Bij de Vaate, Hemispheric Imaging of Galactic Neutral Hydrogen with a Phased Array Antenna System, Experimental Astronomy, Vol. 17., No.1-3, June 2004

[21] A. van Ardenne, J. D. Bregman, W. Van Cappellen, G. W. Kant, J. G. Bij de Vaate, Extending the Field of View with Phased Array Techniques: Result of European SKA Research, Proceedings of the IEEE, vol. 97, no. 8, pp. 1531-1542, Aug 2009

[22] A. J. Faulkner, A. van Ardenne, S. Torchinsky, A. van Es, P. Alexander, R. Bolton, S. Rawlings, J. G. Bij de Vaate, G. W. Kant, J. D. Bregman, S. Montebugnoli, M. Jones, P. Picard, P. Wilkinson, The Aperture Arrays for the SKA: the SKADS White Paper, April 2010, SKA memo 122, available at www.skatelescope.org

[23] A. van Ardenne, H. Butcher, J. G. Bij de Vaate, A. J. Boonstra, J. D. Bregman, B. Woestenburg, K. van der Schaaf, P. N. Wilkinson, M. A. Garrett, The European Concept for the SKA, SKA memo 19, July 2002, available at www.skatelescope.org

[24] J. G. Bij de Vaate, P.D. Patel, A. van Ardenne, "Ramping up to the Square Kilometre Array: A $1000 \mathrm{~m}^{2}$ Aperture Array Prototype", European Microwave Conference, Amsterdam, The Netherlands, Oct. 2004

[25] B. Smolders, G. Hampson, Deterministic RF Nulling in Phased Arrays for the Next Generation of Radio Telescopes, IEEE Transactions on Antennas and Propagation, Vol. 44, Issue 4, 2002

[26] S. van der Tol, A.J. Boonstra, J.G. Bij de Vaate, A. van Ardenne, Multiple Satellite Detection with a Prototype new Generation Phased Array Radio Telescope, ESA Antenna workshop on Satellite Antenna Technology, Noordwijk, the Netherlands, Sept. 2002

[27] J.G. Bij de Vaate, L.I. Gurvits, S.V. Pogrebenko, C.G.M. van ’t Klooster, "Spacecraft Tracking Applications of the Square Kilometre Array", ESA International Workshop on Tracking, Telemetry and Command Systems for Space Applications, Darmstadt, Germany, Sept. 2004

[28] A. van Ardenne, P.N. Wilkinson, P. Patel, J.G. Bij de Vaate, Electronic Multi-beam Radio Astronomy Concept: EMBRACE - The European Demonstrator for SKA, Experimental Astronomy, Vol. 17. , No.1-3, June 2004

[29] G. W. Kant, P. D. Patel, S. J. Wijnholds, M. Ruiter, E. van der Wal, EMBRACE: A MultiBeam 20,000-Element Radio Astronomical Phased Array Antenna Demonstrator, IEEE Transactions on Antennas and Propagation, Vol. 59, No. 6, June 2011

[30] T. S. Ikin, et al., Progress on Analogue Front end for 2PAD, Widefield Science and Technology for the SKA, SKADS Conference 2009, 4-6 November 2009, Château de Limelette, Belgium

[31] A. R. Thompson, J. M. Moran, G. W. Swenson, Interferometry and Synthesis in Radio 
Astronomy, $3^{\text {rd }}$ edition, Springer, June 2016

[32] J. D. Bregman, Scaling of Brightness Sensitivity in Synthesis Imaging, memo, private communication, 19-4-2015

[33] Advancing Astrophysics with the Square Kilometre Array, available at www.skatelescope.org, 2015

[34] A. W. Gunst et al., SKA-AAMID System Requirements, SKA-TEL-MFAA-0200005, $3^{\text {rd }}$ May 2016, Rev. 01

[35] M. Caiazzo, SKA Phase 1 System Requirements Specification, SKA-TEL-SKO-0000008, Rev. 11, 31-7-2017

[36] R. Braun et al., SKA1 Level 0 Science Requirements, SKA-TEL-SKO-0000007, Rev. 02, 2810-2015

[37] B. Mort et al., Analysing the impact of far-out sidelobes on the imaging performance of the SKA-Low telescope, Monthly Notices of the Royal Astronomical Society 465, Nov, 2016

[38] K. Grainge, Aperture Array Configurations for SKA-Low Core, SKA memo 151, Feb. 2014

[39] Hydrogen Epoch of Reionization Array, HERA, www.reionization.org

[40] S. J. Wijnholds, R. Jongerius, Computing Cost of Sensitivity and Survey Speed for Aperture Array and Phased Array Systems, IEEE AfriCon / URSI BEJ meeting, Pointe-Aux-Piments, Mauritius, Sept. 2013

[41] P. S. Kildal, Foundations of Antenna Engineering: A Unified Approach for Line-of-Sight and Multipath, Kildal Antenn AB, 2017

[42] G. C. Medellin, Antenna Noise Temperature Calculation, SKA memo 95, July 2007

[43] R. Braun, W. van Cappellen, Aperture Arrays for the SKA: Dense or Sparse?, SKA memo 87, Nov. 2006, available on www.skatelescope.org

[44] R. Schillizi et al., Preliminary Specifications for the Square Kilometre Array, SKA memo 100, Dec 2007

[45] S. A. Torchinsky et al., SKA-AAMID Science Requirements, SKA-TEL-MFAA-0200009, Rev. 01, 3-5-2016

[46] B. Mort, F. Dulwich, N. Razavi-Ghods, E. de Lera Acedo, K. Grainge, Analysing the impact of far-out side-lobes on the imaging performance of the SKA-LOW telescope, Astro-ph, Feb. 2016

[47] M. Tegmark, M. Zaldarriaga, The Fast Fourier Telescope, Phys. Rev. D, $28^{\text {th }}$ April 2009

[48] M. Tegmark, M. Zaldarriaga, Omniscope: Large Area Telescope Arrays with only $N \log N$ Computational Cost, astro-ph, August 2010

[49] W. A. van Cappellen, S. J. Wijnholds, J. D. Bregman, Sparse antenna array configurations in large aperture synthesis radio telescopes, Proceedings of the $3^{\text {rd }}$ European Radar Conference, Sept. 2006, Manchester, UK

[50] J. G Bij de Vaate, D. B. Davidson and S. J. Wijnholds, Regular Sparse Arrays: the Impact of Grating Lobes on Radio Astronomical Observations, URSI AT-RASC, Gran Canaria, 28 May 
- 1 June 2018

[51] J. G Bij de Vaate, D. B. Davidson, N. Razavi-Ghods, Sparse-regular Aperture Array SKA Telescope Concept, Progress in Electromagnetics Research Symposium, St Petersburg, Russia, May 2017

[52] J. G. Bij de Vaate, D. B. Davidson, P. Benthem, Expanding the Field of View: Design Considerations for a Sparse-regular FFT SKA Radio Telescope, European Conference on Antennas and Propagation, Paris, March 2017

[53] M. I. Skolnik, Introduction to Radar systems, McGraw-Hill International Editions, 1980

[54] N. Razavi-Ghods, Xarray, Cambridge University, 2012, sites.google.com/site/xarraytool

[55] P. Noorishad, S. J. Wijnholds, A. van Ardenne and J. M. van der Hulst, Redundancy calibration of phased-array stations, Astronomy \& Astrophysics, Vol.545 A(108), Sept 2012

[56] S. J. Wijnholds, Impact of calibratability on Mid-Frequency Aperture Array station design, ICEAA, 2017, Verona, Italy

[57] C. R. Wilke, S. J. Wijnholds, J. Gilmore, Performance Improvement of Self-Holography Based Aperture Array Station Calibration, EuCAP 2019, Krakow, Poland

[58] N. Razavi-Ghods, E. de Lera Acedo, A. El-Makadema, P. Alexander, A. Brown, Analysis of sky contributions to system temperature for low frequency SKA aperture array geometries, Experimental Astronomy, 2012

[59] C. G. T. Haslam, U. Klein, C. J. Salter et al., A $408 \mathrm{MHz}$ all-sky continuum survey IObservations at southern declinations and for the North Polar region, Astronomy \& Astrophysics 100, 1981

[60] The OSKAR Simulator, Oxford University, www.oerc.ox.ac.uk/ ska/oskar2

[61] D. R. Sinclair et al., Effect of Gain and Phase Errors on SKA1-Low Imaging Quality from 50$600 \mathrm{MHz}$, SKA Memo 153, August 2014

[62] International Roadmap for Devices and Systems 2018, irds.ieee.org

[63] R. Jongerius, Exascale Computer System Design; The Square Kilometre Array, PhD thesis Eindhoven University, ISBN 978-90-386-4136-2

[64] A. Jiwani, T. Colgate, N. Razavi-Ghods, P. J. Hall, S. Padhi, J. G. Bij de Vaate, Square Kilometre Array station configuration using two stage beamforming, Publications of the Astronomical Society of Australia, March 2013

[65] L. Fiorin, E. Vermij, J. van Lunteren, R. Jongerius, C. Hagleitner, Exploring the Design of an Energy-Efficient Accelerator for the SKA1-Low Central Signal Processor, International Journal of Parallel Programming, October 2016, Volume 44, Issue 5, pp 1003-1027

[66] J. Butler, R. Lowe, Beamforming Matrix Simplifies Design of Electronic Scanned Antennas, Electronic Design, volume 9, April, 1961

[67] K. W. Masui, et al., Algorithms for FFT Beamforming Radio Interferometers, Instrumentation and Methods for Astrophysics, Oct 2017

[68] R. E. Blahut, Fast algorithms for digital signal processing, Cambridge University Press 2010 
[69] Private communication with S. J. Wijnholds, June 2019

[70] R. Kaptijn, COBALT2.0 is ready for use, ASTRON\&Jive daily image, 16-7-2019

[71] W. Turner, LFAA Signal Processing System Detailed Design Document, SKA-TEL-LFAA0500035, rev. 01, 1-11-2018

[72] A. J. Faulkner, K. Zarb-Adami, J. G. Bij de Vaate, New challenges in signal processing in astrophysics: the SKA case, Journal of Instrumentation, Volume 10, July 2015

[73] P. Alexander, A. J. Faulkner, Determining the Specification of an Aperture Array for Cosmological Surveys, SKA Memo 108 at www.skatelescope.org, March 2009

[74] G. Hampson, W. Cazemier, The effects of THEA Tile Configuration on Digital Beamforming and Adaptive Nulling, ASTRON report Memo-001 26640-2-1-R1, Aug 2000

[75] C. Craeye, J.G. Bij de Vaate, Effects of array truncation on the depth of deterministics obtained with a broadband phased array, Antennas and Propagation Symposium, June 2002

[76] G.A. Hampson, J.G. Bij de Vaate, Verification of THEA Tile Calibration and Beamforming Results using a Near Field Scanner, European Microwave Conference, London, UK, Oct. 2001

[77] G.A. Hampson, J.G. Bij de Vaate, Initial Calibration and Beamforming Results from the Thousand Element Phased-Array, Antennas and Propagation Symposium, Boston, USA, July 2001

[78] J. G. Bij de Vaate, P. Benthem, R. Witvers, R. van den Brink, Y. Zhang, S. A. Torchinsky, Mid frequency aperture array technology developments for the SKA, $16^{\text {th }}$ International Symposium on Antenna Technology and Applied Electromagnetics, Aug. 2014

[79] J. Gilmore, D.B. Davidson, J.G. Bij de Vaate, Progress on the Development of a DualPolarized Dense Dipole Array for the SKA Mid-Frequency Aperture Array, European Conference on Antennas and Propagation, Davos, Switzerland, April 2016

[80] E. de Lera Acedo, SKA1 Station Design Report, SKA-TEL-LFAA-0300034 rev. 01, 1-112018

[81] S. Bhaumik, J. G. Bij de Vaate, Hybrid LNAs with SiGe HBTs on 7th Generation BiCMOS Process, European Microwave Conference, Rome, Italy, Oct. 2014

[82] J. G. Bij de Vaate, P. Benthem, R. Witvers, R. van den Brink, Y. Zhang, S.A. Torchinsky, Mid Frequency Aperture Array Technology Developments for the SKA, ANTEM 2014, Victoria, Canada, July 2014

[83] J. G. Bij de Vaate, Front-end Integration Requirements for the Square Kilometre Array Radio Telescope, Compound Semiconductor IC Symposium, Monterey, USA, Oct. 2010

[84] R. H. Witvers, J. G. Bij de Vaate, E. E. M. Woestenburg, Sub 0.15dB Noise Figure Room Temperature GaAs LNA for Next Generation Radio Telescope, European Microwave Conference, Paris, Oct. 2010

[85] J. G Bij de Vaate, L. Bakker, E. E. M. Woestenburg, R. H. Witvers, G. W. Kant, W. van Cappellen, Low Cost Low Noise Phased-Array Feeding Systems for SKA Pathfinders, ANTEM, Banff, Canada, Feb. 2009

[86] A. J. Beaulieu, L. Belostotski, T. Burgess, B. Veidt and J. Haslet, Noise Performance of a 
Phased-Array Feed with CMOS Low-Noise Amplifiers, DOI 10.1109/LAWP.2016.2528818, IEEE Antennas and Wireless Propagation Letters, 11-2-2016

[87] R. H. Witvers, E. E. M. Woestenburg, A Wideband Low Noise Tile for the SKA Mid Frequency Aperture Array, International Conference on Electromagnetics in Advanced Applications (ICEAA), 2015

[88] E. Farhat, K. Zarb-Adami, O. Casha, I. Grech, J. G. Bij de Vaate, Design of a Wideband CMOS LNA for Low Frequency Band SKA Application, 2015 IEEE International Conference on Electronics, Circuits and Systems, Cairo, Egypt, Dec 2015

[89] G. Pupillo et al., Medicina Array Demonstrator: Calibration and Radiation Pattern Characterization using a UAV-mounted Radio-Frequency source, Experimental Astronomy, Volume 39, No. 2, 2015

[90] S. J. Wijnholds, Blind Calibration of Dense Irregular Arrays by Exploiting MultipleMeasured Nearly-Identical Spatial Frequencies, Antennas and Propagation Symposium, APS, Puerto Rico, June 2016

[91] B. Klopper, Antenna Elements for Sparse-Regular Aperture Arrays, dissertation Stellenbosch University, Nov. 2018

[92] R. Z. Syeda, J. G. Bij de Vaate, D. Prinsloo, Regular and Irregular-on-grid sparse array comparison for Mid-Frequency Aperture Arrays, submitted to Antennas and Wireless Propagation Letters, 2019

[93] M. W. Pospieszalski, Modeling of noise parameters of MESFETs and MODFETs and their frequency and temperature dependence, IEEE Transactions on Microwave Theory and Techniques, Volume 37, Issue 9, Sept 1989

[94] F. Balestra, G. Ghibaudo, Device and Circuit Cryogenic Operation for Low Temperature Electronics, Kluwer Academic Publisher, ISBN 0-7923-7377-4

[95] J. G. Bij de Vaate, D. Geskus, R. H. Witvers, Integrated Active Antenna Noise Figure Characterization Using a Cryogenic Anechoic Noise Source, IEEE European Microwave Conference, 2001

[96] R. Maaskant, E. E. M. Woestenburg, Applying the active reflection impedance to achieve noise match in receiving array antennas, IEEE Antennas and Propagation Society International Symposium, 2007

[97] K. F. Warnick, R. Maaskant, M. V. Ivashina, D. B. Davidson, B. D. Jeffs, Phased Arrays for Radio Astronomy, Remote Sensing, and Satellite Communications, Cambridge University Press, ISBN 9781108539258, July 2018

[98] E. E. M. Woestenburg, Aperture Array Noise Temperature Measurements, ASTRON\&Jive Daily Image, 20-9-2011

[99] H. S. Cao, R. H. Witvers, S. Vanapalli, H. J. Holland and J. M. ter Brake, Cooling a low noise amplifier with a micromachined cryogenic cooler, Review of Scientific Instruments, Oct. 2013

[100] F. Schreuder, J. G. Bij de Vaate, Localized LNA Cooling in Vacuum, THERMINIC, Nice, France, 27-29 Sept 2006

[101] www.skyworksinc.com, SKY67150-396LF, accessed March 2019 
[102] M. Gerbers, LFAA Life Cycle Costing Analysis - Costing Sheet, SKA-TEL-LFAA-0000004 rev 13, 5-11-2018

[103] F. Perini et al., Demonstrate RFoF at Target Cost over Maximum Length the Design Requires, SKA-TEL-LFAA-0400026 rev 01, 9-6-2016

[104] B. Juswardy, Field Test Results at the MRO to Assess Gain \& Phase Variation of Fibre-optic Cable, SKA-TEL.LFAA.RE.AST-AADC-R-001 rev 1.1, 2-15-2016

[105] B. Juswardy, Memo on the Phase Stability Consideration for Operating Standard Fibre at Non-standard Wavelength: 1550 nm Case Study, SKA-TEL-LFAA-0400018 rev. 1, 28-92015

[106] E. van der Wal, Reference Spectrum, SKA-TEL-MFAA-0200012, Rev. 01, 3-5-2016

[107] H. Hanenburg, Temperature Test 4: Outdoor test of five models, ASTRON-RP-408Test_4_outdoor, $11^{\text {th }}$ August 2010

[108] www.xilinx.com/products/silicon-devices/soc/rfsoc.html, accessed July 2019

[109] G. A. Hampson, J. G. Bij de Vaate, J. D. Bunton, A. Brown, G. Schoonderbeek, J. Tuthill, R. Beresford, Exploring the next generation of Array Receivers and Signal Processing Systems for the SKA, European Conference on Antennas and Propagation, London, April 2018

[110] M. L. Smatz, R. Jongerius, G. Dittmann, A. Anghel, T. Engbersen, J. van Lunteren, P. Buchmann, Scalable, Efficient ASICS for the Square Kilometre Array: From A/D Conversion to Central Correlation, International Conference on Acoustic, Speech and Signal Processing (ICASSP), 2014

[111] J. D. Bregman, System Design and Wide-field Imaging Aspects of Synthesis Arrays with Phased Array Stations, PhD dissertation, Groningen, The Netherlands, 2012

[112] A. J. Boonstra, R. Nijboer, Radio Telescope Design Optimization Using Costing Constraints: Extrapolating LOFAR Costing to the Square Kilometre Array, Radio Science, Special Section URSI GA 2017

[113] J. Pragt, A. W. Gunst, AA-MID Analogues Power and Cost Analysis, report WP2015.020.010-TR-001 rev E, 16 Nov 2011

[114] P. Crosby, Success in large high-technology projects: What really works, Modeling, System Engineering, and Project Management for Astronomy VI, Montreal, Canada, 22-27 June, 2014

[115] W. A. van Cappellen, Preliminary MFAA Cost and Power Estimate, SKA-TEL-MFAA0100006-MGT-CRE Rev. 01, 3-5-2016

[116] A. W. Gunst, G. H. Kruithof, Antenna Data Storage Concept for Phased Array Radio Astronomical Instruments, Experimental Astronomy, 2018

[117] W. A. van Cappellen et al., MANTIS: The Mid-Frequency Aperture Array Transient and Intensity-Mapping System, AAMID Consortium memo, Jan. 2017 